Florida International University FIU Digital Commons

\title{
Identifying and Intervening on Neural Markers of Attention to Threat in Children with Anxiety Disorders
}

Michele Bechor

mbech001@fiu.edu

DOI: 10.25148 /etd.FIDC006912

Follow this and additional works at: https://digitalcommons.fiu.edu/etd

Part of the Behavior and Behavior Mechanisms Commons, Biological Psychology Commons, Child Psychology Commons, Clinical Psychology Commons, and the Psychological Phenomena and Processes Commons

\section{Recommended Citation}

Bechor, Michele, "Identifying and Intervening on Neural Markers of Attention to Threat in Children with Anxiety Disorders" (2018). FIU Electronic Theses and Dissertations. 3776.

https://digitalcommons.fiu.edu/etd/3776 


\title{
FLORIDA INTERNATIONAL UNIVERSITY
}

Miami, Florida

\section{IDENTIFYING AND INTERVENING ON \\ NEURAL MARKERS OF ATTENTION \\ TO THREAT IN CHILDREN \\ WITH ANXIETY DISORDERS}

\author{
A dissertation submitted in partial fulfillment of the \\ requirements for the degree of \\ DOCTOR OF PHILOSOPHY \\ in \\ PSYCHOLOGY
}

by

Michele Bechor

2018 
To: Dean Michael R. Heithaus

College of Arts, Sciences, and Education

This dissertation, written by Michele Bechor, and entitled Identifying and Intervening on Neural Markers of Attention to Threat in Children with Anxiety Disorders, having been approved in respect to style and intellectual content, is referred to you for judgment.

We have read this dissertation and recommend that it be approved.

Matthew T. Sutherland

$\begin{array}{r}\hline \text { Angela Laird } \\ \hline \text { Bethany C. Reeb-Sutherland } \\ \hline \text { Wendy K. Silverman } \\ \hline \text { Jeremy W. Pettit, Major Professor }\end{array}$

Date of Defense: March 26, 2018

The dissertation of Michele Bechor is approved.

Dean Michael R. Heithaus

College of Arts, Sciences, and Education

Andrés G. Gil

Vice President for Research and Economic Development and Dean of the Graduate School

Florida International University, 2018 
(C) Copyright 2018 by Michele Bechor

All rights reserved. 


\section{DEDICATION}

I dedicate this dissertation to my very loving family: my parents, who continue to model for me the importance of learning, sacrifice, and an unflinching work ethic, and to my sister, my first-ever teacher, who personifies persistence and taught me to love the role of the student. These three inspire me, encourage me, and foster within me an undying pursuit of lessons. 


\section{ACKNOWLEDGMENTS}

I would like to thank my Major Professor, Dr. Jeremy Pettit, and former coadvisor, Dr. Wendy Silverman, for consistently providing thoughtful revisions, strategic resources and professional guidance throughout my graduate training. I would like to thank Dr. Bethany Reeb-Sutherland for willingly opening her lab and providing me with extensive training in a new skill set. I would also like to thank my dissertation committee members, Dr. Angela Laird and Dr. Matthew Sutherland, for their helpful feedback and their continued support of my professional activities. Additionally, I would like to thank Dr. Michael Crowley for providing ongoing support for me in several training opportunities. Without support from these wonderful mentors I would not have been able to achieve ever-new levels of accomplishment thus far, across clinical training opportunities, project management and scholarship. I also extend my gratitude to Dr. Ranu Jung and her team for making available their equipment and laboratory, without which I would not have completed data collection.

I would like to thank all of my colleagues in the two laboratories through which I achieved this work. After six years, I have had the privilege of working with probably over one hundred of them, and for the opportunities to both teach and learn from them, I am grateful. Finally, I extend my very enthusiastic to the families with whom I worked in the FIU Center for Children \& Families, who sacrificed much time and willingness (as we often joked in the lab, for science!). Without all of these contributors, this work would not have been possible. Credits: FIU Presidential Fellowship, 2011-2013; National Research Service Award F31 MH105144-02, 2015-2017. 


\author{
ABSTRACT OF THE DISSERTATION \\ IDENTIFYING AND INTERVENING ON \\ NEURAL MARKERS OF ATTENTION \\ TO THREAT IN CHILDREN \\ WITH ANXIETY DISORDERS
}

by

Michele Bechor

Florida International University, 2018

Miami, Florida

Professor Jeremy W. Pettit, Major Professor

Objective: Attention Bias Modification Training (ABMT) for anxiety aims to train attention away from threatening stimuli and toward neutral stimuli. Although ABMT shows promising anxiety reduction effects in children and adolescents, no study has examined its influence on neural indicators of attention measured using event-related potentials (ERPs) in children or adolescents (i.e., youths). The present study examined the influence of ABMT on the P1, N170, P2 and P3 ERP components during completion of the emotional faces dot probe task in youths with anxiety disorders who failed to respond to cognitive behavioral therapy. Method: Thirty youths $(M$ age $=11.97, S D=$ 2.89 ) with primary DSM-IV-TR anxiety disorders completed the dot probe task while undergoing electroencephalogram (EEG) to obtain ERPs before, immediately after, and eight weeks after eight sessions of either ABMT $(n=14)$ or a control task regimen $(\mathrm{CT})$, $(n=16)$. Results: At post-treatment, statistically significant effects were found for P1 and P3 mean amplitudes: P1 was significantly higher during trials showing neutral-neutral 
(NN) face pairs in the ABMT arm than in the CT arm; P3 was significantly higher during trials showing NN face pairs than during trials showing neutral-threat (NT) face pairs in the ABMT arm, but not the CT arm. At eight-week follow-up, participants in both arms showed significantly higher (more negative) N170 responses for NN trials than for NT trials. Conclusions: Attention Bias Modification Treatment led to increases in neural processing of neutral stimuli in early and late stage attentional processing, as measured by the P1 and P3 components, respectively. These components during the dot probe task are promising neural markers of ABMT's effects on attentional processing in youth with anxiety disorders.

Keywords: Attention bias, Attention Bias Modification Treatment (ABMT), Eventrelated potential, anxiety, youth. Abbreviations: DSM-IV-TR: Diagnostic and Statistical Manual of Mental Disorders, Fourth Edition, Text Revision; ADIS for DSM-IV: C/P: Anxiety Disorders Interview Schedule for DSM-IV: Child and Parent Versions; SCARED-C/P: Screen for Child Anxiety \& Related Disorders, Child \& Parent Versions; PARS: Pediatric Anxiety Rating Scale; ERPs: event-related potentials; EEG: electroencephalogram. 


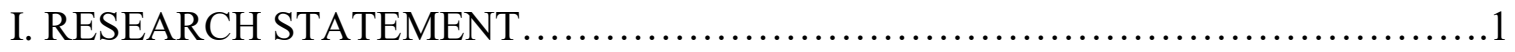

II. CHAPTER 1: NEURAL CORRELATES OF ATTENTIONAL PROCESSING IN YOUTH WITH AND WITHOUT ANXIETY DISORDERS...........................6

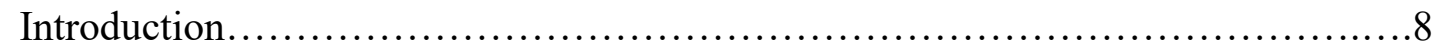

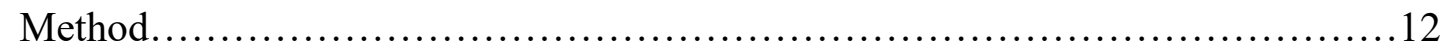

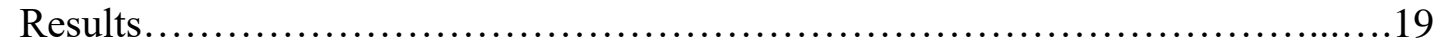

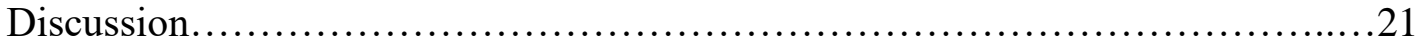

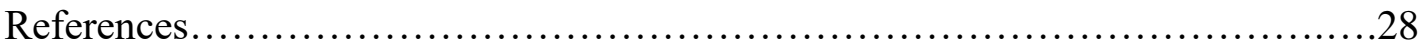

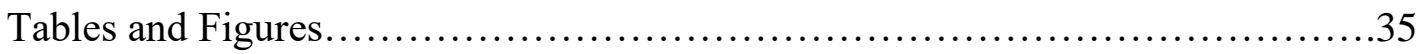

III. CHAPTER 2: ATTENTION BIAS MODIFICATION TREATMENT FOR CHILDREN WITH ANXIETY DISORDERS WHO DO NOT RESPOND TO COGNITIVE BEHAVIORAL THERAPY: A CASE SERIES..........................38

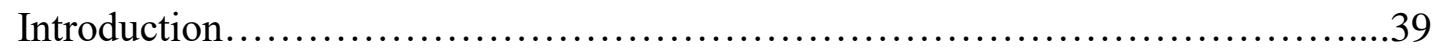

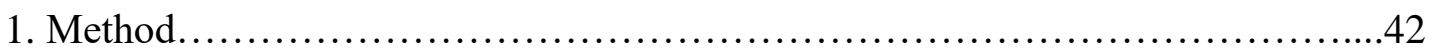

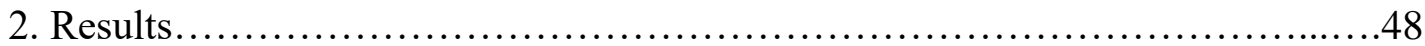

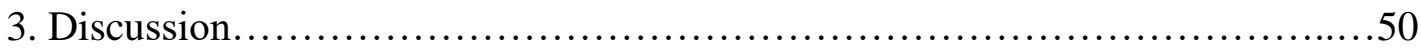

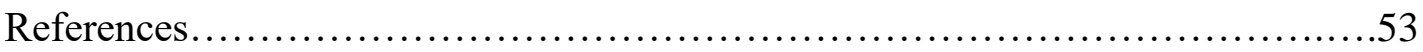

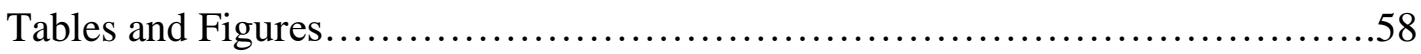

IV. CHAPTER 3: NEURAL MARKERS OF ATTENTION TRAINING IN CHILDREN AND ADOLESCENTS WITH ANXIETY DISORDERS ..............59

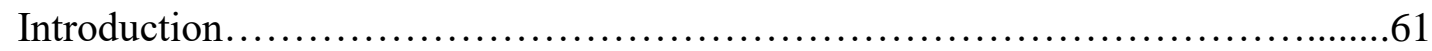

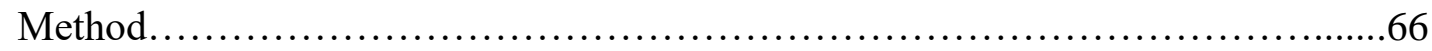

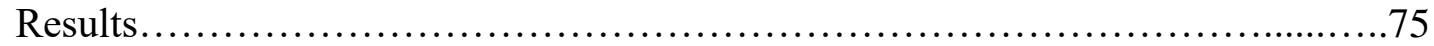

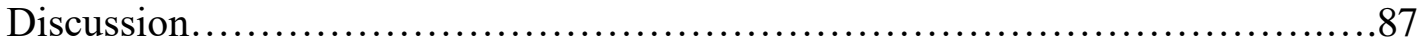

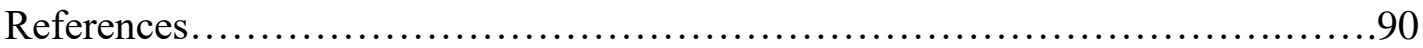

Tables and Figures...................................................... 104

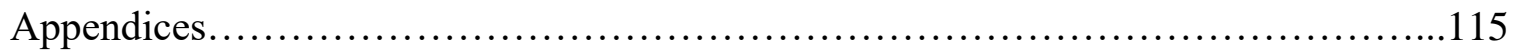

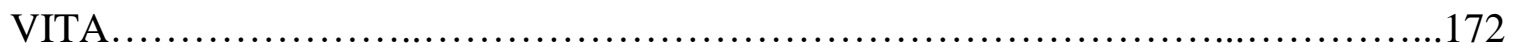




\section{RESEARCH STATEMENT}

I am pursuing a program of developmental translational neuroscience, focused on a) the identification of behavioral and neural markers of attentional processes involved in the development and maintenance of anxiety in children and adolescents, and b) the evaluation of treatments designed to alter the pathophysiology of attentional processes related to anxiety, including Attention Bias Modification Training (ABMT). As such, my training integrates behavioral and neuroscientific methodologies to identify contributing attentional networks and how and for whom neurally-informed treatments are most helpful.

\section{Gaps in Understanding Attention and Anxiety}

Anxiety disorders are among the most prevalent psychiatric disorders in children and adolescents (hereon referred to as “youth"). Up to $50 \%$ of youth continue to meet criteria for anxiety disorders and continue to experience emotional distress and impairment after a full course of cognitive-behavioral therapy (CBT), the leading evidence-based psychosocial treatment for anxiety disorders. These youth continue to suffer emotional distress and impairment associated with anxiety disorders, including frustration by perceived failure to respond to a "treatment that works," and pose a financial burden on the health care system. These findings highlight the need for novel treatments informed by the neural underpinnings of anxiety in youth.

There is substantial evidence of threat-related attention bias in anxiety from behavioral research, including research on youth with anxiety disorders. However, behavioral paradigms are unable to provide precise temporal information about where in the stream of attentional processing perturbations exist for anxious youth. Further, 
although the translational treatment implication of attention bias to threat, ABMT, shows promising anxiety reduction effects, the influence of ABMT on neural activity related to attention bias is not well characterized. That is, whether and how ABMT produces changes in underlying neural processes remains unknown.

To identify the neural correlates of attention processes, including threat-related attention bias, researchers have examined event-related potentials (ERPs) time-locked to the onset of the visual stimuli presented in a dot probe task. With respect to threat-related attention, researchers have focused on ERP components that correspond to early stage processing associated with attention orienting $(\mathrm{P} 1)$ or face recognition $(\mathrm{N} 170)$ and components that correspond to later, more complex attention processes such as stimulus evaluation (P2) and response inhibition (P3). As elaborated in my dissertation studies, past research has provided evidence supporting the potential value of exploring such ERP components to better understand the neural chronometry of attention bias to threat.

\section{My Research Questions}

In light of emergent frameworks designed to narrow the gap between knowledge of clinical symptomology and dysregulated neurobiological systems, my research questions incorporate data from behavioral and neural measurement and treatment paradigms. Investigating these paradigms may help streamline attention-based interventions in youth with anxiety disorders. My research has thus developed along two lines. In the first line, I seek to identify the neural correlates (i.e., ERPs) of attention bias to threat in youth CBT nonresponders in order to identify neural markers for translational intervention research. In the second line, which builds on the first, I seek to examine the effects of ABMT on these neural markers and anxiety symptom severity in youth CBT 
nonresponders. I expect these two lines of research will provide insight into (a) where in the stream of neural processing of threat youth anxiety CBT nonresponders experience perturbations and (b) whether ABMT remediates these perturbations.

\section{Dissertation Portfolio}

My dissertation portfolio includes three studies relevant to my two lines of research. In the first study (Study 1), I identified neural markers of attention to threat in youth anxiety CBT nonresponders. In this study, I compared ERP components (P1, N170, $\mathrm{P} 2$ and P3) as elicited by a dot probe task between CBT nonresponders with anxiety disorders and age-matched typically developing controls. I found that ERP components significantly differentiated youth with and without anxiety disorders, both in early-stage

$(\mathrm{P} 1, \mathrm{~N} 170)$ and late-stage (P2, P3) attentional processing, while behavioral measures of attention to threat did not.

Having identified neural markers in Study 1, I next will describe my efforts to pilot test a translational intervention designed to target these neural markers and reduce anxiety in youth CBT nonresponders (Study 2). Study 2 included six youth CBT nonresponders who completed a four-week course of ABMT; all youths completed sessions without any missed or rescheduled appointments. These youths also displayed significantly lower levels of anxiety symptoms following treatment.

Having established the feasibility and acceptability of ABMT in youth anxiety CBT nonresponders in Study 2, I will conclude by describing my work to examine the influence of ABMT on neural makers of attention to threat in Study 3. In Study 3, I investigated changes in P1, N170, P2, and P3 components in N=30 youth CBT nonresponders who were randomly assigned to either a Control Task (CT, $n=16)$ or 
active treatment (ABMT, $n=14)$. I found that ABMT led to significant increases in attentional processing for neutral facial stimuli as opposed to threat facial stimuli, as indicated by neural markers (ERP components P1, N170 and P3), at post-treatment and at eight weeks after the end of treatment.

In summary, these three studies establish ERP markers elicited in the dot probe task that significantly distinguish youth anxiety CBT nonresponders from typically developing youth, the feasibility of ABMT as a promising adjuvant for CBT nonresponders in youth, and the influence of ABMT on ERP markers. Importantly, these studies also demonstrate significant anxiety reduction effects in ABMT, addressing the problem of 'what to do' with a treatment resistant population, CBT nonresponders.

\section{Current and Future Directions}

Now that I have examined the influence of ABMT on neural markers of attention to threat in youth anxiety CBT nonresponders, I envision multiple future directions. One important direction for future research will be to identify neural markers of attention to threat that prospectively predict CBT nonresponse in youth with anxiety disorders. The identification of such markers would inform the development and evaluation of adaptive strategies to intervene earlier with possible CBT nonresponders using ABMT. Instead of waiting for youth to complete and fail to respond to a full course of CBT, the presence of these neural markers may be used to initiate treatment ABMT monotherapy or concurrent CBT and ABMT. A second direction for future research will be to compare posttreatment neural markers in ABMT responders to typically developing youth without anxiety disorders. This comparison would allow for a determination as to whether ABMT leads to a normalization of neural markers of attention to threat. Further, regarding the 
directionality of attention training of ABMT (i.e., enhancement of attention for neutral stimuli within ABMT, as found in this dissertation) it is still unknown whether ABMT leads youth to identify threat more quickly and thus elicit more attention towards evaluation of neutral stimuli or whether youth with anxiety interpret neutral faces as threatening. Future studies should investigate this in the interest of refining ABMT. I intend to pursue these future directions and also expand my measurement approach to include neuroimaging of attentional networks in the context of ABMT in youth with chronically-impairing internalizing disorders. 


\section{CHAPTER 1}

\section{NEURAL CORRELATES OF ATTENTIONAL PROCESSING}

IN YOUTH WITH AND WITHOUT ANXIETY DISORDERS

This manuscript was resubmitted to Journal of Abnormal Child Psychology on December $12^{\text {th }}, 2017$.

Michele Bechor*, M.S. ${ }^{a}$, Michelle L. Ramos, B.A. ${ }^{a}$, Michael J. Crowley, Ph.D. ${ }^{b}$, Wendy K. Silverman, Ph.D., ABPP ${ }^{\mathrm{b}}$, Jeremy W. Pettit, Ph.D. ${ }^{\mathrm{a}}$, \& Bethany C. Reeb-Sutherland, Ph.D. ${ }^{\mathrm{a}}$

${ }^{\mathrm{a}}$ Department of Psychology, Florida International University, Miami, FL 33199, USA

${ }^{\text {b} Y a l e ~ C h i l d ~ S t u d y ~ C e n t e r, ~ Y a l e ~ U n i v e r s i t y, ~ N e w ~ H a v e n, ~ C T ~ 06520, ~ U S A ~}$

*Corresponding author: Michele Bechor, mbechor@fiu.edu, 305-348-4899, Department of Psychology, Florida International University, Miami, FL 33199.

\section{Acknowledgements}

Work on this project was supported by National Institute of Mental Health grants R34 MH097931 and R01 MH079943 to Jeremy W. Pettit and Wendy K. Silverman, a National Institute of Mental Health grant F31 MH105144-01A1 to Michele Bechor and a National Institute on Drug Abuse K01DA034125 grant to Michael J. Crowley. The 
content is solely the responsibility of the authors and does not necessarily represent the official views of the National Institutes of Health.

\begin{abstract}
Late-stage attentional processing of threatening stimuli, quantified through event-related potentials (ERPs), differentiates youth with and without anxiety disorders. It is unknown whether early-stage attentional processing of threatening stimuli differentiates these groups. Examining both early and late stage attentional processes in youth may advance knowledge and enhance efforts to identify biomarkers for translational prevention and treatment research. Twenty-one youth with primary DSM-IV-TR anxiety disorders (10 males, ages 8-15 years) and 21 typically developing Controls (15 males, ages 8-16 years) completed a dot probe task while electroencephalography (EEG) was recorded, and ERPs were examined. Youth with anxiety disorders showed significantly larger (more positive) P1 amplitudes for threatening stimuli than for neutral stimuli, and Controls showed the opposite pattern. Youth with anxiety showed larger (more negative) N170 amplitudes compared with Controls. Controls showed significantly larger (more positive) P2 and P3 amplitudes, regardless of stimuli valence, compared with youth with anxiety disorders. Event-related potentials observed during the dot probe task indicate youth with anxiety disorders display distinct neural processing during early stage attentional orienting and processing of faces; this was not the case for Controls. Such results suggest these ERP components may have potential as biomarkers of anxiety disorders in youth.
\end{abstract}

Keywords: Event-related potential, youth, anxiety, attention. Abbreviations: DSM-IVTR: Diagnostic and Statistical Manual of Mental Disorders, Fourth Edition, Text 
Revision; ADIS for DSM-IV: C/P: Anxiety Disorders Interview Schedule for DSM-IV:

Child and Parent Versions; ERPs: event-related potentials; EEG: electroencephalogram.

\section{Introduction}

Past research in children and adolescents (hereon referred to as youth) finds heightened attention to threatening stimuli in the development and maintenance of anxiety disorders (Mathews \& MacLeod, 2002b; Mogg \& Bradley, 1998; Vasey, Daleiden, Williams, \& Brown, 1995; Waters, Mogg, Bradley, \& Pine, 2008). Heightened threat processing, commonly documented via behavioral paradigms such as the dot probe task that measure attention bias (Bar-Haim, Lamy, Pergamin, Bakermans-Kranenburg, \& van Ijzendoorn, 2007; Dudeney, Sharpe, \& Hunt, 2015) is consistent with past work on information processing in youth anxiety (Lonigan, Vasey, Phillips, \& Hazen, 2004; Mogg \& Bradley, 1998). Attention is the information processing function that allows individuals to identify and prioritize specific stimuli for elaborated processing, and attention bias refers to the tendency of anxious individuals to selectively allocate attention to threatening stimuli over non-threatening stimuli ( Pine, 2011).

Youth studies using behavioral approaches such as the dot probe task demonstrate their utility in capturing reaction times to emotional stimuli in youth with anxiety (e.g., Price et al., 2013; Waters, Lipp, \& Spence, 2004). However, behavioral paradigms such as the dot probe task assessing reaction times do not provide precise temporal information about where in the stream of attentional processing distinctions exist for anxious compared to typically developing (i.e., control) youth (Bar-Haim et al., 2007; White et al., 2016). The absence of precise temporal information in early attentional 
stages has limited efforts to identify biomarkers that would more accurately inform translational prevention and treatment approaches (Price et al., 2013; Suway et al., 2013). It is unknown whether heightened attention to threat in anxious compared to non-anxious youth reflects differences in early stage orienting and vigilance, response selection, or late stage sustained attention. To advance understanding of the nature of these differences in attentional processing, particularly during the early stages, we examined event-related potentials (ERPs), elicited during a dot probe task in youth with and without anxiety disorders.

Despite concerns about dot probe task reaction time score reliability (e.g., Kappenman, Farrens, Luck, \& Proudfit, 2014), the dot probe can be leveraged with concurrent ERP assessment to capture temporally precise indices of neural activity within a fraction of a second. These neural data, time-locked to the presentation of emotional or neutral faces, may precisely indicate when attentional processes diverge for individuals with anxiety disorders compared with controls. An approach incorporating neural data as such is important because refined temporal knowledge about neural processes offered by ERPs (i.e., with larger component mean amplitudes representing greater allocation of neural resources) allows for consideration of specific early stage attentional processing components that may differentiate youth with anxiety disorders from controls. Such differentiations may lead to refinements in theoretical models of information processing disturbances in anxiety and may suggest biomarkers amenable to prevention and treatment. For example, the existence of early stage attentional processing markers would indicate a need to tailor attention training programs to target early stage orientation and vigilance instead of late stage sustained attention. Further, these components may be used 
as outcome variables to examine the effectiveness of attention training programs that target attention to threat.

In the ERP literature on early attentional processing, the majority of which has used adult samples, four ERP components have been identified as potentially relevant to threat and anxiety disorders, as measured with various behavioral paradigms: P1, P2, P3, and N170. The P1 is an early-stage component related to visuospatial attention to threatening faces (Mueller et al., 2009; Rossignol et al., 2012) and attentional orienting (utilizing the dot probe task; Eldar, Yankelevitch, Lamy, \& Bar-Haim, 2010; Helfinstein, White, Bar-Haim, \& Fox, 2008). The P2 is an early-stage component reflecting activity in response to emotional stimuli with relatively greater salience, especially negativelyvalenced stimuli ( Bar-Haim, Lamy, \& Glickman, 2005; Carretié, Mercado, Hinojosa, Martín-Loeches, \& Sotillo, 2004). The N170 is an early-stage component specifically related to processing of facial structures or formations (Balconi \& Lucchiari, 2005; Eimer, 2000). The P3 is a relatively later-stage component (still within early attentional processing) related to strategic regulation of attention (e.g., Bruin, Kenemans, Verbaten, \& Van der Heijden, 2000), response selection (Falkenstein, Hoormann, \& Hohnsbein, 1999) and response inhibition (Huster, Enriquez-Geppert, Lavallee, Falkenstein, \& Herrmann, 2013).

To date, no study has reported on ERP components associated with attentional processing of threat in youth with anxiety disorders and age-matched control youth using the dot probe task. Information processing models of threat stimuli in anxiety propose that individuals with anxiety disorders display attentional vigilance for potential threat cues in the environment and impaired regulation of attentional deployment to threat cues 
(e.g., Yair Bar-Haim et al., 2007; Cisler \& Koster, 2010). These models suggest distinct processes occurring early in the temporal stream of attentional processing. These early processes of orientation and vigilance for threatening faces can be assessed using the P1, N170 and P2 ERP components, while later regulation of attentional deployment to threatening faces can be quantified by the P3 component. The goal of the current study was to examine early and late stage attentional processing, using the dot probe task and specifically focusing on the P1, P2, P3, and N170 components, in youth with anxiety disorders and control youth.

Research in non-referred samples of youths (and adults) suggests amplitudes in these ERP components during the dot probe task may be significantly associated with anxiety symptom severity. For example, P2 amplitudes during the dot probe task were significantly and positively associated with anxiety severity in a non-referred sample of adults (Eldar et al., 2010), and non-referred adults trained to attend to threatening stimuli displayed pre- to post-training increases in P2 amplitudes during the dot probe task (Suway et al., 2013). Further, P2 amplitudes during the dot probe task were significantly and negatively associated with social anxiety severity in a sample of non-referred youth at risk for anxiety (Thai, Taber-Thomas, \& Pérez-Edgar, 2016). These research findings in non-referred samples highlight the complexity of the association between ERP components during the dot probe task and anxiety, and point to a pressing need to examine whether these ERP components during the dot probe task significantly differ between youth with and without anxiety disorders.

The current study examined whether youth with anxiety disorders significantly differ from age-matched youth without anxiety disorders (Controls) on ERP components 
associated with early and late stage attentional processing of threatening facial stimuli elicited by the dot probe task. Based on research reviewed above, we hypothesized that youth with anxiety disorders compared with age-matched controls would show (1) larger and more positive P1 and P2 amplitudes and more negative N170 amplitudes (i.e., early stage components) when viewing threatening stimuli compared with neutral stimuli, and (2) larger P3 amplitudes (i.e., late stage component) when viewing threatening stimuli compared with neutral stimuli. Such larger amplitudes would represent greater allocation of neural resources when attending to threatening stimuli.

\section{Method}

\section{Participants}

Participants included two groups: 21 youths with anxiety disorders (Anxiety group) and 21 age-matched controls (Control group). The Anxiety group ( $N=21$; mean age: 11.43 years $[\mathrm{SD}=1.99]$, ages 8 to 15 years; 10 males [48\%]) was recruited from a randomized clinical trial of Attention Bias Modification Training (R34 MH097931). All youths in the clinical trial were recruited to participate in the current EEG/ERP study at the baseline assessment of the clinical trial (i.e., before attention bias modification began). Youths from the clinical trial who agreed to participate in the current EEG/ERP study did not significantly differ from youths who declined on any variable of interest, including age, gender, anxiety severity, medication usage or presence of comorbid attention or behavior disorders. All youths in the Anxiety group met criteria for a current, primary DSM-IV-TR anxiety disorder (American Psychiatric Association, 2000): Generalized Anxiety Disorder ( $N=8)$, Social Phobia/Anxiety Disorder $(N=6)$, Specific 
Phobia $(N=3)$, Separation Anxiety Disorder $(N=3)$, and Obsessive-Compulsive Disorder $(N=1)$. Ten youths (48\%) in the Anxiety group met criteria for at least one comorbid anxiety disorder. Five youths in the Anxiety group met diagnostic criteria for a comorbid (non-primary) diagnosis of Attention-Deficit Hyperactivity-Inattentive type (ADHD-I), and three youths met diagnostic criteria for a comorbid (non-primary) diagnosis of Oppositional Defiant Disorder (ODD). Four youths in the Anxiety group were on a stable dose of medication at the time of assessment, for attention deficits $(N=2)$ or for anxiety $(N=2)$.

The Control group ( $N=21$; mean age: 11.52 years [ $\mathrm{SD}=2.25$ ], ages 8 to 16 years; 15 males [71\%]) was recruited via email and flyers. Interested parents of potential Control youth participants completed phone or in-person screening interviews, including screener questions from the Kiddie Schedule for Affective Disorders and Schizophrenia (K-SADS; Kaufman et al., 1997) to confirm that youths did not currently meet criteria for and had never been diagnosed with or treated for neuropsychological, emotional or behavioral disorders, including cognitive impairment, depression, anxiety, ADHD, conduct disorder, or eating disorders. Master's and doctoral level students, trained in the screening protocol, completed screening interviews and made eligibility determinations under the close supervision of the project PIs.

All procedures were approved by the appropriate Institutional Review Board. Informed consent was obtained from all individual participants included in the study. Parents provided informed consent, and youths provided assent. 


\section{Diagnostic Measure}

Anxiety Disorders Interview Schedule for DSM-IV: Child and Parent Versions (ADIS-IV:C/P; Silverman \& A. M. Albano, 1996). The ADIS-IV: C/P is a semi-structured interview designed to assess anxiety and related disorders in youth. Master's and doctoral level graduate students, trained in administration and scoring protocol (having completed didactic instruction, hands on demonstration and role play, and testing out in the assessment protocol), administered the ADIS-C/P to each child and parent in the Anxiety group; diagnoses were given when one or both informants met diagnostic criteria. Before conducting interviews, evaluators met a $100 \%$ reliability criterion on five videotaped child-parent assessments. The ADIS-IV: C/P yields retest reliability kappas between .80 to .92 for diagnoses, and significant associations with youth anxiety ratings (e.g., Silverman, Saavedra, \& Pina, 2001).

\section{Anxiety Severity Ratings}

All youth participants and their parents (usually the mother) were administered the Screen for Child Anxiety Related Emotional Disorders-Child and Parent Versions (SCARED-C/P).

SCARED-C (SCARED-C; Birmaher et al., 1999; Birmaher et al., 1997). The SCARED-C consists of 41 items on which youth rate anxiety symptoms on a three-point scale. Test-retest reliability is satisfactory to excellent (ranging from .70 to .90). The SCARED-C has demonstrated good convergent and divergent validity compared with other widely used screening scales (Birmaher et al., 1999; Birmaher et al., 1997). In this sample, the alpha coefficient was .91 . 
SCARED-P (SCARED-P; Birmaher et al., 1999; Birmaher et al., 1997). The SCARED-P consists of 41 items on which parents rate youth anxiety symptoms on a three-point scale. The reliability and validity of the SCARED-P have been demonstrated repeatedly and mirror those of the SCARED-C (Birmaher et al., 1999; Birmaher et al., 1997). In this sample, the alpha coefficient was .96.

Past studies in this area have either examined SCARED-C and SCARED-P scores separately (e.g., Wren et al., 2007), or have averaged child and parent ratings to examine a single SCARED-C/P score (Roy et al., 2013). To facilitate comparison with all past studies in this area and build the literature on approaches to using ratings from different informants, we separately report on SCARED-C, SCARED-P, and averaged SCARED$\mathrm{C} / \mathrm{P}$ scores.

\section{Dot-Probe Task}

The emotional faces dot-probe task developed by MacLeod, Mathews \& Tata (1986), modified for use in child anxiety studies (TAU-NIMH ABMT initiative; http://people.socsci.tau.ac.il/mu/anxietytrauma/tau-nimh-abmt-initiative-participating/), was used to obtain a behavioral measure of attentional bias towards threatening stimuli.

In each trial, a white fixation cross appeared for 500 milliseconds $(\mathrm{ms})$ in the center of the screen, followed by a pair of faces (chromatic) appearing for $500 \mathrm{~ms}$. The pair of faces of the same actor showing a neutral or angry (i.e., threatening) expression (Tottenham et al., 2009) appeared on the top and bottom of the screen. In each trial, the pair of faces displayed was one of three combinations (80 neutral-angry, 80 angryneutral, or 80 neutral-neutral) for a total of 160 neutral-threat (NT) trials and 80 neutralneutral (NN) trials. Immediately following the faces, a probe (" $<$ " or " >") appeared in the 
location of either the top or bottom face. Participants were instructed to indicate the orientation of the probe by clicking the left or right mouse button (left for "<", right for ">”) using their dominant hand. Stimuli (chromatic photographs of same-actor face pairs, $45 \mathrm{~mm}$ in width and $34 \mathrm{~mm}$ in height) were presented with a laptop with a 14-in monitor. The probe remained on-screen until the participant responded or for $1000 \mathrm{~ms}$, response was followed by an inter-trial interval $(500 \mathrm{~ms})$, and then the next trial began immediately. Angry-face location, probe location, probe type, and actor were fully counterbalanced in presentation. The importance of completing the task as quickly as possible without compromising accuracy was emphasized. Trials were presented using EPrime software (Psychology Software Tools, Pittsburgh, PA).

Responses on the dot-probe task were used to calculate mean reaction times (RT) on trials, total number of accurate trials, and attention bias scores. Trials in which the probe replaced the angry face were considered congruent trials, and trials in which the probe replaced the neutral face were considered incongruent trials. Bias scores were computed as reaction time differences of incongruent minus congruent trials. Positive attention bias scores indicated a bias toward angry faces (i.e., threat) and negative values indicated a bias away from threat. Inaccurate responses, trials with response latencies $<150 \mathrm{~ms}$ and $>1200 \mathrm{~ms}$, and trials with response latencies +/- 2.5 SDs from the participant's mean were excluded (e.g., Eldar et al., 2010).

\section{Electrophysiological Recording}

Each participant was fitted with a 64-electrode elasticized nylon cap (WaveGuard; Advanced Neuro Technology, Enschede, Netherlands) with sewn-in $\mathrm{Ag} / \mathrm{AgCl}$ shielded electrodes following the international 10-20 electrode system. The raw signal was 
amplified by 25,000 using a high-input impedance AsaLab amplifier (Advanced Neuro Technology, Enschede, Netherlands). The EEG data was sampled at $1024 \mathrm{~Hz}$ with a high-pass filter of $.3 \mathrm{~Hz}$. Data acquisition began once impedance values were below 50 $\mathrm{k} \Omega$ (a resistance level used for studies in comparable age ranges; Thai et al., 2016). During recording, ERPs were referenced to $\mathrm{CPz}$, and $\mathrm{AFz}$ served as the ground electrode. The EEG data were further analyzed offline using EEGLAB (Delorme \& Makeig, 2004) and ERPLAB (Lopez-Calderon \& Luck, 2014) software.

Event-related potentials. In post-processing, EEG data were re-referenced to average reference and re-filtered with a low-pass filter of $30 \mathrm{~Hz}$. Data were baselinecorrected to the average voltage during the $100 \mathrm{~ms}$ prior to stimulus onset (i.e., each trial of angry and neutral faces). Data were resampled offline at $512 \mathrm{~Hz}$. Ocular and motor artifacts exceeding $\pm 75 \mathrm{mV}$ were rejected. Data were segmented and visually inspected for additional ocular and motion artifact. Epochs containing blink activity were removed as electrooculogram (EOG) contamination. Trials consisted of a $100 \mathrm{~ms}$ baseline period and $500 \mathrm{~ms}$ period following onset of facial stimuli. Boxplots for numbers of NT and NN trials remaining after rejection were inspected for outliers; an outlier was defined as scores $>2$ SD from the mean on both the NT and NN amplitude of a particular component (P1, P2, P3, N170) at a particular site (POz, Oz). No outliers were identified.

Stimulus-evoked ERP components. Specific components of interest were P1, N170, P2, and P3. In line with previous pediatric (Batty \& Taylor, 2006; O'Toole, DeCicco, Berthod, \& Dennis, 2013; Segalowitz, Santesso, \& Jetha, 2010) and adult (Eldar et al., 2010; Mühlberger et al., 2009) ERP studies, P1, N170, P2, and P3 components were examined at midline parieto-occipital sites $\mathrm{POz}$ and Oz. Mean number 
of epochs remaining after artifact rejection (NT, NN), used to generate grand averaged wave forms, were comparable $(p s>.644)$ across Control (NT: $M=111.95, S D=24.91$; $\mathrm{NN}: M=54.57, S D=13.42)$ and Anxiety $(\mathrm{NT}: M=110.19, S D=23.76 ; \mathrm{NN}: M=56.43$, $S D=12.48$ ) groups. Each participant's grand average waveforms were visually inspected to determine the window in which the maximal peak of each proposed component was found. Exhaustive windows were shaped by minima and maxima of peak onset ranges recorded per participant, and group-wise grand averages were inspected for each component to confirm the latency windows included all participants' components. Nonoverlapping latency windows for P1 (100-160 ms), N170 (170-230 ms), P2 (230-280 ms), and P3 (300-380 ms) were generated separately in ERPLAB and individual mean amplitudes and peak latencies for each component were imported into statistical software program SPSS version 22.0 (SPSS, 2013) for statistical analysis.

\section{Statistical Analysis}

Independent samples $t$-tests were used to examine group differences on age, attention bias reaction time (RT) scores and SCARED-C/P scores; a chi-square analysis was used to examine gender distribution across groups. Initial analyses employed a 2 x 2 x 2 Analysis of Covariance (ANCOVA) with site (POz, Oz) and stimulus (trial type: NT or $\mathrm{NN}$ ) as within-subjects factors and group (Control or Anxious) as the between-subjects factor. A priori decisions were made to include current medication status and comorbid ADHD-I diagnosis as covariates as these may significantly affect attentional processes (Weissman, Chu, Reddy, \& Mohlman, 2012). Additionally, age was included as a covariate to adjust for possible developmental effects on attentional processes. We utilized used the Greenhouse-Geisser correction method for corrections of violations of 
sphericity. For the majority of components, a significant main effect of site was found $\left(\mathrm{P} 1: F[1,37]=13.09, p=.001, \eta_{p}^{2}=.261 ; \mathrm{N} 170: F[1,37]=4.59, p=.039, \eta_{p}^{2}=.036 ; \mathrm{P} 3:\right.$ $\left.F[1,37]=5.11, p=.030, \eta_{p}{ }^{2}=.110 ; \mathrm{P} 2: F[1,37]=2.20, p=.146, \eta_{p}{ }^{2}=.056\right)$, therefore, all subsequent analyses examined effects at $\mathrm{Oz}$ and $\mathrm{POz}$ separately. For each ERP component, mean amplitude and peak latency were separately subjected to a 2 x 2 Analysis of Covariance (ANCOVA) with stimulus (trial type: NT or NN) as withinsubjects factor and with group (Control or Anxious) as between-subjects factor, with the three covariates described above. Post-hoc analyses were used to examine significant interaction and main effects.

\section{Results}

\section{Attention to Threat and Anxiety Severity Ratings}

Groups did not significantly differ by age, $t(40)=.145, p=.885, d=.04$, or gender, $\chi^{2}(1)=2.47, p=.116$. Mean RTs, accuracy scores and threat bias scores on the dot probe task and mean scores on the SCARED-C/P are presented in Table 1. Compared to the Control group, the Anxiety group displayed significantly higher scores on the SCARED-P, $t(40)=-5.17, p<.001, d=1.60$, and the averaged SCARED-C/P, $t(40)=-$ 4.077, $p=<.001, d=1.26$, but not SCARED-C, $t(40)=-.930, p=.358, d=.28$. Mean RTs, accuracy, and bias scores on the dot probe task did not differ significantly between groups $(p s>.793)$.

Electrophysiological Data: early-stage attentional processing. Figure 1(a) shows scalp distributions of mean amplitudes during NT trials across Anxiety and Control groups, and Figures 1(b) and 1(c) present grand average waveforms during NT trials for Anxiety and 
Control groups at sites POz and Oz, respectively. Figures 2(a), 2(b) and 2(c) present the same information as Figures 1(a-c) for NN trials.

P1. No significant main effects for P1 mean amplitude were found at POz or Oz. The stimulus (NT vs NN) by group (Anxiety vs Control) interaction effect for P1 mean amplitude was statistically significant at POz, $F(1,37)=4.06, p=.05, \eta_{\mathrm{p}}{ }^{2}=.10 . \mathrm{P} 1$ amplitude was more positive during NN trials in the Control group $(M=18.78, S E=$ 2.61) than the Anxiety group $(M=17.09, S E=2.12)$ (Figure $1 \mathrm{~b})$. In contrast, P1 amplitude was more positive during NT trials in the Anxiety group $(M=18.08, S E=$ 2.15) than the Control group $(M=17.93, S E=2.61)$ (Figure 2b). No significant main effects of group were found in post-hoc analyses for stimulus type, NT: $F(1,37)=.030, p$ $=.863, \eta_{\mathrm{p}}^{2}=.001 ; \mathrm{NN}: F(1,37)=.244, p=.624, \eta_{\mathrm{p}}^{2}=.007$. No significant main or interaction effects for peak latency were found at $\mathrm{POz}$ or Oz.

N170. The main effect for group on N170 mean amplitude was statistically significant at $\mathrm{Oz}, F(1,37)=4.69, p=.037, \eta_{\mathrm{p}}{ }^{2}=.113$, as was the main effect of stimulus type (NT vs NN), $F(1,37)=5.69, p=.022, \eta_{\mathrm{p}}^{2}=.133$ (Figures $\left.1 \mathrm{c}, 2 \mathrm{c}\right)$. Collapsed across stimulus types, N170 amplitude was significantly more negative for the Anxiety group (NT: $M=-6.40, S E=12.19, \mathrm{NN}: M=-5.71, S E=11.88$ ) than the Control group (NT: $M$ $=-1.68, S E=8.68, \mathrm{NN}: M=-2.21, S E=9.48)$. Collapsed across groups, $\mathrm{N} 170$ amplitude was significantly more negative during NT trials than during NN trials. A significant main effect of stimulus type was also found for peak latency, $F(1,37)=7.24, p=.011$, $\eta_{\mathrm{p}}{ }^{2}=.164$, with peak onset occurring significantly faster for NT trials (Control $M=$ 201.73, $S E=13.79$, Anxiety $M=202.85, S E=18.84)$ than NN trials (Control $M=$ 
202.47, $S E=14.66$, Anxiety $M=205.26, S E=18.28)$. No significant main or interaction effects for N170 mean amplitude or peak latency were found at POz.

P2. The main effect of group on P2 mean amplitude was statistically significant at Oz, $F(1,37)=4.33, p=.044, \eta_{\mathrm{p}}^{2}=.105$ (Figures 1c, 2c). Collapsed across stimulus types, P2 amplitude was significantly more positive for the Control group (NT: $M=5.70, S E=$ $8.82, \mathrm{NN}: M=5.77, S E=9.01)$ than the Anxiety group (NT $M=.092, S E=12.10, \mathrm{NN}$ : $M=-.004, S E=14.65)$. No significant interaction or main effects were found for P2 peak latency. No significant main or interaction effects for P2 mean amplitude or peak latency were found at $\mathrm{POz}$.

\section{Electrophysiological Data: late-stage attentional processing}

P3. The main effect of group on P3 mean amplitude was statistically significant at Oz, $F(1,37)=4.43, p=.042, \eta_{\mathrm{p}}^{2}=.107$ (Figures 1c, 2c). Collapsed across stimulus types, P3 amplitude was significantly more positive for the Control group (NT: $M=7.18, S E=$ $5.31, \mathrm{NN}: M=7.12, S E=6.53)$ than the Anxiety group (NT $M=3.88, S E=11.51, \mathrm{NN}$ : $M=2.65, S E=10.87)$. No significant main or interaction effects were found for P3 peak latency. No significant main or interaction effects for P3 mean amplitude or peak latency were found at $\mathrm{POz}$.

\section{Discussion}

This is the first study to examine neural correlates of attentional processing to threatening and non-threatening facial stimuli elicited by the dot probe task in youth with and without anxiety disorders. Our findings indicate that ERP neural responses reflecting early and late attentional processing, across neutral and threatening facial stimuli, differentiate youth with and without anxiety disorders. For early attentional processing, 
P1 amplitude was larger for threatening stimuli than for neutral stimuli in the Anxiety group, whereas the opposite pattern was observed in the Control group. N170 amplitudes were significantly larger (more negative) in the Anxiety group than in the Control group. P2 was significantly larger in the Control group than in the Anxiety group. For late attentional processing, P3 was significantly larger in the Control group than in the Anxiety group.

Consistent with information processing theories of anxiety, our findings provide evidence of distinct neural processing of facial and/or threatening stimuli in youth with anxiety disorders during attentional stages corresponding to attentional orienting, face recognition and threat detection and, at a later stage, to attentional regulation. The general pattern of findings aligns with previous findings in adults' ERP components elicited by emotional face tasks, including the dot probe task (Bar-Haim et al., 2005; Helfinstein et al., 2008), probe discrimination task (Eldar, Yankelevitch, Lamy \& Bar-Haim, 2010) and emotional Flanker task (Dennis \& Chen, 2009; Moser, Huppert, Duval \& Simons, 2008), in which both early stage attentional processing related to threat identification and later stage attentional processing related to inhibition were significantly associated with anxiety. However, as we elaborate below, specific findings on individual components differ from what has been reported in samples of adults and one sample of children.

Youth with anxiety disorders devoted relatively more early attentional resources when orienting towards threatening facial stimuli (i.e., relatively larger P1) and when processing faces regardless of emotional valence (i.e., relatively larger N170 amplitudes) compared to Controls. In contrast, youth with anxiety disorders devoted fewer attentional resources to processing of emotion (i.e., relatively smaller P2) and late-stage attentional 
regulation (i.e., relatively smaller P3) than Control youth. These findings suggest youth with anxiety respond differentially to emotional stimuli in very early processing (i.e., at P1) but do not differentiate emotional face type in later processing (i.e., at N170, P2 and $\mathrm{P} 3$ ); that is, the findings for $\mathrm{N} 170, \mathrm{P} 2$, and $\mathrm{P} 3$ were not specific to threatening faces. Further, these findings suggest that relative to controls, youth with anxiety disorders show greater use of resources for face recognition and reduced use of resources in late stage attentional regulation. Lower amplitudes for ERP components after early attentional orienting (P2 and P3) in youth with anxiety disorders, and not in controls, may suggest relatively less developed attentional processing (i.e., poorer attentional control; Susa, Pitică, Benga, \& Miclea, 2012) in anxious youth. The current results partially contrast with a recent ERP study in youth with behavioral inhibition (BI), which found early components of attention, such as $\mathrm{P} 1$ and $\mathrm{N} 170$, are relatively insensitive to emotional content in the dot probe task (Thai et al., 2016); youth in our sample responded to emotional content in very early processing (i.e., P1) and did not respond to emotional content in later processing (i.e., N170, P2 \& P3). Further, in the Thai et al. (2016) study, youth with and without BI were not differentiated by P1, and the current study found youth anxiety showed higher P1 in response to threat stimuli compared with controls.

The results found for P1 extend previous findings in nonreferred youth using different emotional face tasks (e.g., Batty \& Taylor, 2006; Taylor, Edmonds, McCarthy, \& Allison, 2001) to youth with anxiety disorders, further demonstrating that the P1 component may be sensitive to emotional versus non-emotional facial stimuli. Our results are also consistent with previous work linking P1 to increased attentional processing of emotional faces in youth with anxiety (Batty \& Taylor, 2003; Hum, Manassis, \& Lewis, 
2013) and adults with anxiety (Holmes, Nielsen, \& Green, 2008; Mueller et al., 2009; Pourtois, Dan, Grandjean, Sander, \& Vuilleumier, 2005).

The current findings for N170 extend previous adult and child anxiety work that showed enhanced N170 components for threat stimuli (e.g., Balconi \& Lucchiari, 2005; Bentin, Allison, Puce, Perez, \& McCarthy, 1996; Eimer, 2000; Kolassa \& Miltner, 2006; Mueller et al., 2009; O'Toole et al., 2013). Compared to Control youth, we observed that youth with anxiety disorders exhibited significantly larger (more negative) N170 mean amplitudes when viewing both threatening and neutral stimulus trials. Threat trials also elicited larger N170 (more negative) responses than neutral trials. It is possible that these components elicited in the dot probe task are more strongly associated with the current presence of an anxiety disorder (as we observed) than future risk for developing an anxiety disorder (i.e., behavioral inhibition). This possibility of strong neural-behavioral association is consistent with the finding that young children with heightened anxiety and enhanced N170 responses to threat faces displayed higher symptoms of anxiety later in childhood (O'Toole et al., 2013).

Past research in youth with BI, not anxiety disorders, found a significant association between larger P2 responses to faces in general (neutral and threat combined; Thai et al., 2016). Control youth in the present study showed a similar pattern, suggesting that larger P2 responses to faces in general may be normative in youth who do not currently experience severe levels of anxiety. In contrast, youth with anxiety disorders displayed smaller P2 responses to faces in general. If replicated, this smaller P2 response to faces in youth with anxiety disorders may indicate dampened allocation of attentional resources to emotionally salient facial stimuli at this stage of processing. The P2 findings 
in this study differ from previous work in adults using the dot probe, with populations with anxiety showing larger P2 responses to threat (O’Toole \& Dennis, 2012; Suway et al., 2013). Possibly, sensitivity to threatening facial stimuli, indexed by the P2, develops in later adolescence or early adulthood.

The P3 component, as with the P2, was larger in Controls compared to youth with anxiety disorders, regardless of stimulus type. Ours was the first study to report larger P3s in control youth. Past research in nonreferred adults found the P3 component differentiates emotional content of faces (Holmes et al., 2008; Moser, Huppert, Duval, \& Simons, 2008; Pourtois, Grandjean, Sander, \& Vuilleumier, 2004), with adults showing larger P3 components when viewing neutral stimuli. Such differentiation of emotional valence was not found in the current study. The discrepancy in findings across youth and adult samples could reflect developmental differences, clinical status differences or paradigm differences. However, framed within the literature on sustained attentional processing and regulation, and as $\mathrm{P} 3$ was higher in Controls than in youth with anxiety disorders (as with P2), this finding is consistent with work in adults linking enhanced P3 with stimulus evaluation and with response selection (Falkenstein, Hohnsbein, \& Hoormann, 1994; Verleger, 1997). Our P3 finding further indicates that late-stage attentional regulation in typically developing youth appears more consistent with that of adults. Studies of P3 in children with anxiety disorders suggest that P3 is enhanced when youth must process and inhibit task-irrelevant stimuli with high emotional valence (Éismont, Lutsyuk, \& Pavlenko, 2009). In the dot probe task, all facial stimuli are taskirrelevant. Thus, a relatively higher P3 during all trials may suggest typically developing 
youth devote more attentional resources to late-stage processing emotional facial stimuli than youth with anxiety disorders.

We know of only one study that has reported on ERP components in youth with and without anxiety disorders using an emotional face-matching task (Kujawa, MacNamara, Fitzgerald, Monk, \& Phan, 2015). Specifically, users were required to select which of two faces (neutral and emotional) matched a given emotional face. After examining three latency windows (early, middle and late) of the late positive potential (LPP), Kujawa and colleagues found that late stage LPP was enhanced following angry and fearful faces (1000-2000 ms) in those with anxiety disorders but not in those without. The Kujawa et al., (2015) study demonstrated youths with anxiety disorders exhibit distinct markers in late stage, sustained attentional processing of emotional stimuli. Measurement of the LPP in the present study was not feasible (given trial length of the dot probe task does not typically exceed 1000-1500 seconds), preventing direct comparisons between the results of the current study and the results of the LPP study. However, taken together, both studies' results suggest both early and late stage attentional processing components may be promising markers of threat processing in youth with anxiety disorders. Future research on the dot probe should include longer trial durations in order to examine the LPP in addition to earlier stage components.

As in some other studies in youth (Benoit, McNally, Rapee, Gamble, \& Wiseman, 2007; Price et al., 2013; Salum et al., 2013), no between groups differences were found on a behavioral reaction time measure of attention bias to threat. Reaction time measures on the dot-probe task may be insensitive to attention-related processes because motor output on attention tasks arises from a complex series of processes, only some of which 
are related to individual differences in anxiety (MacNamara, Kappenman, Black, Bress, \& Hajcak, 2013; White et al., 2016). The present findings indicate that ERP components elicited in the dot-probe task are sensitive to attention-related processes in youth and thus hold greater promise as potential biomarkers for translational prevention and treatment research.

Current findings should be evaluated in light of the study's limitations. One limitation was relatively small sample size, which limited statistical power and prevented us from examining possible individual differences in ERP amplitudes as function of age, sex, anxiety severity or diagnostic category and warrants caution in interpretation of results. The age range of the current study, spanning across puberty, may have limited our ability to account for the influence of this developmental stage. A second limitation was the inclusion of youth with a range of primary anxiety disorders, including specific phobia, a disorder less linked with attention bias to threat. A third limitation was that we relied on a relatively brief window for attention processing $(500 \mathrm{~ms})$, which is in part a result of the duration of stimulus presentation within the dot probe task. Given the current study design and the relatively brief presentation length of the facial stimuli, this current study was unable to assess neural correlates of late-stage attentional processing such as the LPP. Future studies are encouraged to consider very late stage attentional processing of threat, especially in light of evidence that the LPP ERP component may significantly differ between clinic-referred youth with anxiety disorders (Kujawa et al., 2015).

In summary, the current study provides evidence that youth with anxiety disorders significantly differ from typically developing youth in early and late neural correlates of attentional processing of threatening and non-threatening facial stimuli. These results do 
not only indicate heightened attention to threat stimuli in anxiety but also indicate larger attentional responses in early processing and blunted responses in later processing. The neural components (P1, N170, P2, and P3) observed within the context of the dot probe task hold promise as biomarkers in youth for translational prevention and treatment research. Future research is encouraged to investigate these potential biomarkers, including their sensitivity to attention training regimens designed to reduce anxiety (e.g., Attention Bias Modification Training; Yair Bar-Haim, 2010).

\section{Ethical Approval}

All procedures performed in studies involving human participants were in accordance with the ethical standards of the institutional and/or national research committee and with the 1964 Helsinki declaration and its later amendments or comparable ethical standards.

\section{References}

Association, A. P. (2000). Diagnostic and statistical manual of mental disorders DSMIV-TR fourth edition (text revision).

Balconi, M., \& Lucchiari, C. (2005). Event-related potentials related to normal and morphed emotional faces. The Journal of psychology, 139(2), 176-192.

Bar-Haim, Y. (2010). Research review: Attention bias modification (ADM): A novel treatment for anxiety disorders (Vol. - 51, pp. - 859-- 870). United Kingdom United Kingdom: Wiley-Blackwell Publishing Ltd. Blackwell Publishing.

Bar-Haim, Y., Lamy, D., \& Glickman, S. (2005). Attentional bias in anxiety: A behavioral and ERP study. Brain and Cognition, 59(1), 11-22. doi:http://dx.doi.org.ezproxy.fiu.edu/10.1016/j.bandc.2005.03.005

Bar-Haim, Y., Lamy, D., Pergamin, L., Bakermans-Kranenburg, M., \& van Ijzendoorn, M. H. (2007). Threat-related attentional bias in anxious and nonanxious individuals: A meta-analytic study. Psychological bulletin, 133(1), 1-1-24. doi:10.1037/0033-2909.133.1.1

Batty, \& Taylor. (2006). The development of emotional face processing during childhood. Developmental science, 9(2), 207-220. 
Batty, \& Taylor, M. J. (2003). Early processing of the six basic facial emotional expressions. Cognitive Brain Research, 17(3), 613-620.

Benoit, K. E., McNally, R. J., Rapee, R. M., Gamble, A. L., \& Wiseman, A. L. (2007). Processing of emotional faces in children and adolescents with anxiety disorders. Behaviour Change, 24(4), 183-194. doi:http://dx.doi.org.ezproxy.fiu.edu/10.1375/bech.24.4.183

Bentin, S., Allison, T., Puce, A., Perez, E., \& McCarthy, G. (1996). Electrophysiological studies of face perception in humans. Journal of cognitive neuroscience, $8(6)$, 551-565.

Birmaher, B., Brent, D. A., Chiappetta, L., Bridge, J., Monga, S., \& Baugher, M. (1999). Psychometric properties of the Screen for Child Anxiety Related Emotional Disorders (SCARED): a replication study. Journal of the American Academy of Child \& Adolescent Psychiatry, 38(10), 1230-1236.

Birmaher, B., Khetarpal, S., Brent, D., Cully, M., Balach, L., Kaufman, J., \& Neer, S. M. (1997). The screen for child anxiety related emotional disorders (SCARED): Scale construction and psychometric characteristics. Journal of the American Academy of Child \& Adolescent Psychiatry, 36(4), 545-553.

Bruin, K., Kenemans, J., Verbaten, M., \& Van der Heijden, A. (2000). Habituation: an event-related potential and dipole source analysis study. International Journal of Psychophysiology, 36(3), 199-209.

Carretié, L., Mercado, F., Hinojosa, J. A. J. A., Martín-Loeches, M., \& Sotillo, M. (2004). Valence-related vigilance biases in anxiety studied through event-related potentials. Journal of Affective Disorders, 78(2), 119-130. doi:http://dx.doi.org/10.1016/S0165-0327(02)00242-2

Cisler, J. M., \& Koster, E. H. W. (2010). Mechanisms of attentional biases towards threat in anxiety disorders: an integrative review (Vol. - 30, pp. - 203-- 216).

Delorme, A., \& Makeig, S. (2004). EEGLAB: an open source toolbox for analysis of single-trial EEG dynamics including independent component analysis. Journal of neuroscience methods, 134(1), 9-21.

Dudeney, J., Sharpe, L., \& Hunt, C. (2015). Attentional bias towards threatening stimuli in children with anxiety: a meta-analysis. Clinical Psychology Review, 40, 66-75.

Eimer, M. (2000). The face-specific N170 component reflects late stages in the structural encoding of faces. Neuroreport, 11(10), 2319-2324.

Éismont, E., Lutsyuk, N., \& Pavlenko, V. (2009). Reflection of anxiety in the characteristics of evoked EEG potentials in 10-to 11-year-old children. Neurophysiology, 41(6), 435-442. 
Eldar, Yankelevitch, R., Lamy, D., \& Bar-Haim, Y. (2010). Enhanced neural reactivity and selective attention to threat in anxiety. Biological Psychology, 85(2), 252-257. doi:http://dx.doi.org/10.1016/j.biopsycho.2010.07.010

Falkenstein, Hohnsbein, J., \& Hoormann, J. (1994). Event-related potential correlates of errors in reaction tasks. Electroencephalography and clinical neurophysiology. Supplement, 44, 287-296.

Falkenstein, Hoormann, J., \& Hohnsbein, J. (1999). ERP components in Go/Nogo tasks and their relation to inhibition. Acta psychologica, 101(2), 267-291.

Helfinstein, S. M., White, L. K., Bar-Haim, Y., \& Fox, N. A. (2008). Affective primes suppress attention bias to threat in socially anxious individuals. Behaviour Research and Therapy, 46(7), 799-810. doi:http://dx.doi.org/10.1016/j.brat.2008.03.011

Holmes, A., Nielsen, M. K., \& Green, S. (2008). Effects of anxiety on the processing of fearful and happy faces: an event-related potential study. Biological Psychology, 77(2), 159-173.

Hum, K. M., Manassis, K., \& Lewis, M. D. (2013). Neural mechanisms of emotion regulation in childhood anxiety. Journal of Child Psychology and Psychiatry, 54(5), 552-564. doi:http://dx.doi.org.ezproxy.fiu.edu/10.1111/j.1469$\underline{7610.2012 .02609 . x}$

Huster, R. J., Enriquez-Geppert, S., Lavallee, C. F., Falkenstein, M., \& Herrmann, C. S. (2013). Electroencephalography of response inhibition tasks: functional networks and cognitive contributions. International Journal of Psychophysiology, 87(3), 217-233.

Kappenman, E. S., Farrens, J. L., Luck, S. J., \& Proudfit, G. H. (2014). Behavioral and ERP measures of attentional bias to threat in the dot-probe task: Poor reliability and lack of correlation with anxiety.

Kaufman, J., Birmaher, B., Brent, D., Rao, U., Flynn, C., Moreci, P., . . Ryan, N. (1997). Schedule for affective disorders and schizophrenia for school-age children-present and lifetime version (K-SADS-PL): initial reliability and validity data. Journal of the American Academy of Child \& Adolescent Psychiatry, 36(7), 980-988.

Kolassa, I.-T., \& Miltner, W. H. (2006). Psychophysiological correlates of face processing in social phobia. Brain Research, 1118(1), 130-141.

Kujawa, A., MacNamara, A., Fitzgerald, K. D., Monk, C. S., \& Phan, K. L. (2015). Enhanced neural reactivity to threatening faces in anxious youth: Evidence from event-related potentials. Journal of Abnormal Child Psychology. doi:http://dx.doi.org/10.1007/s10802-015-0029-4 
Lonigan, C. J., Vasey, M. W., Phillips, B. M., \& Hazen, R. A. (2004). Temperament, Anxiety, and the Processing of Threat-Relevant Stimuli. Journal of Clinical Child and Adolescent Psychology, 33(1), 8-20.

Lopez-Calderon, J., \& Luck, S. J. (2014). ERPLAB: an open-source toolbox for the analysis of event-related potentials. Frontiers in Human Neuroscience, 8.

MacLeod, C., Mathews, A., \& Tata, P. (1986). Attentional bias in emotional disorders. Journal of abnormal psychology, 95(1), 15.

MacNamara, A., Kappenman, E. S., Black, S. R., Bress, J. N., \& Hajcak, G. (2013). Integratived behavioral and electrocortical measures of attentional bias toward threat. In K. C. Barrett, N. A. Fox, G. A. Morgan, D. J. Fidler, \& L. A. Daunhauer (Eds.), Handbook of self-regulatory processes in development: New directions and international perspectives (pp. 215-243). New York: Psychology Press.

Mathews, A., \& MacLeod, C. (2002). Induced processing biases have causal effects on anxiety. Cognition and Emotion, 16(3), 331-354.

Mogg, K., \& Bradley, B. P. (1998). A cognitive-motivational analysis of anxiety. Behaviour Research and Therapy, 36(9), 809-848.

Moser, J. S., Huppert, J. D., Duval, E., \& Simons, R. F. (2008). Face processing biases in social anxiety: an electrophysiological study. Biological Psychology, 78(1), 93103.

Mueller, E. M., Hofmann, S. G., Santesso, D. L., Meuret, A. E., Bitran, S., \& Pizzagalli, D. A. (2009). Electrophysiological evidence of attentional biases in social anxiety disorder. Psychol Med, 39(7), 1141-1152. doi:10.1017/S0033291708004820

Mühlberger, A., Wieser, M. J., Herrmann, M. J., Weyers, P., Tröger, C., \& Pauli, P. (2009). Early cortical processing of natural and artificial emotional faces differs between lower and higher socially anxious persons. Journal of neural transmission, 116(6), 735-746.

O'Toole, L. J., DeCicco, J. M., Berthod, S., \& Dennis, T. A. (2013). The N170 to angry faces predicts anxiety in typically developing children over a two-year period. Developmental neuropsychology, 38(5), 352-363.

O’Toole, L., \& Dennis, T. A. (2012). Attention training and the threat bias: An ERP study. Brain and Cognition, 78(1), 63-73. doi:http://dx.doi.org.ezproxy.fiu.edu/10.1016/j.bandc.2011.10.007

Pine, D. S. (2011). The brain and behavior in childhood and adolescent anxiety disorders. Anxiety disorders in children and adolescents, 179-197.

Pourtois, G., Dan, E. S., Grandjean, D., Sander, D., \& Vuilleumier, P. (2005). Enhanced extrastriate visual response to bandpass spatial frequency filtered fearful faces: 
Time course and topographic evoked-potentials mapping. Human brain mapping, 26(1), 65-79. doi:http://dx.doi.org.ezproxy.fiu.edu/10.1002/hbm.20130

Pourtois, G., Grandjean, D., Sander, D., \& Vuilleumier, P. (2004). Electrophysiological correlates of rapid spatial orienting towards fearful faces. Cerebral cortex, 14(6), 619-633.

Price, R. B., Siegle, G. J., Silk, J. S., Ladouceur, C., McFarland, A., Dahl, R. E., \& Ryan, N. D. (2013). Sustained neural alterations in anxious youth performing an attentional bias task: A pupilometry study. Depression and Anxiety, 30(1), 22-30. doi:http://dx.doi.org.ezproxy.fiu.edu/10.1002/da.21966

Rossignol, Campanella, S., Maurage, P., Heeren, A., Falbo, L., \& Philippot, P. (2012). Enhanced perceptual responses during visual processing of facial stimuli in young socially anxious individuals. Neuroscience letters, 526(1), 68-73.

Roy, A. K., Fudge, J. L., Kelly, C., Perry, J. S., Daniele, T., Carlisi, C., . . Pine, D. S. (2013). Intrinsic functional connectivity of amygdala-based networks in adolescent generalized anxiety disorder. Journal of the American Academy of Child \& Adolescent Psychiatry, 52(3), 290-299. e292.

Salum, G., Mogg, K., Bradley, B., Gadelha, A., Pan, P., Tamanaha, A., . . Polanczyk, G. (2013). Threat bias in attention orienting: evidence of specificity in a large community-based study. Psychological medicine, 43(04), 733-745.

Segalowitz, S. J., Santesso, D. L., \& Jetha, M. K. (2010). Electrophysiological changes during adolescence: a review. Brain and cognition, 72(1), 86-100.

Silverman, \& Albano, A. M. (1996). Anxiety Disorders Interview Schedule for DSM-IV.: Parent interview schedule (Vol. 1): Oxford University Press.

Silverman, Saavedra, \& Pina. (2001). Test-retest reliability of anxiety symptoms and diagnoses with the anxiety disorders interview schedule for DSM-IV: Child and parent versions. Journal of the American Academy of Child and Adolescent Psychiatry, 40(8), 937-944. doi:10.1097/00004583-200108000-00016

SPSS, I. (2013). IBM SPSS statistics 22. Algorithms. Chicago: IBM SPSS Inc.

Susa, G., Pitică, I., Benga, O., \& Miclea, M. (2012). The self regulatory effect of attentional control in modulating the relationship between attentional biases toward threat and anxiety symptoms in children. Cognition and Emotion, 26(6), 1069-1083. doi:http://dx.doi.org.ezproxy.fiu.edu/10.1080/02699931.2011.638910

Suway, J. G., White, L. K., Vanderwert, R. E., Bar-Haim, Y., Pine, D. S., \& Fox, N. A. (2013). Modification of threat-processing in non-anxious individuals: A preliminary behavioral and ERP study. Journal of Behavior Therapy and Experimental Psychiatry, 44(3), 285-292. doi:http://dx.doi.org.ezproxy.fiu.edu/10.1016/j.jbtep.2012.11.006 
Taylor, M. J., Edmonds, G. E., McCarthy, G., \& Allison, T. (2001). Eyes first! Eye processing develops before face processing in children. Neuroreport, 12(8), 16711676.

Thai, N., Taber-Thomas, B. C., \& Pérez-Edgar, K. E. (2016). Neural correlates of attention biases, behavioral inhibition, and social anxiety in children: An ERP study. Developmental Cognitive Neuroscience, 19, 200-210.

Tottenham, N., Tanaka, J. W., Leon, A. C., McCarry, T., Nurse, M., Hare, T. A., . . Nelson, C. (2009). The NimStim set of facial expressions: judgments from untrained research participants. Psychiatry research, 168(3), 242-249.

Vasey, M. W., Daleiden, E. L., Williams, L. L., \& Brown, L. M. (1995). Biased attention in childhood anxiety disorders: A preliminary study. Journal of Abnormal Child Psychology, 23(2), 267-279. doi:http://dx.doi.org.ezproxy.fiu.edu/10.1007/BF01447092

Verleger, R. (1997). On the utility of P3 latency as an index of mental chronometry. Psychophysiology, 34(2), 131-156.

Waters, Lipp, O., \& Spence, S. (2004). Attentional bias toward fear-related stimuli:: An investigation with nonselected children and adults and children with anxiety disorders. Journal of experimental child psychology, 89(4), 320-337.

Waters, Mogg, K., Bradley, B. P., \& Pine, D. S. (2008). Attentional bias for emotional faces in children with generalized anxiety disorder. Journal of the American Academy of Child \& Adolescent Psychiatry, 47(4), 435-442.

Weissman, A. S., Chu, B. C., Reddy, L. A., \& Mohlman, J. (2012). Attention mechanisms in children with anxiety disorders and in children with attention deficit hyperactivity disorder: Implications for research and practice. Journal of Clinical Child and Adolescent Psychology, 41(2), 117-126. doi:http://dx.doi.org.ezproxy.fiu.edu/10.1080/15374416.2012.651993

White, Britton, J. C., Sequeira, S., Ronkin, E. G., Chen, G., Bar-Haim, Y., . . Leibenluft, E. (2016). Behavioral and neural stability of attention bias to threat in healthy adolescents. NeuroImage.

Wren, F. J., Berg, E. A., Heiden, L. A., Kinnamon, C. J., Ohlson, L. A., Bridge, J. A., . . . Bernal, M. P. (2007). Childhood anxiety in a diverse primary care population: parent-child reports, ethnicity and SCARED factor structure. Journal of the American Academy of Child \& Adolescent Psychiatry, 46(3), 332-340. 
Table 1. Age, Behavioral Questionnaire and Dot Probe task scores. SCARED-P/C = Screen for Child Anxiety Related

Emotional Disorders, Parent \& Child reports, $\mathrm{M}=$ mean, $\mathrm{RT}=$ reaction time, $\mathrm{SD}=$ standard deviation. $\alpha=0.05$.

\begin{tabular}{|c|c|c|c|c|c|c|}
\hline & $\begin{array}{c}\text { Control } \\
\text { Mean }(S D)\end{array}$ & $\begin{array}{c}\text { Anxiety } \\
\text { Mean }(S D)\end{array}$ & $t$ & $d f$ & $p$ & $d$ \\
\hline SCARED-P & $7.52(7.25)$ & $28.05(16.67)$ & -5.17 & 40 & $<.001$ & 1.52 \\
\hline SCARED-C & $16.62(12.12)$ & $24.14(13.17)$ & -.93 & 40 & .36 & .59 \\
\hline Dot Probe Threat Bias Score & $-1.82(14.01)$ & $-3.89(19.60)$ & .39 & 37 & .70 & .12 \\
\hline Dot Probe Accuracy (\%) & $95.60(.04)$ & $95.46(.09)$ & .07 & 40 & .95 & 2.01 \\
\hline Dot Probe RT (ms) & $561.33(95.23)$ & $569.00(93.08)$ & -.26 & 40 & .79 & .08 \\
\hline
\end{tabular}


Table 2. Mean amplitudes and peak latency measures across Anxiety and Control groups for components N170, P1, P2 and P3 (sites POz \& Oz).

\begin{tabular}{|c|c|c|c|c|c|c|c|c|}
\hline \multirow{3}{*}{ Site } & \multicolumn{4}{|c|}{$\begin{array}{c}\text { Anxiety } \\
\text { Mean }(S D)\end{array}$} & \multicolumn{4}{|c|}{$\begin{array}{c}\text { Control } \\
\text { Mean }(S D) \\
\end{array}$} \\
\hline & \multicolumn{2}{|c|}{$\mathrm{POz}$} & \multicolumn{2}{|c|}{$\mathrm{Oz}$} & \multicolumn{2}{|c|}{$\mathrm{POz}$} & \multicolumn{2}{|c|}{$\mathrm{Oz}$} \\
\hline & $N T$ & $N N$ & $N T$ & $N N$ & $N T$ & $N N$ & $N T$ & $N N$ \\
\hline \multicolumn{9}{|c|}{ Mean Amplitude $(\mu V)$} \\
\hline N170 & $-6.40(12.2)$ & $-5.71(11.9)$ & $6.03(14.3)$ & $6.57(13.6)$ & $-1.68(8.7)$ & $-2.21(9.5)$ & $9.22(9.4)$ & $9.18(10.9)$ \\
\hline $\mathrm{P} 1$ & $7.24(7.4)$ & $6.45(7.0)$ & $18.08(9.6)$ & $17.09(9.2)$ & $9.51(7.4)$ & $10.34(8.6)$ & $17.93(12.2)$ & $18.78(12.5)$ \\
\hline $\mathrm{P} 2$ & $.09(14.1)$ & $0(14.7)$ & $9.82(11.7)$ & $9.97(13.1)$ & $5.70(8.8)$ & $5.77(9.0)$ & $13.14(10.7)$ & $14.24(11.1)$ \\
\hline \multicolumn{9}{|c|}{ Peak Latency (ms) } \\
\hline N170 & $202.85(18.8)$ & $205.26(18.3)$ & $199.13(23.2)$ & $196.80(21.9)$ & $201.73(13.8)$ & $202.47(14.7)$ & $201.54(17.0)$ & $199.78(18.6)$ \\
\hline $\mathrm{P} 1$ & $131.70(14.9)$ & $131.23(16.4)$ & $131.98(13.6)$ & $130.02(14.0)$ & $137.18(11.6)$ & $132.44(15.2)$ & $134.58(11.4)$ & $136.53(12.0)$ \\
\hline $\mathrm{P} 2$ & $261.53(16.4)$ & $263.86(18.4)$ & $253.91(16.7)$ & $254.28(19.2)$ & $256.98(15.5)$ & $255.67(16.0)$ & $249.44(16.9)$ & $252.60(16.9)$ \\
\hline P3 & $336.03(25.6)$ & $338.82(23.2)$ & $340.03(24.2)$ & $344.12(25.2)$ & $340.59(25.1)$ & 338.08 (19.2) & 339.66 (25.9) & $339.01(23.0)$ \\
\hline
\end{tabular}


Fig. 1 Grand average mean amplitude ERPs for youth with Anxiety versus Control youth during NT trials, (a) at all sites; grand average waveforms during NT trials across both groups (b) at site POz, and (c) at site Oz.
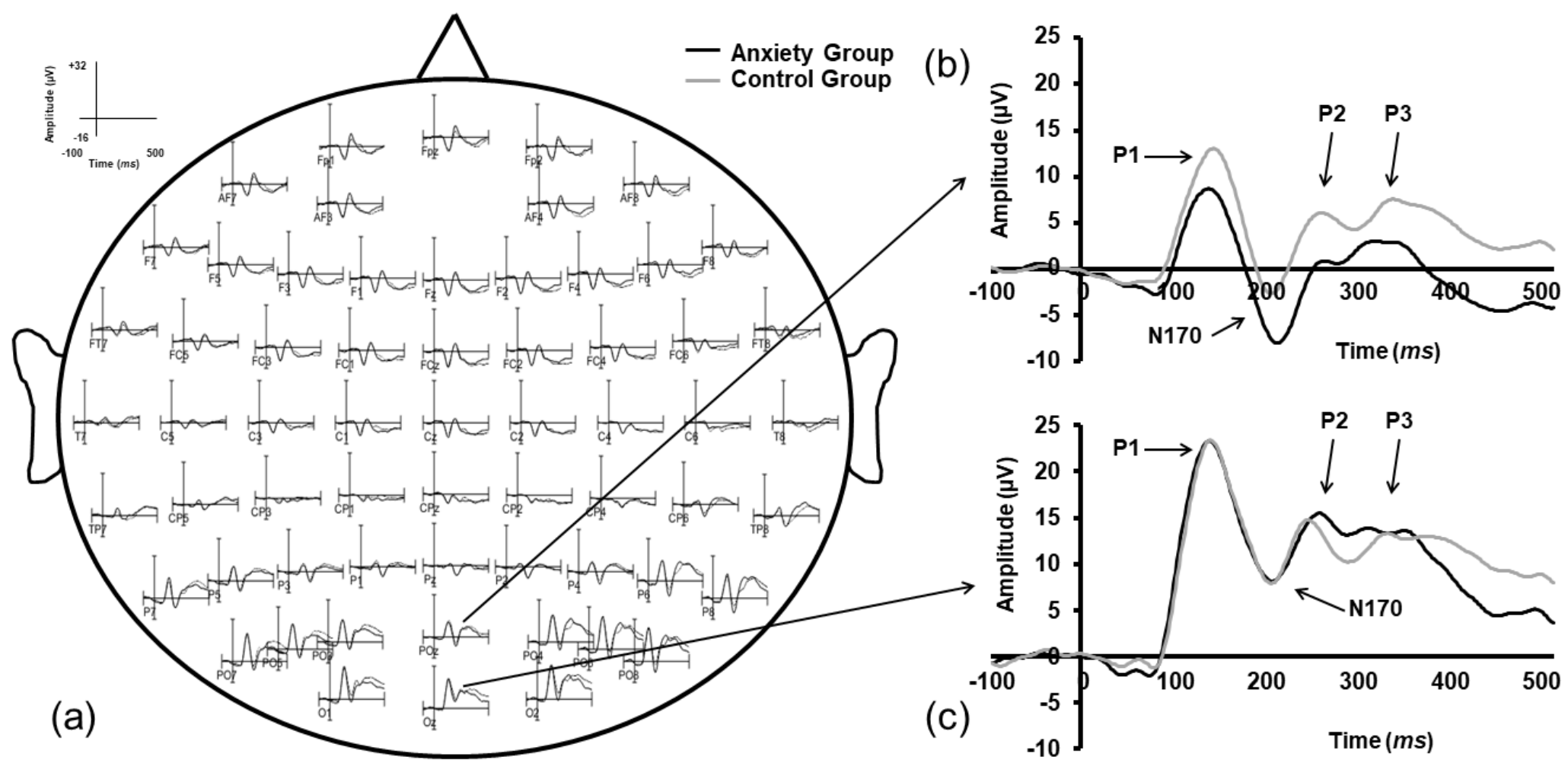

(c)

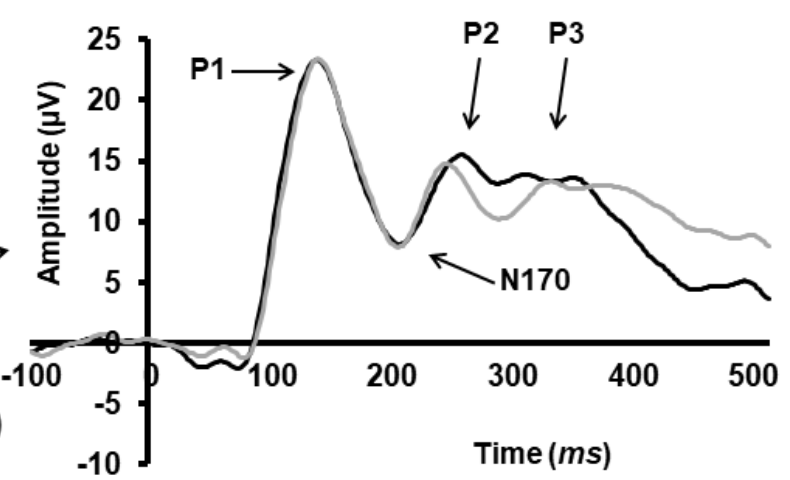


Fig. 2 Grand average mean amplitude ERPs for youth with Anxiety versus Control youth during NN trials, (a) at all sites; grand average waveforms during $\mathrm{NN}$ trials across both groups (b) at site POz, and (c) at site Oz.
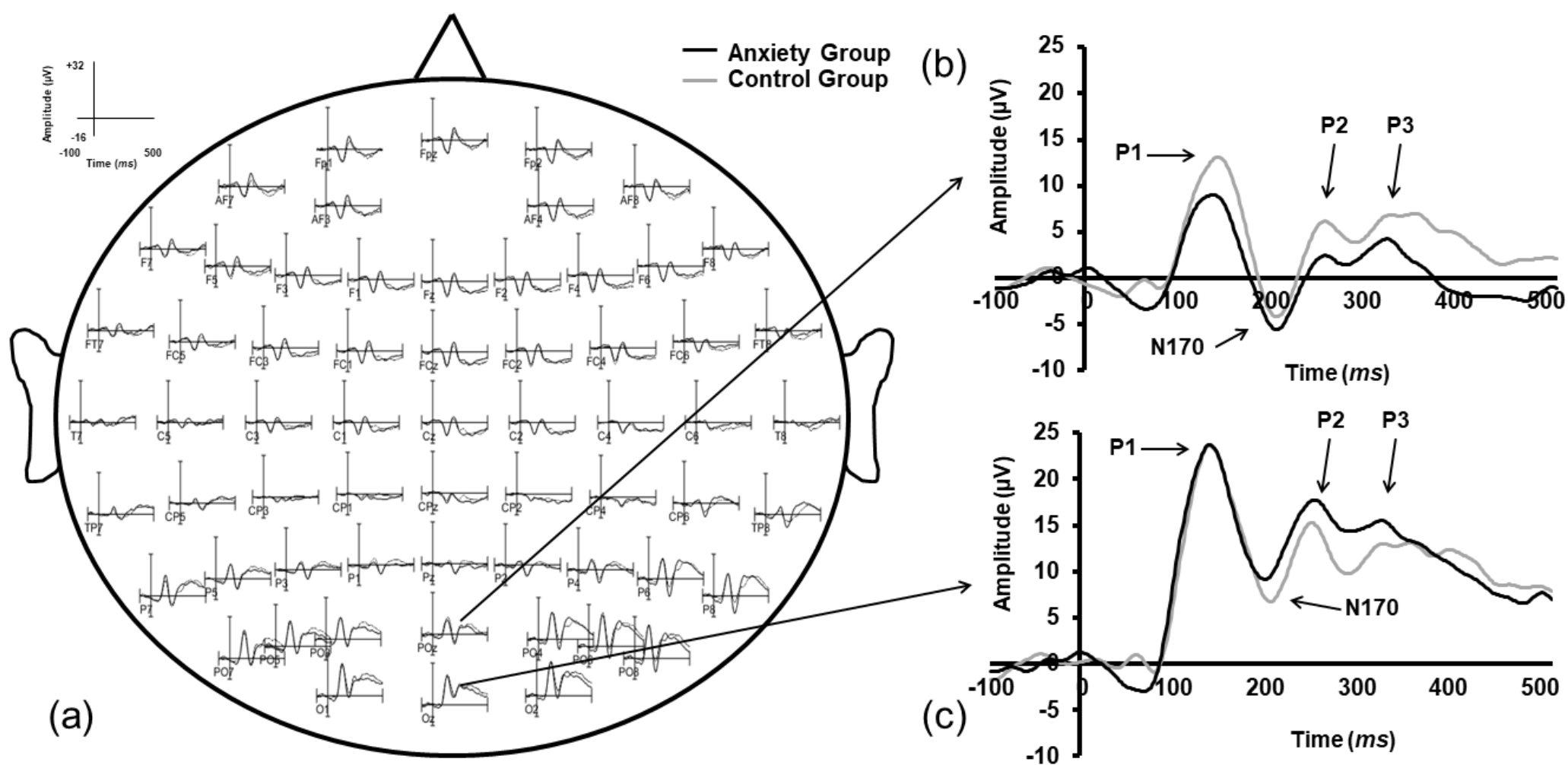

(c)

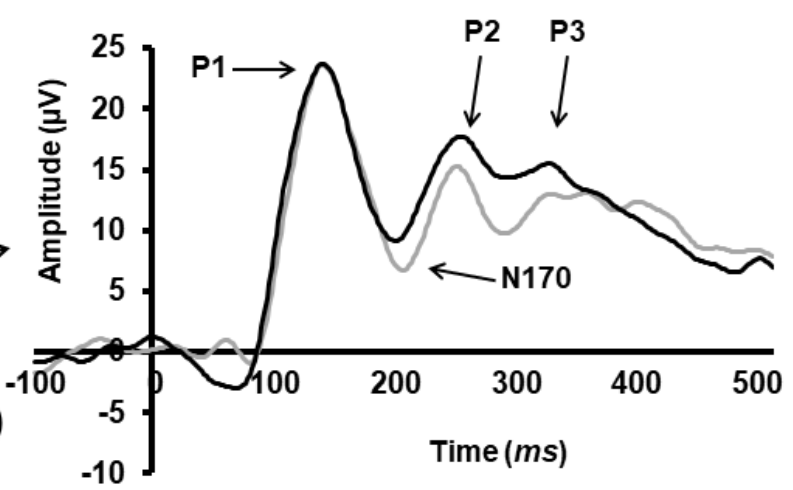




\section{CHAPTER 2}

\section{ATTENTION BIAS MODIFICATION TREATMENT FOR CHILDREN WITH ANXIETY DISORDERS WHO DO NOT RESPOND TO COGNITIVE}

BEHAVIORAL THERAPY: A CASE SERIES

This manuscript has been published in Journal of Anxiety Disorders, Volume 28, pages 154 to 159.

Bechor, M., Pettit, J.W., Silverman, W.K., Bar-Haim, Y., Abend, R., Pine, D.S., Vasey, M., \& Jaccard, J. (2014). Attention bias modification treatment for children with anxiety disorders who do not respond to cognitive behavioral therapy: A case series. Journal of Anxiety Disorders, 28(2), 154-159. doi:10.1016/j.janxdis.2013.09.001. 


\begin{abstract}
Evidence is emerging to support the promise of Attention Bias Modification Treatment $(\mathrm{ABMT})$, a computer-based attention training program, in reducing anxiety in children. ABMT has not been tested as an adjuvant for children with anxiety disorders who do not respond to Cognitive-Behavioral Therapy (CBT). This case series presents findings from an open trial of ABMT among six children (four girls; $M$ age=11.2 years) who completed a CBT protocol and continued to meet diagnostic criteria for an anxiety disorder. All children completed the ABMT protocol with no cancelled or missed sessions. Child selfratings on anxiety symptoms and depressive symptoms significantly decreased from pretreatment to posttreatment, as did parent ratings on child anxiety-related impairment. Parent ratings on child anxiety and internalizing symptoms displayed non-significant decreases from pretreatment to posttreatment. These findings support the potential promise of ABMT as a feasible adjuvant treatment that reduces anxiety and impairment among child anxiety CBT nonresponders.
\end{abstract}

Keywords: Anxiety; Children; Attention; Treatment; Attention bias

\title{
Introduction
}

Anxiety disorders occur in $10 \%$ to $20 \%$ of children and adolescents, pose a huge financial burden on the healthcare system, and are associated with substantial impairment(Rapee, Schniering, \& Hudson, 2009; Silverman, Pina, \& Viswesvaran, 2008).Evidence-based treatments for anxiety in children and adolescents are largely exposure-based cognitive behavioral therapies (CBTs; Rapee et al., 2009; Silverman et 
al., 2008). Despite the strong efficacy evidence for CBT, up to50\% of children and adolescents continue to meet diagnostic criteria for an anxiety disorder after a full course of treatment (Compton et al., 2004; Rapee et al., 2009; Silverman et al., 2008). To our knowledge, no empirical study has examined an adjuvant treatment for children and adolescents who did not benefit from CBT. In this article, we report promising preliminary data on Attention Bias Modification Treatment (ABMT) as an adjuvant for children and adolescents who completed a full course of CBT and continued to meet diagnostic criteria for an anxiety disorder.

Threat-related attention bias has been implicated in the development, etiology and maintenance of anxiety disorders (Bar-Haim, Lamy, Pergamin, Bakermans-Kranenburg, \& van IJzendoorn, 2007; Cisler \& Koster, 2010; Eldar, Ricon, \& Bar-Haim, 2008; Mathews \& MacLeod, 2002). The most commonly used paradigm for assessing threatrelated attention bias is the visual probe-detection task. In the task, a pair of threatening and neutral stimuli is presented simultaneously and then followed immediately by a visual probe. The probe replaces the threatening stimulus on some trials and the neutral stimulus on others. An individual's difference in average response times when identifying the location of the probe following threatening stimuli versus neutral stimuli provides an index of attention bias.

Anxious individuals typically display faster response times on trials in which the probe replaces the threatening stimuli, which reflects an attention bias toward threat (BarHaim et al., 2007). This pattern has been replicated among children(e.g., Vasey, el-Hag, \& Daleiden, 1996), adolescents (e.g., Telzer et al., 2008), and adults (e.g., Mogg, Philippot, \& Bradley, 2004), including youth and adult patients with Social Phobia (SOP; 
e.g., Roy et al., 2008) and Generalized Anxiety Disorder (GAD; e.g., Waters, Mogg, Bradley, \& Pine, 2008), youth patients with Separation Anxiety Disorder (SAD; e.g., Waters, Henry, Mogg, Bradley, \& Pine, 2010), and youth and adults with subclinical anxiety symptoms (e.g., Mogg \& Bradley, 2002).

In response to the well documented role of attention bias to threat in anxiety and its disorders, researchers have developed computer-based attention training programs to reduce anxiety (Amir, Beard, Burns, \& Bomyea, 2009; Eldar et al., 2012; Schmidt, Richey, Buckner, \& Timpano, 2009). ABMT is based on the idea that attention bias can be shaped via repetitive computer based training methods, although the mediators of ABMT's anxiety reduction effects require further empirical testing (Bar-Haim, 2010). In ABMT, patients complete the visual-probe detection task described above, with the critical exception that the probe always or almost always replaces the neutral stimulus and not the threatening stimulus.

ABMT has shown promising anxiety reduction effects in clinic referred adults and children (Eldar et al., 2012; Hakamata et al., 2010).Three attention training studies have been conducted with clinic referred samples of children and adolescents with anxiety disorders (Cowart \& Ollendick, 2011; Eldar et al., 2012; Rozenman, Weersing, \& Amir, 2011).Findings from these studies support the feasibility and promise of ABMT as a frontline treatment for children and adolescents with anxiety disorders. Whether ABMT would demonstrate similar feasibility and promise as an adjuvant among children and adolescents with anxiety disorders who do not respond to CBT is an unaddressed empirical issue. This is an important issue, however, given, as noted above, that up to $50 \%$ of anxious children and adolescents who receive CBT fail to benefit. 
The purpose of the current case series was to examine preliminarily the feasibility and potential promise of ABMT as an adjuvant treatment for children and adolescents who still met criteria for anxiety disorder diagnosis following a full course of CBT. Six children (four girls) identified as nonresponders following a 12 to 14 week CBT protocol completed an open trial of ABMT. Nonresponse was operationally defined as continuing to meet criteria for a primary diagnosis of $\mathrm{GAD}, \mathrm{SAD}$, or $\mathrm{SOP}$ at the posttreatment and 12 month follow up evaluations in the parent CBT trial. Consistent with most past ABMT research (Amir, Beard, Burns, et al., 2009; Amir, Beard, Taylor, et al., 2009; Schmidt et al., 2009), participants completed a pretreatment assessment followed by eight sessions of ABMT over four weeks, and then completed a posttreatment assessment. Outcomes included child self ratings and parent ratings on anxiety and related impairment. To determine whether ABMT had a general effect on negative emotions or a specific effect on anxiety, child self ratings on depressive symptoms also were collected.

\section{Method}

\subsection{Participants}

Participants were recruited from a large, ongoing clinical trial of CBT for children and adolescents with GAD, SOP, or SAD. All potential participants had completed a 1214 week CBT protocol similar to that used in previous trials(see Silverman, Kurtines, Jaccard, \& Pina, 2009). At the time of this study, approximately 190 participants had enrolled in the CBT trial and approximately 120 participants had completed the full CBT protocol, a posttreatment assessment, and a 12-month follow up assessment ( $M$ age at follow up= 11 years; $47 \%$ girls; $81 \%$ Hispanic). Youth were eligible for ABMT if they 
were between ages 8 to 14 years and met criteria for a primary DSM-IV diagnosis of GAD, SOP, or SAD at post and 12-month follow-up assessments of the CBT protocol. Exclusion criteria were (a) meeting diagnostic criteria for Organic Mental Disorders, Psychotic Disorders, Pervasive Developmental Disorders, or Mental Retardation, (b) showing high likelihood and/or serious intent of self-harm; (c) not living with a primary caregiver who was legally able to give consent for participation, (d) having a serious, uncorrected vision problem and (e) having a physical disability which interfered with the child's ability to click a mouse button rapidly and repeatedly. Children with comorbid ADHD, minimally impairing tics or impulse control problems or depressive disorders were eligible, as long as the comorbid disorder was treated with medication and stable.

Of the children who had completed 12-month follow up assessment and met inclusion criteria for the present study, ten were identified, and attempts were made to contact their families to inform them about this new treatment opportunity. Eight families were contacted, and six families agreed to participate. Two families declined and cited distance and travel time as the reason; the remaining two families could not be reached. The six participants (four girls, two boys) ranged in age from 10 to 13 years $(M=11.2$ years, $S D=1.17)$. Age, sex, and diagnostic status of each of the six participants are provided in Table 1. Five participants were Hispanic and one participant was AfricanAmerican. The mean age, ethnic distribution, and gender distribution of participants in this study were comparable to those in the larger CBT trial. Three met criteria for a primary diagnosis of SOP, and three met criteria for a primary diagnosis of SAD. One child met criteria for a secondary diagnosis of ADHD, was on a stable dose of medication 
prior to study entry and remained on a stable dose of medication through the end of the study.

\subsection{Measures}

1.2.1. Diagnosis and severity/impairment rating. Anxiety Disorders Interview Schedule for DSM-IV: Child and Parent Versions(ADIS-C/P; W. K. Silverman \& A.

M. Albano, 1996). Carefully trained evaluators administered the ADIS-C/P to each child and mother to assess current anxiety and related disorders in the child. Before conducting interviews, evaluators met a $100 \%$ reliability criterion on five video-taped child-parent assessments. The ADIS-C/P contains 0- to 8-point clinician severity rating (CSR) scales to assess the severity and interference of diagnosis. Interviewers assigned diagnoses that child and mother agreed were most interfering. In cases of disagreement, the interviewer considered both informants' views to derive a final diagnosis. In cases of multiple diagnoses, the relative interference of each disorder was determined by obtaining interference ratings from each source and prioritizing each disorder from most to least interfering or disturbing. The disorder deemed most interfering or disturbing was viewed as primary. In the present study, CSR ratings based on interviews with mothers and children were used separately to examine severity and interference at pre and post. Research supports the CSR's reliability (Silverman \& Eisen, 1992; Silverman \& Nelles, 1988) and its sensitivity to change following treatment (Mendlowitz et al., 1999; Silverman et al., 1999).

\subsubsection{Measures completed by youth.}

\subsubsection{Multidimensional Anxiety Scale for Children(MASC; March, Parker,} Sullivan, Stallings, \& Conners, 1997). The MASC is a youth self rating scale of child 
anxiety symptoms. It contains 39 items distributed across four factors aligned with DSMIV diagnostic categories for anxiety disorders: Physical Symptoms, Social Anxiety, Harm Avoidance, and Separation Anxiety. Ratings are made on a four-point Likert scale ( $1=$ never, 2 = rarely, $3=$ sometimes, $4=$ often). Test-retest reliability is satisfactory to excellent (intra-class correlations $>$.87). The factor structure has been supported(March et al., 1997) and convergent validity has been established via significant associations with other anxiety measures (Baldwin \& Dadds, 2007).

\subsubsection{Revised Children's Manifest Anxiety Scale Child version (RCMAS - C;} Reynolds \& Richmond, 1978).The RCMAS is a 37 -item self-rating scale designed to assess child anxiety symptoms. Twenty-eight items are summed to yield a Total Anxiety score. Each item is rated yes or no and scored 1 or 0.Pela and Reynolds (1982) reported a three-week test-retest reliability of .98 for the Total Anxiety scale.

\subsubsection{Children's Depression Inventory(CDI; Kovacs, 1985). The CDI is a} widely used 27 -item measure of depressive symptoms. Each item contains three choices, and children select the one that best describes them during the previous two weeks. The CDI possesses good internal consistency, and convergent validity has been demonstrated via significant correlations with clinician rated measures of depressive symptoms and other self-rated depression scales (Brooks \& Kutcher, 2001; Klein, Dougherty, \& Olino, 2005; Shain, Naylor, \& Alessi, 1990).

1.2.2.4.Attention Bias to Threatening Stimuli. The attention dot-probe task developed by MacLeod, Matthews,\& Tata (1986), modified for use in child anxiety studies (TAU-NIMH ABMT initiative; http://tau.ac.il/ yair1/ABMT.html), was used to obtain a performance-based measure of attentional bias towards threatening stimuli. 
Facial stimuli selected for this task had been used in previous studies (Bar-Haim, Morag, \& Glickman, 2011; Eldar et al., 2012). During the task, children were presented with 120trials. In each trial, a white fixation cross appeared for 500 milliseconds (ms) in the center of the screen, followed by a pair of faces (chromatic) appearing for $500 \mathrm{~ms}$. The pair of faces (of the same actor showing a neutral or threatening expression) appeared on the top and bottom of the screen. In each trial, the pair of faces displayed was one of three combinations (neutral-anger, anger-neutral, or neutral-neutral). Immediately following the faces, a probe (“<” or " >”) appeared in the location of either the top or bottom face. Participants were instructed to indicate the orientation of the probe by clicking the left or right mouse button (left for " $<$ ", right for ">”) using their dominant hand. The probe remained on-screen until the participant responded, and then the next trial began immediately. Angry-face location, probe location, probe type, and actor were fully counterbalanced in presentation. Reaction time differences of incongruent minus congruent trials provided a measure of attention bias, such that positive values indicated bias toward angry faces and negative values indicated bias away from angry faces. Inaccurate responses, trials with response latencies $<150 \mathrm{~ms}$ and $>1200 \mathrm{~ms}$, and trials with response latencies+/- 2.5 SDs from the subject's mean were excluded.

\subsubsection{Measures completed by parents.}

\subsubsection{Revised Children's Manifest Anxiety Scale Parent version(RCMAS - P;}

Reynolds \& Richmond, 1978). In the RCMAS-P, the wording of RCMAS items was changed from I to my child, as done in past research (e.g., Kendall, 1994; Silverman et al., 1999; Silverman et al., 2009). Each item is rated either yes or no and scored 1 or 0. Twenty-eight items are summed to yield a Total Anxiety score. 


\subsubsection{Child Behavior Checklist Anxious/Depressed Subscale(CBCL;}

Achenbach \& Rescorla, 2001). The CBCL contains 118 parent rated items to assess specific child behavioral and emotional problems. These items are rated by parents on a

3-point scale $(0=$ not true; $1=$ somewhat or sometimes true; $2=$ very true or often true $)$. The CBCL includes two broadband scales (i.e., Externalizing, Internalizing) and eight narrowband subscales. In the present study, we examined dimensional T-scores on the Anxious/Depressed narrowband subscale because, relative to other scales on the CBCL, it has shown a high correlation with the severity of anxiety disorders (Aschenbrand, Angelosante, \& Kendall, 2005).

\subsection{Procedures}

This study was conducted as approved by the Institutional Review Board. Parents provided informed consent and children provided assent. Assessments and training sessions were conducted by graduate students who had been thoroughly trained in the study's procedures.

1.3.1. Attention bias modification training. The ABMT task was identical to the attention bias assessment task but with three exceptions. First, a unique set of faces was used in this task (i.e., different from those used in the attention bias assessment task). Second, the task consisted of 160 trials: 120 angry-neutral presentations and 40 neutralneutral presentations. Third, the probe replaced the neutral face on $100 \%$ of the trials. Threat face location (top or bottom) and actor were fully counterbalanced. Probe type (< or >) was not factorially counterbalanced but appeared with equal probability for each of the following: angry-face location, probe location, or actor. On $75 \%$ of these trials, the 
location of the threat face predicted the location of the probe (behind neutral); on the other $25 \%$, subjects saw neutral-neutral face pairs.

\section{Results}

Pretreatment and posttreatment scores on all measures for each of the six participants are provided in Table 1. All six patients completed the study protocol, including a pre-treatment assessment, eight ABMT training sessions, and a posttreatment assessment within one week of the final training session. None of the families missed or cancelled a session. This perfect attendance record was corroborated by patients' and parents' anecdotal reports of very high satisfaction with the short duration of each treatment session (15 minutes) and the short course of treatment (four weeks).

\subsection{Severity Ratings for DSM-IV Anxiety Disorder Diagnoses}

As shown in Table 1, four of the six child participants rated their primary anxiety disorder diagnoses as clinically interfering $(\geq 4)$ at pre assessment, whereas only one participant rated her diagnosis in the clinical range $(<4)$ at post. Mean child self ratings on severity/interference $(0-8)$ decreased from pre $(M=4.33)$ to post $(M=2.33)$. In a paired samples t-test, this change was not statistically significant, $t(5)=1.73, p=0.14$.

All parent severity/interference ratings were in the clinical range at pre $(\geqq 4)$, whereas half of parents' severity/interference ratings were in the clinical range $(<4)$ at post. Mean parent ratings on severity/interference significantly decreased from pre (5.67) to post $(3.50), t(5)=3.08, p=0.03$.

\subsection{Child Rated Symptoms}

As shown in Table 1, child self ratings on the MASC decreased from pre to post for all participants, and child self ratings on the RCMAS-C decreased from pre to post for 
all participants except Participant 6. A pre-post paired samples t-test on mean MASC scores revealed a significant decrease from pre $(M=42.17)$ to post $(M=33.17), t(5)=$ 3.58, $p=0.02$. Similarly, mean scores on the RCMAS-C significantly decreased from pre $(M=5.83)$ to post $(M=2.50), t(5)=3.26, p=0.02$.

Child self ratings on the CDI decreased from pre to post for all participants except Participant 6. Statistically significant pre $(M=4.67)$ to post $(M=0.83)$ decreases on mean CDI scores were observed, $t(5)=4.39, p=0.01$.

\subsection{Parent Rated Child Symptoms}

Parent ratings on the RCMAS-P decreased from pre to post for all participants except Participant 6 (Table 1). Mean scores on the RCMAS-P decreased from pre $(M=11.60)$ to post $(M=8.40)$; this difference was not statistically significant, $t(5)=1.612, p=$ 0.18.Similarly, CBCL-Anxious Depressed scores decreased from pre to post for all participants except Participant 1 and Participant 6 (Table 1). The decrease in mean Tscores of the CBCL Anxious-Depressed subscale from pre $(M=62.67)$ to post $(M=$ 58.83) was not statistically significant, $t(5)=1.93, p=0.11$.

\subsection{Attention Bias to Threatening Stimuli}

Mean attention bias scores decreased from pre $(M=27.00)$ to $\operatorname{post}(M=8.40)$, but this change was not statistically significant, $t(4)=0.246, p=0.82$. Although the mean attention bias score at pre was positive, indicating a bias toward threat on average, three of the six participants displayed a negative attention bias score at pre, indicating a bias away from threat. Attention bias scores decreased substantially from pre to post for Participant 1 (pre $=195$, post $=-117)$, increased modestly for Participants 2,3 , and $4(M$ 
increase $=33.00)$, and increased substantially for Participant $6($ pre $=10$, post $=129)$. The pre attention bias score for Participant 5 was missing due to a data collection error.

\section{Discussion}

The purpose of this case series was to examine preliminarily the feasibility and promise of $\mathrm{ABMT}$ as an adjuvant treatment for children who continued to meet diagnostic criteria for a primary anxiety disorder following a full course of CBT. Ten eligible children were identified; we were able to establish contact with the families of eight of these children. Of these eight families, six agreed to attend the clinic twice weekly for ABMT sessions. All six families completed the eight sessions of ABMT over four weeks with no cancellations. These findings support the feasibility of ABMT as an adjunct for children with anxiety disorders who do not respond to a full course of CBT.

With regard to anxiety reduction effects, ABMT led to significant mean reductions of anxiety symptoms on child self-report anxiety measures (MASC, RCMASC). Further, mean parent report of disorder interference decreased significantly from pretreatment to posttreatment. Reductions in parent report of children's anxiety symptoms also were observed from pretreatment to posttreatment, but were not statistically significant. A statistically significant reduction in mean levels of child self report depressive symptoms also was found, suggesting the effects of ABMT may not be specific to anxiety but rather impact emotional distress in general. Similar conclusions have been drawn in prior studies of ABMT among children (Rozenman et al., 2011) and adults (Hazen, Vasey, \& Schmidt, 2009).

Findings regarding the statistical significance of effects, including discrepancies between the statistical significance of child self-ratings and parent ratings, should be 
interpreted with caution given the small sample size. Although discrepancies between child self-ratings and parent ratings are common in the child anxiety literature (Silverman \& Ollendick, 2005), all anxiety reduction effects, even those that were not statistically significant, were in the expected direction regardless of informant source. Findings regarding the clinical significance of effects were generally supportive of ABMT's promise as an adjuvant treatment. Parent ratings of interference remained in the clinical range at posttreatment for half the sample, which suggests eight sessions of ABMT may be sufficient for some but not all children who do not respond to CBT. If this finding is replicated in larger trials, it will be important to investigate whether additional sessions of $\mathrm{ABMT}$ or $\mathrm{CBT}$, or a switch to a different treatment modality (e.g., pharmacotherapy), may lead to higher response rates.

Mean attention bias scores showed a nonsignificant decrease from pretreatment to posttreatment, suggesting participants' attention was trained away from threat on average. Three participants displayed a bias toward threat at the pre assessment, and the other three participants displayed a bias away from threat. As in the multiple baseline study by Cowart and Ollendick (2011), some children displaying attention biases away from threat at pretreatment exhibited pre to post decreases in anxiety. Future studies with larger samples are needed to address whether treatment response differs as a function of pretreatment attention bias scores.

On the level of individual cases, pre to post decreases in most child report and parent report measures were observed for five of the six participants. The sixth participant evidenced pre to post decreases in anxiety severity/interference ratings, but generally did not show pre to post changes on symptom measures. This was due in part to 
scores of zero on two child report measures at pre, although a similar pattern of no pre to post change was observed for parent ratings on child anxiety symptoms. It is interesting to note the sixth participant was the only participant to evidence a large increase in attention bias scores from pre to post. The other four participants with available data evidenced either a substantial decrease in attention bias (Participant 1) or modest increase in attention bias from pre to post (Participants 2-4).

The findings of this case series are generally consistent with those of previous studies on ABMT in clinic referred children and adolescents with anxiety disorders (Eldar et al., 2012; Rozenman et al., 2011) and extend the use of ABMT to anxiety disordered children who do not respond well to CBT. Nevertheless, the findings should be interpreted in light of the study's limitations. As with most case series, the absence of a control group and the small sample size prevent conclusions about the efficacy of ABMT for CBT nonresponders. Similarly, the absence of follow-up data prevents conclusions regarding the maintenance of ABMT's effects over time. Future trials of ABMT as an adjuvant treatment should include follow-up assessments.

In summary, the current case series provides initial data to support the feasibility of ABMT as an adjuvant treatment option for children with anxiety disorders who do not respond well to $\mathrm{CBT}$. The findings of this case series also suggest ABMT has promise in reducing anxiety symptoms and related impairment among children with anxiety who do not respond to CBT. Future research is encouraged to examine the efficacy of ABMT as a CBT augmentation strategy in larger samples using a randomized controlled design. 


\section{Acknowledgements}

This project was supported by National Institute of Mental Health Grant MH079943 to

Wendy K. Silverman, National Institute of Mental Health Grant MH097931 to Wendy K.

Silverman \& Jeremy W. Pettit, and a Florida International University Presidential

Fellowship to Michele Bechor.

\section{References}

Achenbach, T., \& Rescorla, L. (2001). Manual for the ASEBA School-Age Forms \& Profiles. Burlington, VT: University of Vermont, Research Center for Children, Youth, and Families.

Amir, N., Beard, C., Burns, M., \& Bomyea, J. (2009). Attention modification program in individuals with generalized anxiety disorder. Journal of Abnormal Psychology, 118(1), 28-33. doi: 2009-01738-016 [pii]10.1037/a0012589

Amir, N., Beard, C., Taylor, C. T., Klumpp, H., Elias, J., Burns, M., \& Chen, X. (2009). Attention training in individuals with generalized social phobia: A randomized controlled trial. Journal of Consulting and Clinical Psychology, 77(5), 961-973. doi: 2009-17643-016 [pii]10.1037/a0016685

Aschenbrand, S. G., Angelosante, A. G., \& Kendall, P. C. (2005). Discriminant validity and clinical utility of the CBCL with anxiety-disordered youth. Journal of Clinical Child and Adolescent Psychology, 34(4), 735-746. doi: 10.1207/s15374424jccp3404_15

Baldwin, J. S., \& Dadds, M. R. (2007). Reliability and validity of parent and child versions of the multidimensional anxiety scale for children in community samples. Journal of the American Academy of Child and Adolescent Psychiatry, 46(2), 252-260. doi: 10.1097/01.chi.0000246065.93200.a1S0890-8567(09)618335 [pii]

Bar-Haim, Y. (2010). Research review: Attention bias modification (ABM): a novel treatment for anxiety disorders. Journal of Child Psychology and Psychiatry, 51(8), 859-870. doi: JCPP2251 [pii]10.1111/j.1469-7610.2010.02251.x

Bar-Haim, Y., Lamy, D., Pergamin, L., Bakermans-Kranenburg, M. J., \& van IJzendoorn, M. H. (2007). Threat-related attentional bias in anxious and nonanxious individuals: A meta-analytic study. Psychological Bulletin, 133(1), 124. doi: Doi 10.1037/0033-2909.133.1.1 
Bar-Haim, Y., Morag, I., \& Glickman, S. (2011). Training anxious children to disengage attention from threat: a randomized controlled trial. Journal of Child Psychology and Psychiatry. doi: 10.1111/j.1469-7610.2011.02368.x

Brooks, S. J., \& Kutcher, S. (2001). Diagnosis and measurement of adolescent depression: a review of commonly utilized instruments. Journal of Child and Adolescent Psychopharmacology, 11(4), 341-376.

Cisler, J. M., \& Koster, E. H. (2010). Mechanisms of attentional biases towards threat in anxiety disorders: An integrative review. Clinical Psychology Review, 30(2), 203216. doi: S0272-7358(09)00158-5 [pii]10.1016/j.cpr.2009.11.003

Compton, S. N., March, J. S., Brent, D., Albano, A. M., Weersing, V. R., \& Curry, J. (2004). Cognitive-behavioral psychotherapy for anxiety and depressive disorders in children and adolescents: An evidence-based medicine review. Journal of the American Academy of Child and Adolescent Psychiatry, 43(8), 930-959. doi: DOI 10.1097/01.chi.0000127589.57468.bf

Cowart, M. J., \& Ollendick, T. H. (2011). Attention training in socially anxious children: a multiple baseline design analysis. Journal of Anxiety Disorders, 25(7), 972-977. doi: S0887-6185(11)00111-3 [pii]10.1016/j.janxdis.2011.06.005

Eldar, S., Apter, A., Lotan, D., Edgar, K. P., Naim, R., Fox, N. A., Pine, D. S., \&BarHaim, Y. (2012). Attention bias modification treatment for pediatric anxiety disorders: a randomized controlled trial. American Journal of Psychiatry, 169(2), 213-220.

Eldar, S., Ricon, T., \& Bar-Haim, Y. (2008). Plasticity in attention: implications for stress response in children. Behaviour Research and Therapy, 46(4), 450-461. doi: S0005-7967(08)00012-0 [pii]10.1016/j.brat.2008.01.012

Hakamata, Y., Lissek, S., Bar-Haim, Y., Britton, J. C., Fox, N. A., Leibenluft, E., Ernst, M., \& Pine, D. S. (2010). Attention bias modification treatment: a meta-analysis toward the establishment of novel treatment for anxiety. Biological Psychiatry, 68(11), 982-990. doi: S0006-3223(10)00766-3 [pii]10.1016/j.biopsych.2010.07.021

Hazen, R. A., Vasey, M. W., \& Schmidt, N. B. (2009). Attentional retraining: a randomized clinical trial for pathological worry. Journal of Psychiatric Research, 43(6), 627-633. doi: S0022-3956(08)00141-6 [pii]10.1016/j.jpsychires.2008.07.004

Kendall, P. C. (1994). Treating anxiety disorders in children: results of a randomized clinical trial. Journal of Consulting and Clinical Psychology, 62(1), 100-110. 
Klein, D. N., Dougherty, L. R., \& Olino, T. M. (2005). Toward guidelines for evidencebased assessment of depression in children and adolescents. Journal of Clinical Child and Adolescent Psychology, 34(3), 412-432.

Kovacs, M. (1985). The Children's Depression, Inventory (CDI). Psychopharmacol Bulletin, 21(4), 995-998.

MacLeod, C., Mathews, A., \& Tata, P. (1986). Attentional bias in emotional disorders. Journal of Abnormal Psychology, 95(1), 15-20.

March, J. S., Parker, J. D., Sullivan, K., Stallings, P., \& Conners, C. K. (1997). The Multidimensional Anxiety Scale for Children (MASC): factor structure, reliability, and validity. Journal of the American Academy of Child and Adolescent Psychiatry, 36(4), 554-565. doi: S0890-8567(09)62527-2 [pii]10.1097/00004583-199704000-00019

Mathews, A., \& MacLeod, C. (2002). Induced processing biases have causal effects on anxiety. Cognition \& Emotion, 16(3), 331-354. doi: Doi $10.1080 / 02699930143000518$

Mendlowitz, S. L., Manassis, K., Bradley, S., Scapillato, D., Miezitis, S., \& Shaw, B. F. (1999). Cognitive-behavioral group treatments in childhood anxiety disorders: the role of parental involvement. Journal of the American Academy of Child and Adolescent Psychiatry, 38(10), 1223-1229.

Mogg, K., \& Bradley, B. P. (2002). Selective orienting of attention to masked threat faces in social anxiety. Behaviour Research and Therapy, 40(12), 1403-1414. doi: S0005796702000177 [pii]

Mogg, K., Philippot, P., \& Bradley, B. P. (2004). Selective attention to angry faces in clinical social phobia. Journal of Abnormal Psychology, 113(1), 160-165. doi: 10.1037/0021-843X.113.1.1602004-11098-018 [pii]

Pela, O. A., \& Reynolds, C. R. (1982). Cross-cultural application of the RevisedChildren's Manifest Anxiety Scale: normative and reliability data for Nigerian primary school children. Psychological Reports, 51 (3 Pt 2), 1135-1138.

Rapee, R. M., Schniering, C. A., \& Hudson, J. L. (2009). Anxiety disorders during childhood and adolescence: origins and treatment. Annual Review of Clinical Psychology, 5, 311-341. doi: 10.1146/annurev.clinpsy.032408.15362810.1146/annurev.clinpsy.032408.153628 [pii]

Reynolds, C. R., \& Richmond, B. O. (1978). What I think and feel: a revised measure of children's manifest anxiety. Journal of Abnormal Child Psychology, 6(2), 271280. 
Roy, A. K., Vasa, R. A., Bruck, M., Mogg, K., Bradley, B. P., Sweeney, M., . . Pine, D. S. (2008). Attention bias toward threat in pediatric anxiety disorders. Journal of the American Academy of Child and Adolescent Psychiatry, 47(10), 1189-1196. doi: 10.1097/CHI.0b013e3181825aceS0890-8567(08)60105-7 [pii]

Rozenman, M., Weersing, V. R., \& Amir, N. (2011). A case series of attention modification in clinically anxious youths. Behaviour Research and Therapy, 49(5), 324-330. doi: DOI 10.1016/j.brat.2011.02.007

Schmidt, N. B., Richey, J. A., Buckner, J. D., \& Timpano, K. R. (2009). Attention training for generalized social anxiety disorder. Journal of Abnormal Psychology, 118(1), 5-14. doi: 2009-01738-019 [pii]10.1037/a0013643

Shain, B. N., Naylor, M., \& Alessi, N. (1990). Comparison of self-rated and clinicianrated measures of depression in adolescents. American Journal of Psychiatry, 147(6), 793-795.

Silverman, W. K., \& Albano, A. M. (1996). Anxiety Disorders Interview Schedule for Children-IV (Child and Parent Versions). . San Antonio, TX: Psychological Corporation.

Silverman, W. K., \& Eisen, A. R. (1992). Age-Differences in the Reliability of Parent and Child Reports of Child Anxious Symptomatology Using a Structured Interview. Journal of the American Academy of Child and Adolescent Psychiatry, 31(1), 117-124.

Silverman, W. K., Kurtines, W. M., Ginsburg, G. S., Weems, C. F., Lumpkin, P. W., \& Carmichael, D. H. (1999). Treating anxiety disorders in children with group cognitive-behaviorial therapy: A randomized clinical trial. Journal of Consulting and Clinical Psychology, 67(6), 995-1003.

Silverman, W. K., Kurtines, W. M., Jaccard, J., \& Pina, A. A. (2009). Directionality of change in youth anxiety treatment involving parents: an initial examination. Journal of Consulting and Clinical Psychology, 77(3), 474-485. doi: 2009-08093010 [pii]10.1037/a0015761

Silverman, W. K., \& Nelles, W. B. (1988). The Anxiety Disorders Interview Schedule for Children. Journal of the American Academy of Child and Adolescent Psychiatry, 27(6), 772-778.

Silverman, W. K., \& Ollendick, T. H. (2005). Evidence-based assessment of anxiety and its disorders in children and adolescents. Journal of Clinical Child and Adolescent Psychology, 34(3), 380-411.

Silverman, W. K., Pina, A. A., \& Viswesvaran, C. (2008). Evidence-based psychosocial treatments for phobic and anxiety disorders in children and adolescents. Journal 
of Clinical Child and Adolescent Psychology, 37(1), 105-130. doi: Doi 10.1080/15374410701817907

Telzer, E. H., Mogg, K., Bradley, B. P., Mai, X., Ernst, M., Pine, D. S., \& Monk, C. S. (2008). Relationship between trait anxiety, prefrontal cortex, and attention bias to angry faces in children and adolescents. Biological Psychiatry, 79(2), 216-222. doi: S0301-0511(08)00125-7 [pii]10.1016/j.biopsycho.2008.05.004

Vasey, M. W., el-Hag, N., \& Daleiden, E. L. (1996). Anxiety and the processing of emotionally threatening stimuli: distinctive patterns of selective attention among high- and low-test-anxious children. Child Development, 67(3), 1173-1185.

Waters, A. M., Henry, J., Mogg, K., Bradley, B. P., \& Pine, D. S. (2010). Attentional bias towards angry faces in childhood anxiety disorders. Journal of Behavior Therapy andExperimental Psychiatry, 41(2), 158-164. doi: S0005-7916(09)00100-1 [pii]10.1016/j.jbtep.2009.12.001

Waters, A. M., Mogg, K., Bradley, B. P., \& Pine, D. S. (2008). Attentional bias for emotional faces in children with generalized anxiety disorder. Journal of the American Academy of Child and Adolescent Psychiatry, 47(4), 435-442. doi: 10.1097/CHI.0b013e3181642992S0890-8567(09)62399-6 [pii] 
Table 1. Demographics and Measure Scores for 6 CBT Non-Responders Undergoing ABMT.

\begin{tabular}{|c|c|c|c|c|c|c|c|c|c|c|c|}
\hline \multirow[t]{2}{*}{$\begin{array}{c}\text { Subject } \\
\#\end{array}$} & \multirow[t]{2}{*}{$\begin{array}{c}\text { Gende } \\
\mathbf{r}\end{array}$} & \multirow[t]{2}{*}{ Age } & \multirow[t]{2}{*}{$\begin{array}{l}\text { DSM-IV- } \\
\text { TR } \\
\text { Diagnosis }\end{array}$} & & \multicolumn{2}{|c|}{$\begin{array}{c}\text { ADIS-C/P } \\
\text { Severity/Impairment } \\
\text { Ratings }\end{array}$} & \multirow[t]{2}{*}{ MASC } & \multirow[t]{2}{*}{$\begin{array}{c}\text { RCMAS- } \\
\text { C }\end{array}$} & \multirow[t]{2}{*}{$\begin{array}{l}\text { RCMAS- } \\
\quad \text { P }\end{array}$} & \multirow[t]{2}{*}{$\begin{array}{c}\text { CBCL } \\
\text { Anxious/Depresse } \\
\text { d T-Score }\end{array}$} & \multirow[t]{2}{*}{ CDI } \\
\hline & & & & & Parent & Child & & & & & \\
\hline \multirow[t]{2}{*}{1} & $\mathrm{~F}$ & 10 & SAD & Pre & 4 & 6 & 41 & 6 & 3 & 56 & 6 \\
\hline & & & & Post & 2 & 0 & 28 & 0 & 1 & 58 & 0 \\
\hline \multirow[t]{2}{*}{2} & $\mathrm{M}$ & 11 & SAD & Pre & 5 & 5 & 54 & 12 & 14 & 64 & 8 \\
\hline & & & & Post & 3 & 6 & 53 & 6 & 12 & 59 & 3 \\
\hline \multirow[t]{2}{*}{3} & $\mathrm{~F}$ & 13 & SAD & Pre & 4 & 3 & 27 & 9 & 11 & 77 & 5 \\
\hline & & & & Post & 5 & 2 & 13 & 5 & 10 & 65 & 1 \\
\hline \multirow[t]{2}{*}{4} & $\mathrm{M}$ & 10 & SOP & Pre & 6 & 5 & 42 & 3 & 16 & 65 & 3 \\
\hline & & & & Post & 2 & 0 & 33 & 0 & 5 & 62 & 0 \\
\hline \multirow[t]{2}{*}{5} & $\mathrm{~F}$ & 11 & SOP & Pre & 7 & 3 & 54 & 5 & 9 & 75 & 6 \\
\hline & & & & Post & 4 & 3 & 52 & 4 & 7 & 70 & 1 \\
\hline \multirow[t]{2}{*}{6} & $\mathrm{~F}$ & 12 & SOP & Pre & 8 & 4 & 35 & 0 & 8 & 39 & 0 \\
\hline & & & & Post & 5 & 3 & 20 & 0 & 8 & 39 & 0 \\
\hline
\end{tabular}

Note: SAD: Separation Anxiety Disorder; SOP: Social Phobia; ADIS-C/P: Anxiety Disorders Interview Schedule

(Child/Parent versions); MASC: Multidimensional Anxiety Scale for Children; RCMAS: Revised Children's Manifest Anxiety

Scale (Child/Parent versions); CBCL: Child Behavior Checklist; CDI: Children's Depression Inventory. 
IV. CHAPTER 3

\section{NEURAL MARKERS OF ATTENTION TRAINING IN CHILDREN AND ADOLESCENTS WITH ANXIETY DISORDERS}

Michele Bechor, M.S., ${ }^{a}$ Michelle Ramos, M.S., ${ }^{a}$ Michael J. Crowley, Ph.D., ${ }^{b}$ Bethany C. Reeb-Sutherland, Ph.D., ${ }^{a}$ Wendy K. Silverman, Ph.D., ABPP, ${ }^{\mathrm{b}} \&$ Jeremy W. Pettit, Ph.D. ${ }^{a}$

aDepartment of Psychology, Florida International University, Miami, FL 33199, USA

${ }^{\text {b} Y a l e ~ C h i l d ~ S t u d y ~ C e n t e r, ~ Y a l e ~ U n i v e r s i t y, ~ N e w ~ H a v e n, ~ C T ~ 06520, ~ U S A ~}$ 


\begin{abstract}
Objective: Attention Bias Modification Training (ABMT) for anxiety aims to train attention away from threatening stimuli and toward neutral stimuli. Although ABMT shows promising anxiety reduction effects in children and adolescents, no study has examined its influence on neural indicators of attention measured using event-related potentials (ERPs) in children or adolescents (i.e., youths). The present study examined the influence of ABMT on the P1, N170, P2 and P3 ERP components during completion of the emotional faces dot probe task in youths with anxiety disorders who failed to respond to cognitive behavioral therapy. Method: Thirty youths (16 females, $M$ age = $11.97, S D=2.89$ ) with primary DSM-IV-TR anxiety disorders completed the dot probe task while undergoing electroencephalogram (EEG) to obtain ERPs before, immediately after, and eight weeks after eight sessions of either ABMT $(n=14)$ or a control task regimen $(\mathrm{CT}),(n=16)$. Results: At post-treatment, statistically significant effects were found for P1 and P3 mean amplitudes: P1 was significantly higher during trials showing neutral-neutral (NN) face pairs in the ABMT arm than in the CT arm; P3 was significantly higher during trials showing NN face pairs than during trials showing neutral-threat (NT) face pairs in the ABMT arm, but not the CT arm. At eight-week follow-up, participants in both arms showed significantly higher (more negative) N170 responses for NN trials than for NT trials. Conclusions: Attention Bias Modification Treatment led to increases in neural processing of neutral stimuli in early and late stage attentional processing, as measured by the $\mathrm{P} 1$ and $\mathrm{P} 3$ components, respectively. These components during the dot probe task are promising neural markers of ABMT's effects on attentional processing in youth with anxiety disorders.
\end{abstract}


Keywords: Attention bias, Attention Bias Modification Treatment (ABMT), Eventrelated potential, anxiety, youth. Abbreviations: DSM-IV-TR: Diagnostic and Statistical Manual of Mental Disorders, Fourth Edition, Text Revision; ADIS for DSM-IV: C/P: Anxiety Disorders Interview Schedule for DSM-IV: Child and Parent Versions; SCARED-C/P: Screen for Child Anxiety \& Related Disorders, Child \& Parent Versions; PARS: Pediatric Anxiety Rating Scale; ERPs: event-related potentials; EEG: electroencephalogram.

\section{Introduction}

Anxiety disorders are among the most prevalent psychiatric disorders in children and adolescents (i.e., youths; Costello, Egger, Copeland, Erkanli, \& Angold, 2011), lead to substantial impairments (Silverman \& Ollendick, 2005) and are associated with enormous mental health costs (Simon, Dirksen, Bögels, \& Bodden, 2012). The leading evidence-based treatment for youth anxiety disorders is cognitive-behavioral therapy (CBT). Cognitive-behavioral therapy primarily targets "top down," strategic cognitive processes such as identifying and modifying interpretations of ambiguous events and situations. Despite the demonstrated efficacy of CBT, up to $50 \%$ of youths continue to meet criteria for anxiety disorders and experience emotional distress and impairment after a full course of treatment (Compton et al., 2004; Rapee, Schniering, \& Hudson, 2009; Silverman, Pina, \& Viswesvaran, 2008). Thus, youth anxiety CBT nonresponders represent a large and clinically challenging population. Perhaps youths who do not respond well to a top-down approach like CBT would alternatively respond better to an approach that targets bottom-up, implicit processes (Bechor et al., 2014). 
Cognitive theories of anxiety emphasize the role of heightened attention to threat as a bottom up, implicit process involved in the development and maintenance of anxiety disorders (Lonigan et al., 2004; Mogg \& Bradley, 1998). Heightened attention to threat, or attention bias to threat, has been documented in individuals with anxiety disorders, including youths (Bar-Haim et al., 2007; Dudeney et al., 2015). The translational treatment implication of heightened attention to threat is attention bias modification training (ABMT). This dissertation study presents findings on the influence of ABMT on neural markers (event-related potential components) of attention to threat at immediate posttreatment, and at a follow-up assessment eight weeks after treatment, in youth anxiety CBT nonresponders.

\section{Neural Markers of Attention to Threat}

Anxiety is notable for its marked cross-species conservation of brain-behavior associations; changes in neural network engagement and information processing occur when an organism confronts a threat (Pine, 2009). These associations and changes have been shown in referred and nonreferred youths and adults (Lindstrom et al., 2009), suggesting developmental continuity in the neural processes underlying response to threat. To identify the neural correlates of attention processes, including attention bias to threat, past research has examined event-related potentials (ERPs) time-locked to the onset of the visual stimuli presented in an emotional faces dot probe task (Bar-Haim et al., 2005; Eldar \& Bar-Haim, 2010; Luck, 2005; Thai et al., 2016). ERPs refer to the electrophysiological response to a sensory, cognitive or motor stimulus (Luck, 2005; in this instance, threatening and/or neutral stimuli) and can be used to track the time course 
or chronometry of neural activity involved in threat processing (Heeren, De Raedt, Koster, \& Philippot, 2013; O’Toole \& Dennis, 2012; Suway et al., 2013).

Past research provides evidence linking four ERP components to the neural chronometry of attention bias to threat: P1, N170, P2 and P3 amplitudes in youths (Bechor et al., unpublished manuscript; O'Toole et al., 2013) . P1, which represents attention orienting to visual stimuli (Hillyard et al., 1996), has been associated with sensory processing of emotional faces (Lang, Bradley, \& Cuthbert, 1998). The N170 is a negative deflection component that is related to early processing of and discrimination of facial structures or formations; the N170 can be regarded as an index of selection and discrimination of faces (Balconi \& Lucchiari, 2005; Batty \& Taylor, 2003; Eimer, 2000; Wronka \& Walentowska, 2011). The P2 component represents a neural response to threatening stimuli in the dot probe assessment task (O'Toole \& Dennis, 2012). The P3 component represents later-stage, strategic attention processing (Eldar \& Bar-Haim, 2010; Heeren et al., 2013), and has been linked to extended stimulus evaluation and cognitive processes like response selection ( Falkenstein, Hohnsbein, \& Hoormann, 1994; Verleger, 1997). These four ERP components (i.e., P1, N170, P2, P3) thus represent potential neural markers of attention to threat.

\section{Influence of Attention Training on Neural Markers of Attention to Threat}

As noted, ABMT is the translational treatment implication of attention bias to threat (Eldar et al., 2012; Yuko Hakamata et al., 2010). Attention Bias Modification Treatment aims to shape attention bias via repetitive, computer-based training. In ABMT, participants complete hundreds of trials of a modified dot probe task in which the probe always replaces a neutral stimulus and never replaces a threatening stimulus (Bar-Haim, 
2010; Bechor et al., 2014). Over repeated trials, this establishes a contingency between neutral face and probe location, leading to increased attention to neutral stimuli and reduced attention to threatening stimuli (Yair Bar-Haim, 2010; Suway et al., 2013). ABMT has shown promising anxiety reduction effects in nonreferred (Bar-Haim et al., 2005; Eldar, Ricon, \& Bar-Haim, 2008) and referred youths (Bechor et al., 2014; Cowart \& Ollendick, 2011; Eldar et al., 2012; Pergamin-Hight, Naim, Bakermans-Kranenburg, van, \& Bar-Haim, 2015; Pettit et al., 2017; Rozenman et al., 2011).

Reduction in neural processes subserving attention bias to threat has been theorized as the mediator of ABMT (O'Toole \& Dennis, 2012). However, whether ABMT produces changes in underlying neural processes, or is mediated by changes in such processes, remains unknown (Bar-Haim, 2010; Hakamata et al., 2010; Heeren et al., 2013). This is an important gap in the literature because it remains unclear how ABMT leads to reductions in anxiety. Further, multiple studies have found anxiety reduction effects following an attention control task regimen that is identical to ABMT with the exception that the probe replaces the neutral stimulus and the threatening stimulus with equal probability (i.e., there is no training contingency; Pergamin-Hight, Pine, Fox, \& Bar-Haim, 2016). This anxiety-reduction effect has provoked calls for research into which components of attention processing are influenced by ABMT as well as the control task (Mogg, Waters, \& Bradley, 2017). Findings that shed light on which ERP components change in response to $\mathrm{ABMT}$ and the control task in youth may guide future treatment outcome research and investigation into which components of attention training yield maximal anxiety symptom reduction. 
The current study responds to these calls and addresses this important gap in the literature by collecting ERP data at the pretreatment, posttreatment, and eight-week follow-up assessments in a randomized controlled trial of ABMT in youths with anxiety disorders who did not respond to CBT. ERP data provide precise information about where in neural information processing stream attention training exerts its effects (Suway et al., 2013). This ERP data may provide insight into which ERP components are associated with anxiety reduction effects and also be used to refine and streamline attention training programs to target specific neural markers at specific time points (Cuthbert, 2014; Cuthbert \& Insel, 2013).

The influence of ABMT on neural markers of attention to threat, as measured via ERPs, has never been studied in youths. Past research in nonreferred samples of adults suggests that the P1, N170, P2 and P3 components during the dot probe task may be sensitive to attention training. For example, studies in samples of non-referred adults found that attention training away from threat, as is used in ABMT, led to decreases in the P1 (Dennis-Tiwary, Egan, Babkirk, \& Denefrio, 2016; O’Toole \& Dennis, 2012), P2, and P3 amplitudes (Eldar \& Bar-Haim, 2010), and increases (i.e., potentiation) in the N170 amplitude (Dennis-Tiwary et al., 2016) during threat trials of the dot probe task. Further, studies in non-referred adults found that attention training toward threat, the opposite approach of that used in ABMT, led to increases in the P2 and P3 amplitudes during threat trials of the dot probe task (Eldar \& Bar-Haim, 2010; Suway et al., 2013). These findings support the sensitivity of these ERP components to attention training in adults. 
The present study builds on these findings to examine the influence of ABMT versus a control task on neural markers of attention to threat in youths with anxiety disorders who did not respond to CBT. On the basis of the research findings reviewed above, I considered three hypotheses. Hypothesis 1 was that attention bias scores during threat trials on the dot probe task will significantly and positively correlate with higher P1, P2 and P3 and larger (more negative) N170 amplitudes, and with greater anxiety symptom severity, at pre-treatment; Hypothesis 2 was that youth in the ABMT arm will exhibit significantly decreased P1, P2 and P3 and stronger (more negative) N170 amplitudes during threat trials following treatment compared to youth in the Control Task arm; Hypothesis 3 was that youth in the ABMT arm will continue to exhibit significantly decreased P1, P2 and P3 and stronger (more negative) N170 amplitudes during threat trials eight weeks after post-treatment compared to youth in the control arm, suggesting maintenance effects of ABMT.

\section{Method}

\section{Participants}

Participants were recruited upon entry to an RCT of ABMT for youth with anxiety disorders who did not respond to CBT. All participants had completed a 12-14 week CBT protocol (see Silverman, Kurtines, Jaccard, \& Pina, 2009).Youth were eligible for the RCT if they were between ages seven to 18 years and met criteria for a primary DSM-IV (American Psychiatric Association, 2000) diagnosis of Generalized Anxiety Disorder (GAD), Social Phobia (SOP), or Separation Anxiety Disorder (SAD) at posttreatment and 12-month follow-up assessments of the CBT protocol. Exclusion criteria were (a) meeting diagnostic criteria for Organic Mental Disorders, Psychotic Disorders, 
Pervasive Developmental Disorders, or Mental Retardation, (b) showing high likelihood and/or serious intent of self-harm; (c) not living with a primary caregiver who was legally able to give consent for participation, (d) having a serious, uncorrected vision problem and (e) having a physical disability which interfered with the child's ability to click a mouse button rapidly and repeatedly. Children with comorbid ADHD, minimally impairing tics or impulse control problems or depressive disorders were eligible, as long as each comorbid disorder was treated and stable.

Upon consenting/assenting to the RCT, youth and their parents were asked to take part in an additional, supplemental ERP study, requiring completion of EEG measurement at each of three assessment points (pre-treatment, post-treatment, eightweek follow-up). Fifty-three candidate participants were eligible and approached; 46 (87\%) consented/assented and completed pre-treatment ERP measurement, 35 of the 46 (76\%) completed post-treatment ERP measurement, and 32 of the 35 (91\%) completed eight-week follow-up ERP measurement. One post-treatment and one eight-week followup ERP measure were discarded due to instrumentation error. Thus, $N=30$ youths completed all aspects of the protocol including pre-treatment, post-treatment, and eightweek follow-up ERP measurements, and their diagnostic (Anxiety Disorders Interview Schedule for DSM-IV: Child and Parent Versions [ADIS-C/P]), behavioral (Pediatric Anxiety Rating Scale [PARS]; Screen for Child Anxiety \& Related Disorders-Child and Parent versions[SCARED-C/P]; dot probe threat bias scores) and neural data (P1, N170, P2 \& P3 mean amplitudes) were utilized in statistical analyses. Of the $N=30$ youths, 16 were randomized to the Control Task (CT) arm (mean age: 11.19 years [SD $=2.87$, ages 7 to 16 years; 8 males [50\%]), and $N=14$ were randomized to the ABMT arm (mean age: 
12.86 years [SD $=2.77$ ], ages 8 to 18 years; 6 males [43\%]). Table 1 provides a breakdown of diagnoses and Pediatric Anxiety Rating Scale (PARS) total scores across arms. Six youths in the CT arm met diagnostic criteria for a comorbid (non-primary) diagnosis of Attention-Deficit Hyperactivity-Inattentive type (ADHD-I) and one met criteria for Attention-Deficit Hyperactivity-Combined type (ADHD-C). The distribution of ADHD diagnosis significantly differed across study arms, $\chi^{2}(1)=7.99, p=0.01$. Thus, as mentioned below, ADHD diagnosis was included as a statistical covariate in all main analyses. Three youths in the CT arm were on a stable dose of medication at the time of assessment, for attention deficits $(n=2)$ or for anxiety $(n=1)$; five youths in the ABMT arm were on a stable dose of medication at the time of assessment, for attention deficits $(n=1)$ or for anxiety $(n=3)$ and for anxiety-related medical problems $(n=1)$; the number of youths on medications did not significantly differ across study arms, $\chi^{2}(1)=1.10, p=$ 0.30. All procedures were approved by the appropriate Institutional Review Board.

\section{Measures}

\section{Diagnostic measure.}

\section{Anxiety Disorders Interview Schedule for DSM-IV: Child and Parent Versions}

(ADIS-IV:C/P.) The ADIS-IV: C/P (Albano \& Silverman, 1996) is a semi-structured interview designed to assess anxiety and related disorders in youth. Carefully trained evaluators administered the ADIS-C/P to each youth and parent; diagnoses were given when one or both informants met diagnostic criteria. Before conducting interviews, evaluators met a $100 \%$ reliability criterion on five videotaped child-parent assessments. The ADIS-IV: C/P yields retest reliability kappas between .80 to .92 for diagnoses and significant associations with youth anxiety ratings (e.g., Silverman et al., 2001). 


\section{Anxiety severity ratings.}

Pediatric Anxiety Rating Scale (PARS . Independent Evaluator (IE) rated anxiety severity was measured at pre-treatment, post-treatment and eight-week follow-up. The PARS (RUPP Anxiety Study Group, 2002) assesses global anxiety severity across SOP, $\mathrm{SAD}$, and GAD in youth ages 6-17. Using information obtained from interviews with parents and youths, an IE scores each of 50 anxiety symptoms as present or absent during the past week. Endorsed symptoms are rated by the IE on seven dimensions. Each dimension is rated from zero to five; total scores range from 0-35, with higher scores indicating more anxiety. Before conducting interviews, IEs met a $80 \%$ reliability criterion on five audiotaped child-parent assessments. The PARS has adequate internal consistency ( $\alpha$ s .64-.91) and interrater reliability (intra-class correlations .78-.97), sensitivity to change in treatment studies, and convergent validity (Mogg \& Bradley, 1999; RUPP Anxiety Study Group, 2002). In this sample, the alpha coefficient was .90 .

Screen for Child Anxiety \& Related Disorders-Child version (SCARED-C;

Birmaher et al., 1999; Birmaher et al., 1997). The SCARED-C consists of 41 items on which youth rate their anxiety symptoms on a three-point scale. Test-retest reliability is satisfactory to excellent (ranging from .70 to .90). The SCARED-C has demonstrated good convergent and divergent validity compared with other widely used screening scales (Birmaher et al., 1999; Birmaher et al., 1997). In this sample, the alpha coefficient was .91.

Screen for Child Anxiety \& Related Disorders- Parent version (SCARED-P; Birmaher et al., 1999; Birmaher et al., 1997). The SCARED-P consists of 41 items on which parents rate youth anxiety symptoms on a three-point scale. The reliability and 
validity of the SCARED-P have been demonstrated repeatedly and mirror those of the SCARED-C (Birmaher et al., 1999; Birmaher et al., 1997). In this sample, the alpha coefficient was .96 .

\section{Dot probe task.}

Behavioral assessment. The emotional faces dot probe task developed by MacLeod, Mathews \& Tata (1986), modified for use in child anxiety studies (TAUNIMH ABMT initiative; http://people.socsci.tau.ac.il/mu/anxietytrauma/tau-nimh-abmtinitiative-participating/), was used to obtain a behavioral measure of attentional bias towards threatening stimuli.

In each trial, a white fixation cross appeared for 500 milliseconds (ms) in the center of the screen, followed by a pair of faces (chromatic) appearing for $500 \mathrm{~ms}$. The pair of faces of the same actor showing a neutral or angry (i.e., threatening) expression appeared on the top and bottom of the screen. In each trial, the pair of faces displayed was one of three combinations (80 neutral-angry, 80 angry-neutral, or 80 neutral-neutral) for a total of 160 neutral-threat (NT) trials and 80 neutral-neutral (NN) trials.

Immediately following the faces, a probe ("<" or ">") appeared in the location of either the top or bottom face. Participants were instructed to indicate the orientation of the probe by clicking the left or right mouse button (left for " $<$ ", right for " $>$ ") using their dominant hand. The probe remained on-screen until the participant responded or for 1000 $m s$. A response was followed by an inter-trial interval $(500 \mathrm{~ms})$, and then the next trial began immediately. Angry-face location, probe location, probe type, and actor were fully counterbalanced in presentation. The importance of completing the task as quickly as 
possible without compromising accuracy was emphasized. Trials were presented using EPrime software (Psychology Software Tools, Pittsburgh, PA).

Responses on the dot probe behavioral assessment task were used to calculate mean reaction times $(\mathrm{RT})$ on trials, total number of accurate trials, and attention bias scores. Trials in which the probe replaced angry face were considered congruent trials, and trials in which the probe replaced the neutral face were considered incongruent trials. Bias scores were computed as reaction time differences of incongruent minus congruent trials. Positive attention bias scores indicate a bias toward angry faces (i.e., threat) and negative values indicate a bias away from threat. Inaccurate responses, trials with response latencies $<150 \mathrm{~ms}$ and $>1200 \mathrm{~ms}$, and trials with response latencies +/- 2.5 SDs from the participant's mean were excluded (e.g., Eldar et al., 2010).

ABMT or CT task. As part of the randomized treatment protocol of the RCT, each participant completed eight sessions of either the ABMT task or the CT task. The ABMT task was identical to the dot probe behavioral assessment task but with three exceptions. First, a unique set of faces was used in this task (i.e., different from those used in the dot probe behavioral assessment task). Second, the task consisted of 160 trials: 120 angry-neutral presentations and 40 neutral-neutral presentations. Third, the probe replaced the neutral face on 100\% of the trials. Threat face location (top or bottom) and actor were fully counterbalanced. Across the entire task, on $75 \%$ of the trials, the location of the threat face predicted the location of the probe (behind neutral); on the other $25 \%$, subjects saw neutral-neutral face pairs.

The CT task was identical to the dot probe behavioral assessment task with two exceptions. First, a unique set of faces was used in this task (i.e., different from those 
used in the dot probe behavioral assessment task). Second, the task consisted of 160 trials: 120 angry-neutral presentations and 40 neutral-neutral presentations. In the CT task, the probe replaced the neutral face on $50 \%$ of trials and replaced the threat face on $50 \%$ of trials.

Electrophysiological recording. Each participant was fitted with a 64-electrode elasticized nylon cap (WaveGuard; Advanced Neuro Technology, Enschede, Netherlands) with sewn-in $\mathrm{Ag} / \mathrm{AgCl}$ shielded electrodes following the international 10-20 electrode system. The raw signal was amplified by 25,000 using a high-input impedance AsaLab amplifier (Advanced Neuro Technology, Enschede, Netherlands). The EEG data was sampled at $1024 \mathrm{~Hz}$ with a high-pass filter of .3 Hz. Data acquisition began once impedance values were below $50 \mathrm{k} \Omega$ (a resistance level used for studies in comparable age ranges; Thai et al., 2016). During recording, ERPs were referenced to CPz. AFz served as the ground electrode. The EEG data were further analyzed offline using EEGLab (Delorme \& Makeig, 2004) and ERPLab (Lopez-Calderon \& Luck, 2014) software. EEG data were collected at three time points: pre-assessment, post-assessment and eight-week follow-up assessment. EEG data were not collected during the training sessions (CT or ABMT).

Event Related Potentials. In post-processing, EEG data were re-referenced to average reference and re-filtered with a low-pass filter of $30 \mathrm{~Hz}$. Data were baselinecorrected to the average voltage during the $100 \mathrm{~ms}$ prior to stimulus onset (i.e., onset of facial pair stimuli). Data were resampled offline at $512 \mathrm{~Hz}$. Ocular and motor artifacts exceeding $\pm 75 \mathrm{mV}$ were rejected. Data were segmented and visually inspected for additional ocular and motion artifact. Epochs containing blink activity were removed as 
electrooculogram (EOG) contamination. Trials consisted of a $100 \mathrm{~ms}$ baseline period and $500 \mathrm{~ms}$ period following onset of facial stimuli.

Stimulus-Evoked ERP Components. Specific components of interest were P1, P2, P3 and N170. In line with previous studies, P1, P2, P3 and N170 components were examined at midline parieto-occipital sites (Oz and POz; Batty \& Taylor, 2006; Eldar et al., 2010; Mühlberger et al., 2009; O'Toole et al., 2013; Segalowitz et al., 2010). Each participant's grand average waveforms were visually inspected to determine the window in which the maximal peak of each proposed component was found. Exhaustive windows were shaped by minima and maxima of peak onset ranges recorded per participant, and group-wise grand averages were inspected for each component to confirm the latency windows included all participants' components. Non-overlapping latency windows for P1 (100-160 ms), N170 (170-230 ms), P2 (230-280 ms), and P3 (300-380 ms) were generated separately in ERPLAB and individual mean amplitudes and peak latencies for each component were imported into the statistical software program SPSS version 22.0 (SPSS, 2013) for statistical analysis.

\section{Statistical Analysis}

Independent samples $t$-tests were used to examine group differences (i.e., across study arms) on age, PARS total scores, dot probe behavioral assessment reaction time (RT) scores and SCARED-C/P scores; a chi-square analysis was used to examine gender distribution across arms. Youths in the CT arm were significantly more likely to meet diagnostic criteria for ADHD than youths in the ABMT arm, so ADHD diagnosis was included as a covariate in all statistical analyses. Variables considered in these between- 
group analyses were anxiety level (PARS; SCARED-C/P), attention bias (AB) score (dot probe task), and $\mathrm{P} 1, \mathrm{~N} 170, \mathrm{P} 2$ and $\mathrm{P} 3$ mean amplitudes at POz and Oz.

Initial ERP analyses employed a 3 × 2 × 2 × 2 repeated measures Analysis of Covariance (ANCOVA) with time point (pre-treatment, post-treatment, eight-week follow-up), site (POz, Oz) and stimulus (trial type: NT or NN) as within-subjects factors, $\operatorname{arm}(\mathrm{CT}$ or $\mathrm{ABMT})$ as a between-subjects factor, and age, current medication status and comorbid ADHD diagnosis as covariates. Because the study population included a relatively large age range (eight to 18 years), age was also included as a covariate in all analyses. Medication usage was included as a covariate in all analyses because of its potential effects on anxiety and attention symptoms. Preliminary analyses found a significant main effect of site for each component $\left(\mathrm{P} 1: F[1,25]=53.84, p<.001, \eta_{p}{ }^{2}=\right.$ $.68 ; \mathrm{N} 170: F[1,25]=25.12, p<.001, \eta_{p}{ }^{2}=.501 ; \mathrm{P} 2: F[1,25]=11.41, p=.002, \eta_{p}{ }^{2}=.31$; P3: $\left.F[1,25]=17.33 p<.001, \eta_{p}{ }^{2}=.41\right)$; therefore, all subsequent analyses examined effects at $\mathrm{Oz}$ and $\mathrm{POz}$ separately.

To examine the associations between behavioral and neural measures of attention bias at a pre- and again at post-treatment assessment, I calculated Pearson's correlations between the attention bias score and each of the P1, N170, P2 and P3 amplitudes in response to threatening or neutral stimuli. To examine the associations between neural measures of attention bias and anxiety symptoms, I calculated Pearson's correlations between (a) scores on the SCARED-C/P and PARS and each of the P1, N170, P2 and P3 components' mean amplitude and (b) scores on the dot probe behavioral assessment task and each of the P1, N170, P2 and P3 components' mean amplitude. 
To examine differences in mean amplitudes as a function of study arm, I subjected each ERP component (P1, N170, P2 and P3) to a 2 x 2 repeated measures ANCOVA with stimulus (trial type: NT or NN) as within-subjects factor and arm (CT or ABMT) as between-subjects factor, and age, current medication status, and comorbid ADHD diagnosis as covariates at immediate post-treatment. I also included pre-treatment scores (NT \& NN mean amplitudes) as covariates to increase statistical power as well as control for any potential group differences observed in pre-treatment measures. Post-hoc analyses examined significant stimulus type by arm interaction effects and main effects of arm or stimulus type.

To examine maintenance effects, I used the same analytic approach as described in the preceding paragraph, using eight-week follow-up scores as the outcome variables and pre-treatment scores (NT \& NN mean amplitudes) and post-treatment scores (NT and $\mathrm{NN}$ mean amplitudes) as covariates to increase statistical power.

\section{Results}

\section{Attention to Threat and Anxiety Severity Ratings}

Age and gender did not significantly differ for CT $(M=11.19, S D=2.86)$ and ABMT $(M=12.86, S D=2.77)$ arms (age: $t(28)=-1.62, p=.12, d=0.59$; gender: $\chi^{2}(1)=$ $0.15, p=.70)$. Mean RTs, accuracy scores and threat bias scores on the dot probe task and mean scores on the PARS and SCARED-C/P are presented in Table 1. Mean scores on the SCARED-C/P, PARS, threat bias scores, and dot probe task mean RTs or accuracy did not significantly differ between study arms at pre-treatment, post-treatment or eightweek follow-up $(p s>.08)$. 


\section{Electrophysiological Data}

Mean number of epochs remaining after artifact rejection $(\mathrm{NT}+\mathrm{NN})$ at pretreatment did not differ significantly between CT $(M=148.44, S D=57.40)$ and ABMT $(M=173.57, S D=25.52)$ arms, $t(21.29)=-1.58, p=.13, d=0.57$. At post-treatment, youths in the CT arm had fewer total number of epochs $(M=145.81, S D=53.31)$ than youths in the ABMT arm $(M=181.79, S D=26.35), t(22.52)=-2.39, p=.03, d=0.86$. At eight-week follow-up, youths in the CT arm had fewer total number of epochs ( $M$ $=148.19, S D=52.85)$ than youths in the ABMT $\operatorname{arm}(M=189.71, S D=21.94), t(20.57)=$ $-2.87, p=.01, d=1.03$. As total number of epochs results from a combination of youths' accuracy on trials (incorrect trials are excluded from processing) and from amount of ocular artifact removed from each dot probe assessment, I measured arm differences in accuracy at each assessment wave; differences were not statistically significant at any assessment wave $(p$ s $>.11)$. Thus, I did not include accuracy as a covariate in analyses.

Results on the influence of ABMT on ERP amplitudes are presented in two parts. The first part presents results of statistical analyses as planned in the original dissertation proposal. The second part presents the same analyses with one critical exception: instead of utilizing separate amplitude measures for NT and NN trials as covariates in analyses, a difference score between mean amplitudes on these trials (NT-NN) was utilized as a covariate. As explained below, in preliminary analyses I found statistically significant differences in ERP amplitudes between study arms at pre-treatment. These differences presented challenges for interpretation of findings. The inclusion of differences scores for mean amplitudes (Part II) eliminated pre-treatment arm differences to facilitate interpretation of findings. 


\section{Part I: Testing Hypotheses without Adjusting for Pre-treatment Differences between Study Arms}

\section{Correlations between ERP measures and behavioral data at pre-treatment.}

My first set of hypotheses (i.e., Hypothesis 1) was that attention bias scores on the dot probe task will be significantly and positively correlated with higher P1, P2, and P3 amplitudes during threat trials, larger (more negative) N170 amplitudes during threat trials, and greater anxiety symptom severity. All correlation coefficients relevant to Hypothesis 1 are presented in Table 2. At pre-treatment, attention bias (AB) scores on the dot probe task were not significantly correlated with P1, N170, P2 or P3 mean amplitudes at site POz or Oz, or with anxiety symptom severity as measured by the SCARED-P, SCARED-C, and PARS.

\section{Influence of ABMT on ERP Measures at Post-treatment.}

My second set of hypotheses (i.e., Hypothesis 2) was that youths in the ABMT arm will exhibit significantly decreased P1, P2 and P3 and stronger (more negative) N170 amplitudes during NT trials at post-treatment as compared to youths in the CT arm.

Figure 1 presents the ERP waveforms at pre-treatment, post-treatment and eight-week follow-up across both arms at site POz. Figure 2 presents the waveforms at pre-treatment, post-treatment and eight-week follow-up across both arms at site Oz. In the following sections, I present findings separately for each ERP component.

\section{P1.}

Site $\mathrm{POz}$. The stimulus type by arm interaction effect was statistically significant, $F(1,23)=6.95, p=.02, \eta_{p}^{2}=.23$. Post-hoc analyses revealed a marginally significant main effect of arm on P1 mean amplitude during NN trials, $F(1,24)=3.14, p=.09, \eta_{p}{ }^{2}=$ 
.12; amplitudes in the ABMT arm $(M=8.39, S E=1.49)$ were higher than in the CT arm $(M=4.39, S E=1.37)$. The main effect of arm on P1 mean amplitude during NT trials did not approach significance, $F(1,24)=.04, p=.85, \eta_{p}{ }^{2}=.00$. Main effects of stimulus type were nonsignificant in the $\mathrm{CT}$ arm, $F(1,10)=1.11, p=.32, \eta_{p}{ }^{2}=.10$, and the ABMT arm, $F(1,9)=.89, p=.37, \eta_{p}{ }^{2}=.09$. See Figure 3(a) for a bar graph depicting the main effect of arm within NN trials.

Site $O z$. The stimulus type by arm interaction effect was not statistically significant, $F(1,23)=.98, p=.33, \eta_{p}{ }^{2}=.04$. The main effects of arm and stimulus type were not statistically significant.

\section{N170.}

Site $P O z$. The stimulus type by arm interaction effect was not statistically significant, $F(1,23)=2.32, p=.14, \eta_{p}{ }^{2}=.09$. The main effects of arm and stimulus type were not statistically significant.

Site $O z$. The stimulus type by arm interaction effect was not statistically significant, $F(1,23)=.14, p=.71, \eta_{p}{ }^{2}=.01$. The main effects of arm and stimulus type were not statistically significant.

\section{P2.}

Site $P O z$. The stimulus type by arm interaction effect was marginally significant, $F(1,23)=3.69, p=.07, \eta_{p}^{2}=.14$. Post-hoc analyses revealed a nonsignificant main effect of arm on P2 mean amplitude during NN trials, $F(1,24)=1.56, p=.22, \eta_{p}{ }^{2}=.06$; amplitudes in the ABMT arm $(M=3.74, S E=2.66)$ were higher than in the CT $\operatorname{arm}(M=$ -1.47, $S E=2.44)$. The main effect of arm on P2 mean amplitude during NT trials did not approach significance, $F(1,24)=.17, p=.68, \eta_{p}^{2}=.01$. Main effects of stimulus type 
were nonsignificant in the CT arm, $F(1,10)=.74, p=.41, \eta_{\mathrm{p}}^{2}=.07$, and the ABMT arm, $F(1,9)=.00, p=.99, \eta_{p}^{2}=.00$.

Site $O z$. The stimulus type by arm interaction effect was not statistically significant, $F(1,23)=.69, p=.41, \eta_{p}{ }^{2}=.03$. The main effects of arm and stimulus type were not statistically significant.

\section{P3.}

Site $P O z$. The stimulus type by arm interaction effect was statistically significant, $F(1,23)=4.53, p=.04, \eta_{p}{ }^{2}=.16$. Post-hoc analyses revealed a nonsignificant main effect of stimulus on $\mathrm{P} 3$ mean amplitude in the ABMT arm, $F(1,9)=1.98, p=.19, \eta_{p}{ }^{2}=.18$, and the CT arm, $F(1,10)=.80, p=.39, \eta_{p}{ }^{2}=.07$. The main effect of arm on P3 mean amplitude during NT trials across groups did not approach significance, $F(1,24)=.49, p$ $=.49, \eta_{p}{ }^{2}=.02$, nor did the main effect of arm on P3 mean amplitude during NN trials, $F(1,24)=.14, p=.71, \eta_{p}{ }^{2}=.01$. See Figure 3(b) for a bar graph depicting the significant stimulus-type-by-arm interaction effect for P3 mean amplitudes at post-treatment.

Site $O z$. The stimulus type by arm interaction effect was not statistically significant, $F(1,23)=1.50, p=.24, \eta_{p}^{2}=.06$. The main effects of arm and stimulus type were not statistically significant.

\section{Influence of ABMT on ERP Measures at Eight-week Follow-up.}

My third set of hypotheses (i.e., Hypothesis 3) was that youths in the ABMT arm will exhibit significantly decreased P1, P2 and P3 and stronger (more negative) N170 amplitudes during NT trials at eight-week follow-up as compared to youths in the CT arm. In the following sections, I present findings separately for each ERP component. 


\section{$P 1$.}

Site $P O z$. The stimulus type by arm interaction effect was not statistically significant, $F(1,21)=2.88, p=.80, \eta_{p}^{2}=.00$. However, there was a significant main effect of arm, $F(1,21)=5.28, p=.03, \eta_{p}{ }^{2}=.20$; collapsed across stimulus type, P1 mean amplitude was significantly larger in the $\mathrm{CT} \operatorname{arm}(M=6.63, S E=2.22)$ than the ABMT arm, $(M=-2.31, S E=2.44)$. See Figure 4(a) for a bar graph of the significant main effect of treatment arm on P1 mean amplitudes at eight-week follow-up. The main effect of stimulus type was not statistically significant.

Site $O z$. The stimulus type by arm interaction effect was not statistically significant, $F(1,21)=.11, p=.75, \eta_{p}{ }^{2}=.01$. The main effects of arm and stimulus type were not statistically significant.

\section{N170.}

Site $\mathrm{POz}$. The stimulus type by arm interaction effect was not statistically significant, $F(1,21)=.01, p=.92, \eta_{p}{ }^{2}=.00$. However, there was a significant main effect of stimulus type, $F(1,21)=6.09, p=.02, \eta_{p}{ }^{2}=.23$; collapsed across arms, N170 mean amplitude was significantly larger (more negative) during NN trials $(M=2.02, S E=$ 2.07) than NT trials $(M=2.70, S E=1.01)$. See Figure 4(b) for a bar graph of the significant main effect of stimulus type within the CT group for N170 mean amplitudes at eight-week follow-up. The main effect of arm was not statistically significant.

Site $O z$. The stimulus type by arm interaction effect was not statistically significant, $F(1,21)=.30, p=.59, \eta_{p}{ }^{2}=.01$. The main effects of arm and stimulus type were not statistically significant. 
P2.

Site $P O z$. The stimulus type by arm interaction effect was not statistically significant, $F(1,21)=.52, p=.48, \eta_{p}{ }^{2}=.02$. The main effects of arm and stimulus type were not statistically significant.

Site $O z$. The stimulus type by arm interaction effect was not statistically significant, $F(1,21)=.09, p=.77, \eta_{p}{ }^{2}=.00$. The main effects of arm and stimulus type were not statistically significant.

P3.

Site POz. The stimulus type by arm interaction effect was not statistically significant, $F(1,21)=1.59, p=.22, \eta_{p}^{2}=.07$. The main effects of arm and stimulus type were not statistically significant.

Site $O z$. The stimulus type by arm interaction effect was not statistically significant, $F(1,21)=.40, p=.53, \eta_{p}{ }^{2}=.02$. The main effects of arm and stimulus type were not statistically significant.

\section{Part II: Testing Hypotheses after Adjusting for Pre-treatment Differences between Study Arms}

In preliminary analyses, I found statistically significant differences in ERP amplitudes between the two study arms at pre-treatment: POz (N170 \& P2) and Oz (P1, P2 and P3). I also found statistically significant differences in ERP amplitudes between stimulus types at pre-treatment: POz (P1) and Oz (P1, N170). See Table 3(a) for details. These significant ERP differences between study arms were unexpected and occurred despite random assignment to conditions. 
In order to account for significant ERP differences between study arms and stimulus types at pre-treatment, I computed a difference score between NT amplitudes and NN amplitudes (NT - NN) for each component (P1, N170, P2, P3) at both sites of interest $(\mathrm{POz}, \mathrm{Oz})$ at each time point (pre-treatment, post-treatment, eight-week followup). A larger value for P1, P2, and P3 and a smaller value for $\mathrm{N} 170$ represents greater activation during NT trials compared to NN trials. Similarly, a greater positive difference score for P1, P2, or P3 reflect greater attention toward threat stimuli compared to neutral stimuli. In contrast, a greater negative difference score for N170 reflects greater attention allocated toward threat compared to neutral stimuli. The use of the difference score allows for the control of significant between-group differences in amplitudes at pretreatment while preserving within group differences in amplitudes observed for NT and NN at post-treatment and two-month follow-up. See Table 3(b) which shows results of univariate ANCOVAs for arm effects at each time point, per component, per site; this table shows that calculating a NT-NN difference score yields no significant main effect of arm at pre-treatment. Using these difference scores, I then re-ran the same analyses as reported in Part I of the Results without including stimulus type as a within-subjects variable. See Figure 5 for NT-NN difference scores between arms at each time point at site POz, and see Figure 6 for such differences at site Oz. To test Hypothesis 2, I ran a univariate ANCOVA with post-treatment difference (NT-NN) scores as within subjects factor and arm (CT, ABMT) as between-subjects factor, with pre-treatment difference (NT-NN) scores, age, medication status, and ADHD diagnosis as covariates. To test Hypothesis 3, I ran the same analyses as in Hypothesis 2 but with eight-week follow-up difference (NT-NN) scores as within subjects factor, with both pre-treatment and post- 
treatment difference (NT-NN) scores, age, medication status, and ADHD diagnosis as covariates.

\section{Correlations between ERP measures and behavioral data at pre-treatment.}

All Hypothesis 1 correlations utilizing difference scores (NT-NN) are listed in Table 4.

Site POz. At pre-treatment, SCARED-C was significantly positively correlated with P2 mean amplitude difference (NT-NN) score, $(r=.35, N=34, p=.04)$. Relatively more neural activity during NT trials than during NN trials was significantly associated with higher levels of anxiety symptom severity (as per youth report).

Site $O z$. At pre-treatment, attention bias $(\mathrm{AB})$ score on the dot probe task was significantly negatively correlated with P2 mean amplitude difference (NT-NN) score ( $r$ $=-.37, N=32, p=.03$ ) such that relatively more neural activity during $\mathrm{NN}$ trials than during NT trials was associated with higher levels of attention bias toward threat.

\section{Influence of ABMT on ERP Measures at Post-treatment.}

\section{$P 1$.}

Site POz. A significant main effect of arm was found at $\mathrm{POz}$ at post-treatment, $F(1,24)=4.64, p=.04, \eta_{p}{ }^{2}=.16$, wherein the difference score (NT-NN) for P1 mean amplitude was more positive for the CT arm, $(M=2.86, S E=1.09)$ than for the ABMT $\operatorname{arm}(M=-.95, S E=1.18)$. At post-treatment, the CT arm had higher P1 mean amplitudes for NT stimuli than for NN stimuli, while the ABMT arm had lower P1 mean amplitudes for NT stimuli than for NN stimuli. See Figure 5.

Site $O z$. A nonsignificant main effect of arm was found $F(1,24)=.95, p=.34$, $\eta_{p}^{2}=.04$ 
N170.

Site POz. A nonsignificant main effect of arm was found $F(1,24)=2.75, p=.11$, $\eta_{p}^{2}=.10$.

Site $O z$. A nonsignificant main effect of arm was found $F(1,24)=.89, p=.35$, $\eta_{p}^{2}=.04$.

$\boldsymbol{P 2}$.

Site POz. A nonsignificant main effect of arm was found $F(1,24)=1.29, p=.27$, $\eta_{p}^{2}=.05$.

Site $O z$. A nonsignificant main effect of arm was found $F(1,24)=.31, p=.59$, $\eta_{p}^{2}=.01$.

P3.

Site POz. A nonsignificant main effect of arm was found $F(1,24)=2.92, p=.10$, $\eta_{p}^{2}=.11$

Site $O z$. A nonsignificant main effect of arm was found $F(1,24)=1.18, p=.29$, $\eta_{p}^{2}=.05$.

\section{Influence of ABMT on ERP Measures at Eight-week Follow-up.}

P1.

Site $P O z$. A nonsignificant main effect of arm was found $F(1,23)=.60, p=.45$, $\eta_{p}{ }^{2}=.03$.

Site $O z$. A nonsignificant main effect of arm was found $F(1,23)=1.12, p=.30$, $\eta_{p}^{2}=.05$. 
N170.

Site POz. A nonsignificant main effect of arm was found $F(1,23)=1.42, p=.25$, $\eta_{p}^{2}=.06$.

Site $O z$. A nonsignificant main effect of arm was found $F(1,23)=1.28, p=.27$, $\eta_{p}^{2}=.05$.

$P 2$.

Site POz. A nonsignificant main effect of arm was found $F(1,23)=1.43, p=.24$, $\eta_{p}{ }^{2}=.06$.

Site $O z$. A nonsignificant main effect of arm was found $F(1,23)=.70, p=.41$, $\eta_{p}^{2}=.03$.

P3.

Site POz. A nonsignificant main effect of arm was found $F(1,23)=2.17, p=.15$, $\eta_{p}^{2}=.09$.

Site $O z$. A significant main effect of arm was found, $F(1,23)=4.92, p=.04, \eta_{p}{ }^{2}=$ .18, wherein the difference score (NT-NN) for P3 mean amplitude was more positive for the $\mathrm{CT}$ arm, $(M=3.73, S E=1.76)$ than for the ABMT arm $(M=-2.67, S E=1.91)$. At eight-week follow-up, the CT arm had higher P3 mean amplitudes for NT stimuli than for NN stimuli (i.e., a positive difference score of NT-NN), while the ABMT arm had lower P3 mean amplitudes for NT stimuli than for NN stimuli. See Figure 6.

\section{Comparison of Part I and Part II Findings}

Regarding Hypothesis 1, in Part I, mean amplitudes of all components were not significantly correlated with attention bias or anxiety symptom measures, but in Part II, 
when utilizing difference scores, attention bias score and youth self-rated anxiety were correlated significantly with the P2 component.

Regarding Hypotheses 2 and 3, results in Part I and Part II were similar for posttreatment, and Part II also revealed a treatment maintenance effect (at eight-week followup). For P1 amplitude, Part I analyses revealed significantly higher amplitudes in the $\mathrm{ABMT}$ arm than in the CT arm within NN trials at post-treatment; Part II analyses revealed a similar pattern but showed attentional differences based on stimulus type; the CT arm showed higher amplitudes for NT than for NN trials, and the reverse pattern was found in the ABMT arm (i.e., higher amplitudes for NN than for NT). For N170, Part I analyses showed stronger N170 for NN trials than for NT trials within the CT arm; in contrast, Part II analyses revealed no significant between-arm differences in mean amplitude difference scores at post-treatment or at eight-week follow-up. P2 results across Parts I and II were comparable to those for N170, in which there was a weak interaction effect between stimulus type and arm in Part I analyses, but Part II analyses revealed no significant differences in stimulus difference scores at post-treatment or at eight-week follow-up. For P1, N170 and P2, all significant effects reported were at site POz, across Parts I and II. For P3, however, Part I analyses revealed the ABMT group showed higher amplitudes during NN trials than during NT trials at post-treatment at POz, whereas in Part II, analyses showed the reverse: NT-NN difference scores were positive in the $\mathrm{CT}$ arm and negative in the ABMT arm. However, this pattern in Part II was found at eight-week follow-up, not post-treatment, and at site Oz, not POz. Given the significant effects of site found in initial analyses, these discrepant findings for P3 
suggest the effects found are distinct, and future studies should consider treatment effects as a function of site.

\section{Discussion}

The current study examined the influence of a bottom-up, implicit training regimen, ABMT, on neural markers of attention to threat in youth anxiety CBT nonresponders. At post-treatment, I found that ABMT led to enhanced neural reactivity (i.e., larger amplitudes) in early-stage (P1) and late stage (P3) markers of attention in response to neutral stimuli. Using NT-NN difference scores, a proxy for differential attention across emotional valence in facial stimuli, I also found that ABMT led to relatively less allocation of neural resources towards threat stimuli than neutral stimuli in an early stage neural marker (P1), whereas the CT arm led to relatively greater allocation of neural resources towards threat stimuli than neutral stimuli in the same early stage neural marker (P1). These findings suggest early attentional orienting (i.e., P1) may shift as a result of $\mathrm{ABMT}$, such that before treatment, youth with anxiety disorders allocate more early stage neural resources to processing threat stimuli, but after treatment, allocate more early stage neural resources to processing neutral stimuli.

This pattern of findings is consistent with the theoretical model underlying ABMT, in that repetitive implicit training leads to a shift in attentional resources away from threatening stimuli and towards neutral stimuli. Further, it provides evidence that this shift happens early in the stream of attentional processing (P1). This highlights the plasticity of early attentional processing, such as attentional orientation, to emotional stimuli in response to training, and suggests that the ABMT regimen specifically influences this early stage of processing instead of later stages of processing. Intriguingly, 
another recent study reported that a single session of either a gamified ABMT protocol or a control task led to enhanced early stage (P1) markers of attention in response to threatening stimuli (Dennis-Tiwary et al., 2016). That finding similarly highlights the plasticity of early attentional processing in response to training but differs from the current finding in that enhancement effects were seen in processing of threatening stimuli instead of neutral stimuli. The difference in findings between Dennis-Tiwary et al. and the current study may be due to differences in the training regimen protocols, including format and number of sessions (one versus eight), and/or to differences in the ages and anxiety severity levels of the samples.

In the current study, at posttreatment, youth in the ABMT arm showed an ERP profile during early attention processing similar to a profile that was found in typically developing youth (i.e., larger P1 amplitudes in response to neutral stimuli; Bechor et al., unpublished manuscript). This similar profile suggests that ABMT may lead to a "normalization" of early stage attentional processing in youth with anxiety disorders by immediate posttreatment. Based on this finding, I speculate ABMT may enhance the allocation of early stage attentional resources towards emotionally ambiguous stimuli (i.e., neutral stimuli) in the service of more accurate identification of emotional valence.

At an eight-week follow-up evaluation, I found that youth participants in both study arms displayed significantly greater allocation of neural resources to early-stage processing of neutral facial stimuli (i.e., more negative N170 amplitudes), relative to pretreatment. Using NT-NN difference scores, a proxy for differential attention across emotional valence in facial stimuli, I found that youth participants in the CT arm displayed significantly greater allocation of neural resources to late-stage processing (i.e., 
P3) of threatening stimuli than neutral stimuli, whereas youth participants in the ABMT arm displayed significantly greater allocation of neural resources to late-stage processing (i.e., P3) of neutral stimuli than threatening stimuli. Enhanced P3 has been linked to greater stimulus evaluation and response selection (M. Falkenstein et al., 1994; Verleger, 1997). The current findings indicate that ABMT may selectively lead to greater later stage evaluation of emotionally ambiguous stimuli eight weeks after treatment ends. Overall, these findings at eight-week-follow-up suggest both forms of attention training lead to enhanced early stage neural processing (N170) of neutral stimuli in the weeks following treatment, while the ABMT task specifically leads to enhanced late stage neural processing $(\mathrm{P} 3)$ of neutral stimuli in the weeks following treatment.

Consistent with a growing body of research, the current study overall did not find statistically significant associations between a behavioral reaction time measure of attention bias toward threat and ERP components or anxiety symptom severity, with one exception. The one exception was that the scores on behavioral reaction time measure were significantly correlated with the P2 amplitude on an NT-NN difference score, but the direction of the correlation was unexpected. Overall, these findings add to a literature indicating that behavioral reaction time measures may not provide sensitive or reliable measures of attentional processing (Brown et al., 2014; Kappenman, Farrens, Luck, \& Proudfit, 2014a; Staugaard, 2009; Waechter, Nelson, Wright, Hyatt, \& Oakman, 2014; Waechter \& Stolz, 2015).

Current findings should be evaluated in light of the study's limitations. One limitation was relatively small sample size, which limited statistical power and prevented me from examining possible individual differences in ERP amplitudes as a function of 
age, sex, anxiety severity or diagnostic category. Further, pre-treatment differences in ADHD diagnosis across arms posed difficulty in drawing conclusions about the effects of treatment. Reducing stimulus effects to a singular measure via the use of the NT-NN difference scores simplified analyses and reduced main effects of arm assignment at pretreatment; however, difference scores present challenges for interpretation of treatment effects (i.e., if both $\mathrm{NT}$ and $\mathrm{NN}$ amplitudes increased or decreased over time, their relative difference score may not have shown statistical change).

In spite of these limitations, the current findings identified possible neural markers of ABMT's influence on attentional processes in youth with anxiety disorders. The findings further suggest that ABMT may lead to a normalization of attentional processing at post-treatment, such that youth with anxiety disorders who receive ABMT show an early stage ERP profile that is similar to typically developing youth and characterized by relatively greater neural processing of emotionally ambiguous stimuli than threatening stimuli. Future studies are encouraged to replicate the current findings in larger and diverse samples. Future studies should also include waitlist control arms to evaluate more stringently the training effects of the CT task, especially in light of the results found for facial stimuli processing.

\section{References}

Achenbach, T., \& Rescorla, L. (2001). Manual for the ASEBA School-Age Forms \& Profiles. Burlington, VT: University of Vermont, Research Center for Children, Youth, and Families.

Albano, A. M., \& Silverman, W. K. (1996). Anxiety disorders interview schedule for DSM-IV: child version; clinician manual: OUP. 
Amir, N., Beard, C., Burns, M., \& Bomyea, J. (2009). Attention modification program in individuals with generalized anxiety disorder. J Abnorm Psychol, 118(1), 28-33. doi:2009-01738-016 [pii] 10.1037/a0012589

Amir, N., Beard, C., Taylor, C. T., Klumpp, H., Elias, J., Burns, M., \& Chen, X. (2009). Attention training in individuals with generalized social phobia: A randomized controlled trial. J Consult Clin Psychol, 77(5), 961-973. doi:10.1037/a0016685

Aschenbrand, S. G., Angelosante, A. G., \& Kendall, P. C. (2005). Discriminant validity and clinical utility of the CBCL with anxiety-disordered youth. J Clin Child Adolesc Psychol, 34(4), 735-746. doi:10.1207/s15374424jccp3404_15

Association, A. P. (2000). Diagnostic and statistical manual of mental disorders DSMIV-TR fourth edition (text revision).

Balconi, M., \& Lucchiari, C. (2005). Event-related potentials related to normal and morphed emotional faces. The Journal of psychology, 139(2), 176-192.

Baldwin, J. S., \& Dadds, M. R. (2007). Reliability and validity of parent and child versions of the multidimensional anxiety scale for children in community samples. J Am Acad Child Adolesc Psychiatry, 46(2), 252-260. doi:10.1097/01.chi.0000246065.93200.a1S0890-8567(09)61833-5 [pii]

Bar-Haim, Y. (2010). Research review: Attention bias modification (ABM): a novel treatment for anxiety disorders. J Child Psychol Psychiatry, 51(8), 859-870. doi:JCPP2251 [pii] 10.1111/j.1469-7610.2010.02251.x

Bar-Haim, Y. (2010). Research review: Attention bias modification (ADM): A novel treatment for anxiety disorders (Vol. - 51, pp. - 859-- 870). United Kingdom United Kingdom: Wiley-Blackwell Publishing Ltd. Blackwell Publishing.

Bar-Haim, Y., Lamy, D., \& Glickman, S. (2005). Attentional bias in anxiety: A behavioral and ERP study. Brain and Cognition, 59(1), 11-22. doi:http://dx.doi.org.ezproxy.fiu.edu/10.1016/j.bandc.2005.03.005

Bar-Haim, Y., Lamy, D., Pergamin, L., Bakermans-Kranenburg, M., \& van Ijzendoorn, M. H. (2007). Threat-related attentional bias in anxious and nonanxious individuals: A meta-analytic study. Psychological bulletin, 133(1), 1-1-24. doi:10.1037/0033-2909.133.1.1

Bar-Haim, Y., Lamy, D., Pergamin, L., Bakermans-Kranenburg, M. J., \& van IJzendoorn, M. H. (2007). Threat-related attentional bias in anxious and nonanxious individuals: A meta-analytic study. Psychological Bulletin, 133(1), 124. doi:Doi 10.1037/0033-2909.133.1.1 
Bar-Haim, Y., Morag, I., \& Glickman, S. (2011). Training anxious children to disengage attention from threat: a randomized controlled trial. J Child Psychol Psychiatry. doi:10.1111/j.1469-7610.2011.02368.x

Batty, \& Taylor. (2006). The development of emotional face processing during childhood. Developmental science, 9(2), 207-220.

Batty, \& Taylor, M. J. (2003). Early processing of the six basic facial emotional expressions. Cognitive Brain Research, 17(3), 613-620.

Bechor, M., Pettit, J. W., Silverman, W. K., Bar-Haim, Y., Abend, R., Pine, D. S., . . Jaccard, J. (2014). Attention Bias Modification Treatment for children with anxiety disorders who do not respond to cognitive behavioral therapy: a case series. Journal of Anxiety Disorders, 28(2), 154-159. doi:http://dx.doi.org/10.1016/j.janxdis.2013.09.001

Bechor, M., Ramos, M. L., Crowley, M. J., Silverman, W. K., Pettit, J. W., \& ReebSutherland, B. C. Neural Correlates of Attentional Processing of Threat in Youth with and without Anxiety Disorders. (submitted manuscript).

Benoit, K. E., McNally, R. J., Rapee, R. M., Gamble, A. L., \& Wiseman, A. L. (2007). Processing of emotional faces in children and adolescents with anxiety disorders. Behaviour Change, 24(4), 183-194. doi:http://dx.doi.org.ezproxy.fiu.edu/10.1375/bech.24.4.183

Bentin, S., Allison, T., Puce, A., Perez, E., \& McCarthy, G. (1996). Electrophysiological studies of face perception in humans. Journal of cognitive neuroscience, $8(6)$, 551-565.

Birmaher, B., Brent, D. A., Chiappetta, L., Bridge, J., Monga, S., \& Baugher, M. (1999). Psychometric properties of the Screen for Child Anxiety Related Emotional Disorders (SCARED): a replication study. Journal of the American Academy of Child \& Adolescent Psychiatry, 38(10), 1230-1236.

Birmaher, B., Khetarpal, S., Brent, D., Cully, M., Balach, L., Kaufman, J., \& Neer, S. M. (1997). The screen for child anxiety related emotional disorders (SCARED): Scale construction and psychometric characteristics. Journal of the American Academy of Child \& Adolescent Psychiatry, 36(4), 545-553.

Brooks, S. J., \& Kutcher, S. (2001). Diagnosis and measurement of adolescent depression: a review of commonly utilized instruments. J Child Adolesc Psychopharmacol, 11(4), 341-376.

Brown, H., Eley, T., Broeren, S., MacLeod, C., Rinck, M., Hadwin, J., \& Lester, K. (2014). Psychometric properties of reaction time based experimental paradigms 
measuring anxiety-related information-processing biases in children. Journal of Anxiety Disorders, 28(1), 97-107.

Bruin, K., Kenemans, J., Verbaten, M., \& Van der Heijden, A. (2000). Habituation: an event-related potential and dipole source analysis study. International Journal of Psychophysiology, 36(3), 199-209.

Carretié, L., Mercado, F., Hinojosa, J. A. J. A., Martín-Loeches, M., \& Sotillo, M. (2004). Valence-related vigilance biases in anxiety studied through event-related potentials. Journal of Affective Disorders, 78(2), 119-130. doi:http://dx.doi.org/10.1016/S0165-0327(02)00242-2

Cisler, J. M., \& Koster, E. H. (2010). Mechanisms of attentional biases towards threat in anxiety disorders: An integrative review. Clinical Psychology Review, 30(2), 203216. doi:S0272-7358(09)00158-5 [pii] 10.1016/j.cpr.2009.11.003

Cisler, J. M., \& Koster, E. H. W. (2010). Mechanisms of attentional biases towards threat in anxiety disorders: an integrative review (Vol. - 30, pp. - 203-- 216).

Compton, S. N., March, J. S., Brent, D., Albano, A. M., Weersing, V. R., \& Curry, J. (2004). Cognitive-behavioral psychotherapy for anxiety and depressive disorders in children and adolescents: An evidence-based medicine review. Journal of the American Academy of Child and Adolescent Psychiatry, 43(8), 930-959. doi:DOI 10.1097/01.chi.0000127589.57468.bf

Compton, S. N., March, J. S., Brent, D., Albano, A. M., Weersing, V. R., \& Curry, J. (2004). Cognitive-Behavioral Psychotherapy for Anxiety and Depressive Disorders in Children and Adolescents: An Evidence-Based Medicine Review. Journal of the American Academy of Child \& Adolescent Psychiatry, 43(8), 930930-959. doi:10.1097/01.chi.0000127589.57468.bf

Costello, E. J., Egger, H. L., Copeland, W., Erkanli, A., \& Angold, A. (2011). The developmental epidemiology of anxiety disorders: Phenomenology, prevalence, and comorbidity. Anxiety disorders in children and adolescents: Research, assessment and intervention, 56-75.

Cowart, M. J., \& Ollendick, T. H. (2011). Attention training in socially anxious children: a multiple baseline design analysis. J Anxiety Disord, 25(7), 972-977. doi:10.1016/j.janxdis.2011.06.005

Cowart, M. J. W., \& Ollendick, T. H. (2011). Attention training in socially anxious children: a multiple baseline design analysis. Journal of Anxiety Disorders, 25(7), 972-977. 
Cuthbert, B. N. (2014). The RDoC framework: facilitating transition from ICD/DSM to dimensional approaches that integrate neuroscience and psychopathology. World Psychiatry, 13(1), 28-35.

Cuthbert, B. N., \& Insel, T. R. (2013). Toward the future of psychiatric diagnosis: the seven pillars of RDoC. BMC medicine, 11(1), 126.

Delorme, A., \& Makeig, S. (2004). EEGLAB: an open source toolbox for analysis of single-trial EEG dynamics including independent component analysis. Journal of neuroscience methods, 134(1), 9-21.

Dennis-Tiwary, T. A., Egan, L. J., Babkirk, S., \& Denefrio, S. (2016). For whom the bell tolls: Neurocognitive individual differences in the acute stress-reduction effects of an attention bias modification game for anxiety. Behaviour research and therapy, $77,105-117$.

Dudeney, J., Sharpe, L., \& Hunt, C. (2015). Attentional bias towards threatening stimuli in children with anxiety: a meta-analysis. Clinical Psychology Review, 40, 66-75.

Eimer, M. (2000). The face-specific N170 component reflects late stages in the structural encoding of faces. Neuroreport, 11(10), 2319-2324.

Éismont, E., Lutsyuk, N., \& Pavlenko, V. (2009). Reflection of anxiety in the characteristics of evoked EEG potentials in 10-to 11-year-old children. Neurophysiology, 41(6), 435-442.

Eldar, Apter, A., Lotan, D., Edgar, K. P., Naim, R., Fox, N. A., . . Bar-Haim, Y. (2012). Attention bias modification treatment for pediatric anxiety disorders: A randomized controlled trial. The American Journal of Psychiatry, 169(2), 213220. doi:http://dx.doi.org/10.1176/appi.ajp.2011.11060886

Eldar, \& Bar-Haim. (2010). Neural plasticity in response to attention training in anxiety. Psychological medicine, 40(4), 667-677.

Eldar, Ricon, T., \& Bar-Haim, Y. (2008). Plasticity in attention: implications for stress response in children. Behaviour Research and Therapy, 46(4), 450-461.

Eldar, Yankelevitch, R., Lamy, D., \& Bar-Haim, Y. (2010). Enhanced neural reactivity and selective attention to threat in anxiety. Biological Psychology, 85(2), 252-257. doi:http://dx.doi.org/10.1016/j.biopsycho.2010.07.010

Eldar, S., Apter, A., Lotan, D., Edgar, K. P., Naim, R., Fox, N. A., . . Bar-Haim, Y. (2012). Attention bias modification treatment for pediatric anxiety disorders: a randomized controlled trial. Am J Psychiatry, 169(2), 213-220. 
Eldar, S., Ricon, T., \& Bar-Haim, Y. (2008). Plasticity in attention: implications for stress response in children. Behav Res Ther, 46(4), 450-461.

doi:10.1016/j.brat.2008.01.012

Falkenstein, Hohnsbein, J., \& Hoormann, J. (1994). Event-related potential correlates of errors in reaction tasks. Electroencephalography and clinical neurophysiology. Supplement, 44, 287-296.

Falkenstein, Hoormann, J., \& Hohnsbein, J. (1999). ERP components in Go/Nogo tasks and their relation to inhibition. Acta psychologica, 101(2), 267-291.

Falkenstein, M., Hohnsbein, J., \& Hoormann, J. (1994). Effects of choice complexity on different subcomponents of the late positive complex of the event-related potential. Electroencephalography and Clinical Neurophysiology/Evoked Potentials Section, 92(2), 148-160.

Group, R. A. S. (2002). The pediatric anxiety rating scale (PARS): Development and psychometric properties. J Am Acad Child Adolesc Psychiatry, 41(9), 1061-1069.

Hakamata, Y., Lissek, S., Bar-Haim, Y., Britton, J. C., Fox, N. A., Leibenluft, E., . . Pine, D. S. (2010). Attention bias modification treatment: a meta-analysis toward the establishment of novel treatment for anxiety. Biological psychiatry, 68(11), 982-990. doi:http://dx.doi.org.ezproxy.fiu.edu/10.1016/j.biopsych.2010.07.021

Hakamata, Y., Lissek, S., Bar-Haim, Y., Britton, J. C., Fox, N. A., Leibenluft, E., . . Pine, D. S. (2010). Attention bias modification treatment: a meta-analysis toward the establishment of novel treatment for anxiety. Biol Psychiatry, 68(11), 982990. doi:10.1016/j.biopsych.2010.07.021

Hazen, R. A., Vasey, M. W., \& Schmidt, N. B. (2009). Attentional retraining: a randomized clinical trial for pathological worry. J Psychiatr Res, 43(6), 627-633. doi:S0022-3956(08)00141-6 [pii]10.1016/j.jpsychires.2008.07.004

Heeren, A., De Raedt, R., Koster, E. H. W., \& Philippot, P. (2013). The (neuro) cognitive mechanisms behind attention bias modification in anxiety: Proposals based on theoretical accounts of attentional bias. Frontiers in Human Neuroscience, 7. doi:http://dx.doi.org.ezproxy.fiu.edu/10.3389/fnhum.2013.00119

Helfinstein, S. M., White, L. K., Bar-Haim, Y., \& Fox, N. A. (2008). Affective primes suppress attention bias to threat in socially anxious individuals. Behaviour Research and Therapy, 46(7), 799-810. doi:http://dx.doi.org/10.1016/j.brat.2008.03.011

Hillyard, S. A., Anllo-Vento, L., Clark, V. P., Heinze, H.-J., Luck, S. J., \& Mangun, G. R. (1996). Neuroimaging approaches to the study of visual attention: A tutorial. 
Holmes, A., Nielsen, M. K., \& Green, S. (2008). Effects of anxiety on the processing of fearful and happy faces: an event-related potential study. Biological Psychology, 77(2), 159-173.

Hum, K. M., Manassis, K., \& Lewis, M. D. (2013). Neural mechanisms of emotion regulation in childhood anxiety. Journal of Child Psychology and Psychiatry, 54(5), 552-564. doi:http://dx.doi.org.ezproxy.fiu.edu/10.1111/j.14697610.2012.02609.x

Huster, R. J., Enriquez-Geppert, S., Lavallee, C. F., Falkenstein, M., \& Herrmann, C. S. (2013). Electroencephalography of response inhibition tasks: functional networks and cognitive contributions. International Journal of Psychophysiology, 87(3), $217-233$.

Kappenman, E. S., Farrens, J. L., Luck, S. J., \& Proudfit, G. H. (2014a). Behavioral and ERP measures of attentional bias to threat in the dot-probe task: poor reliability and lack of correlation with anxiety. Frontiers in Psychology, 5.

Kappenman, E. S., Farrens, J. L., Luck, S. J., \& Proudfit, G. H. (2014b). Behavioral and ERP measures of attentional bias to threat in the dot-probe task: Poor reliability and lack of correlation with anxiety.

Kaufman, J., Birmaher, B., Brent, D., Rao, U., Flynn, C., Moreci, P., . . Ryan, N. (1997). Schedule for affective disorders and schizophrenia for school-age children-present and lifetime version (K-SADS-PL): initial reliability and validity data. Journal of the American Academy of Child \& Adolescent Psychiatry, 36(7), 980-988.

Kendall, P. C. (1994). Treating anxiety disorders in children: results of a randomized clinical trial. J Consult Clin Psychol, 62(1), 100-110.

Klein, D. N., Dougherty, L. R., \& Olino, T. M. (2005). Toward guidelines for evidencebased assessment of depression in children and adolescents. Journal of Clinical Child and Adolescent Psychology, 34(3), 412-432.

Kolassa, I.-T., \& Miltner, W. H. (2006). Psychophysiological correlates of face processing in social phobia. Brain Research, 1118(1), 130-141.

Kovacs, M. (1985). The Children's Depression, Inventory (CDI). Psychopharmacol Bull, 21(4), 995-998.

Kujawa, A., MacNamara, A., Fitzgerald, K. D., Monk, C. S., \& Phan, K. L. (2015). Enhanced neural reactivity to threatening faces in anxious youth: Evidence from event-related potentials. Journal of Abnormal Child Psychology. doi:http://dx.doi.org/10.1007/s10802-015-0029-4 
Lang, P. J., Bradley, M. M., \& Cuthbert, B. N. (1998). Emotion, motivation, and anxiety: brain mechanisms and psychophysiology. Biological psychiatry, 44(12), 12481263.

Lindstrom, K. M., Guyer, A. E., Mogg, K., Bradley, B. P., Fox, N. A., Ernst, M., . . Monk, C. S. (2009). Normative data on development of neural and behavioral mechanisms underlying attention orienting toward social-emotional stimuli: An exploratory study. Brain Research, 1292, 61-70.

Lonigan, C. J., Vasey, M. W., Phillips, B. M., \& Hazen, R. A. (2004). Temperament, Anxiety, and the Processing of Threat-Relevant Stimuli. Journal of Clinical Child and Adolescent Psychology, 33(1), 8-20.

Lopez-Calderon, J., \& Luck, S. J. (2014). ERPLAB: an open-source toolbox for the analysis of event-related potentials. Frontiers in Human Neuroscience, 8.

Luck, S. J. (2005). An introduction to the event-related potential technique (cognitive neuroscience).

MacLeod, C., Mathews, A., \& Tata, P. (1986). Attentional bias in emotional disorders. $J$ Abnorm Psychol, 95(1), 15-20.

MacLeod, C., Mathews, A., \& Tata, P. (1986). Attentional bias in emotional disorders. Journal of abnormal psychology, 95(1), 15.

MacNamara, A., Kappenman, E. S., Black, S. R., Bress, J. N., \& Hajcak, G. (2013). Integratived behavioral and electrocortical measures of attentional bias toward threat. In K. C. Barrett, N. A. Fox, G. A. Morgan, D. J. Fidler, \& L. A. Daunhauer (Eds.), Handbook of self-regulatory processes in development: New directions and international perspectives (pp. 215-243). New York: Psychology Press.

March, J. S., Parker, J. D., Sullivan, K., Stallings, P., \& Conners, C. K. (1997). The Multidimensional Anxiety Scale for Children (MASC): factor structure, reliability, and validity. J Am Acad Child Adolesc Psychiatry, 36(4), 554-565. doi:S0890-8567(09)62527-2 [pii] 10.1097/00004583-199704000-00019

Mathews, A., \& MacLeod, C. (2002a). Induced processing biases have causal effects on anxiety. Cognition \& Emotion, 16(3), 331-354. doi:Doi $10.1080 / 02699930143000518$

Mathews, A., \& MacLeod, C. (2002b). Induced processing biases have causal effects on anxiety. Cognition and Emotion, 16(3), 331-354.

Mendlowitz, S. L., Manassis, K., Bradley, S., Scapillato, D., Miezitis, S., \& Shaw, B. F. (1999). Cognitive-behavioral group treatments in childhood anxiety disorders: the role of parental involvement. J Am Acad Child Adolesc Psychiatry, 38(10), 12231229. 
Mogg, K., \& Bradley, B. P. (1998). A cognitive-motivational analysis of anxiety. Behaviour Research and Therapy, 36(9), 809-848.

Mogg, K., \& Bradley, B. P. (2002). Selective orienting of attention to masked threat faces in social anxiety. Behav Res Ther, 40(12), 1403-1414. doi:S0005796702000177 [pii]

Mogg, K., Philippot, P., \& Bradley, B. P. (2004). Selective attention to angry faces in clinical social phobia. J Abnorm Psychol, 113(1), 160-165. doi:10.1037/0021843X.113.1.160

Mogg, K., Waters, A. M., \& Bradley, B. P. (2017). Attention Bias Modification (ABM): Review of Effects of Multisession ABM Training on Anxiety and Threat-Related Attention in High-Anxious Individuals. Clinical Psychological Science, 2167702617696359.

Moser, J. S., Huppert, J. D., Duval, E., \& Simons, R. F. (2008). Face processing biases in social anxiety: an electrophysiological study. Biological Psychology, 78(1), 93103.

Mueller, E. M., Hofmann, S. G., Santesso, D. L., Meuret, A. E., Bitran, S., \& Pizzagalli, D. A. (2009). Electrophysiological evidence of attentional biases in social anxiety disorder. Psychol Med, 39(7), 1141-1152. doi:10.1017/S0033291708004820

Mühlberger, A., Wieser, M. J., Herrmann, M. J., Weyers, P., Tröger, C., \& Pauli, P. (2009). Early cortical processing of natural and artificial emotional faces differs between lower and higher socially anxious persons. Journal of neural transmission, 116(6), 735-746.

O'Toole, L. J., DeCicco, J. M., Berthod, S., \& Dennis, T. A. (2013). The N170 to angry faces predicts anxiety in typically developing children over a two-year period. Developmental neuropsychology, 38(5), 352-363.

O'Toole, L., \& Dennis, T. A. (2012). Attention training and the threat bias: An ERP study. Brain and Cognition, 78(1), 63-73. doi:http://dx.doi.org.ezproxy.fiu.edu/10.1016/j.bandc.2011.10.007

Pela, O. A., \& Reynolds, C. R. (1982). Cross-cultural application of the RevisedChildren's Manifest Anxiety Scale: normative and reliability data for Nigerian primary school children. Psychol Rep, 51(3 Pt 2), 1135-1138.

Pergamin-Hight, L., Naim, R., Bakermans-Kranenburg, M. J., van, I. M. H., \& Bar-Haim, Y. (2015). Content specificity of attention bias to threat in anxiety disorders: a meta-analysis. Clin Psychol Rev, 35, 10-18. doi:10.1016/j.cpr.2014.10.005 
Pergamin-Hight, L., Pine, D. S., Fox, N. A., \& Bar-Haim, Y. (2016). Attention bias modification for youth with social anxiety disorder. Journal of Child Psychology and Psychiatry, 57(11), 1317-1325.

Pettit, J. W., Rey, Y., Bechor, M., Melendez, R., Vaclavik, D., Buitron, V., . . . Silverman, W. K. (2017). Can less be more? Open trial of a stepped care approach for child and adolescent anxiety disorders. Journal of Anxiety Disorders, 51, 7-13.

Pine, D. S. (2009). Integrating research on development and fear learning: a vision for clinical neuroscience? Depression and Anxiety, 26(9), 775-779.

Pine, D. S. (2011). The brain and behavior in childhood and adolescent anxiety disorders. Anxiety disorders in children and adolescents, 179-197.

Pourtois, G., Dan, E. S., Grandjean, D., Sander, D., \& Vuilleumier, P. (2005). Enhanced extrastriate visual response to bandpass spatial frequency filtered fearful faces: Time course and topographic evoked-potentials mapping. Human brain mapping, 26(1), 65-79. doi:http://dx.doi.org.ezproxy.fiu.edu/10.1002/hbm.20130

Pourtois, G., Grandjean, D., Sander, D., \& Vuilleumier, P. (2004). Electrophysiological correlates of rapid spatial orienting towards fearful faces. Cerebral cortex, 14(6), 619-633.

Price, R. B., Siegle, G. J., Silk, J. S., Ladouceur, C., McFarland, A., Dahl, R. E., \& Ryan, N. D. (2013). Sustained neural alterations in anxious youth performing an attentional bias task: A pupilometry study. Depression and Anxiety, 30(1), 22-30. doi:http://dx.doi.org.ezproxy.fiu.edu/10.1002/da.21966

Rapee, R. M., Schniering, C. A., \& Hudson, J. L. (2009). Anxiety disorders during childhood and adolescence: origins and treatment. Annu Rev Clin Psychol, 5, 311341. doi:10.1146/annurev.clinpsy.032408.153628 10.1146/annurev.clinpsy.032408.153628 [pii]

Rapee, R. M., Schniering, C. A., \& Hudson, J. L. (2009). Anxiety disorders during childhood and adolescence: Origins and treatment. Annual Review of Clinical Psychology, 5, 311-311-341. doi:10.1146/annurev.clinpsy.032408.153628

Reynolds, C. R., \& Richmond, B. O. (1978). What I think and feel: a revised measure of children's manifest anxiety. J Abnorm Child Psychol, 6(2), 271-280.

Rossignol, Campanella, S., Maurage, P., Heeren, A., Falbo, L., \& Philippot, P. (2012). Enhanced perceptual responses during visual processing of facial stimuli in young socially anxious individuals. Neuroscience letters, 526(1), 68-73.

Roy, A. K., Fudge, J. L., Kelly, C., Perry, J. S., Daniele, T., Carlisi, C., . . Pine, D. S. (2013). Intrinsic functional connectivity of amygdala-based networks in 
adolescent generalized anxiety disorder. Journal of the American Academy of Child \& Adolescent Psychiatry, 52(3), 290-299. e292.

Roy, A. K., Vasa, R. A., Bruck, M., Mogg, K., Bradley, B. P., Sweeney, M., . . Pine, D. S. (2008). Attention bias toward threat in pediatric anxiety disorders. J Am Acad Child Adolesc Psychiatry, 47(10), 1189-1196. doi:10.1097/CHI.0b013e3181825ace S0890-8567(08)60105-7 [pii]

Rozenman, M., Weersing, V. R., \& Amir, N. (2011). A case series of attention modification in clinically anxious youths. Behaviour Research and Therapy, 49(5), 324-330. doi:DOI 10.1016/j.brat.2011.02.007

Salum, G., Mogg, K., Bradley, B., Gadelha, A., Pan, P., Tamanaha, A., . . Polanczyk, G. (2013). Threat bias in attention orienting: evidence of specificity in a large community-based study. Psychological medicine, 43(04), 733-745.

Schmidt, N. B., Richey, J. A., Buckner, J. D., \& Timpano, K. R. (2009). Attention training for generalized social anxiety disorder. J Abnorm Psychol, 118(1), 5-14. doi:2009-01738-019 [pii] 10.1037/a0013643

Segalowitz, S. J., Santesso, D. L., \& Jetha, M. K. (2010). Electrophysiological changes during adolescence: a review. Brain and Cognition, 72(1), 86-100.

Shain, B. N., Naylor, M., \& Alessi, N. (1990). Comparison of self-rated and clinicianrated measures of depression in adolescents. Am J Psychiatry, 147(6), 793-795.

Silverman, \& Albano, A. M. (1996). Anxiety Disorders Interview Schedule for DSM-IV.: Parent interview schedule (Vol. 1): Oxford University Press.

Silverman, Kurtines, W. M., Jaccard, J., \& Pina, A. A. (2009). Directionality of Change in Youth Anxiety Treatment Involving Parents: An Initial Examination. Journal of Consulting and Clinical Psychology, 77(3), 474-485. doi:10.1037/a0015761

Silverman, \& Ollendick. (2005). Evidence-based assessment of anxiety and its disorders in children and adolescents. Journal of Clinical Child and Adolescent Psychology, 34(3), 380-411. doi:10.1207/s15374424jccp3403_2

Silverman, Pina, \& Viswesvaran. (2008). Evidence-based psychosocial treatments for phobic and anxiety disorders in children and adolescents. Journal of Clinical Child and Adolescent Psychology, 37(1), 105-130. doi:10.1080/15374410701817907

Silverman, Saavedra, \& Pina. (2001). Test-retest reliability of anxiety symptoms and diagnoses with the anxiety disorders interview schedule for DSM-IV: Child and parent versions. Journal of the American Academy of Child and Adolescent Psychiatry, 40(8), 937-944. doi:10.1097/00004583-200108000-00016 
Silverman, W. K., \& Albano, A. M. (1996). Anxiety Disorders Interview Schedule for Children-IV (Child and Parent Versions). . San Antonio, TX: Psychological Corporation.

Silverman, W. K., \& Eisen, A. R. (1992). Age-Differences in the Reliability of Parent and Child Reports of Child Anxious Symptomatology Using a Structured Interview. Journal of the American Academy of Child and Adolescent Psychiatry, 31(1), 117-124.

Silverman, W. K., Kurtines, W. M., Ginsburg, G. S., Weems, C. F., Lumpkin, P. W., \& Carmichael, D. H. (1999). Treating anxiety disorders in children with group cognitive-behaviorial therapy: A randomized clinical trial. Journal of Consulting and Clinical Psychology, 67(6), 995-1003. doi:10.1037//0022-006X.67.6.995

Silverman, W. K., Kurtines, W. M., Jaccard, J., \& Pina, A. A. (2009). Directionality of change in youth anxiety treatment involving parents: an initial examination. $J$ Consult Clin Psychol, 77(3), 474-485. doi:2009-08093-010 [pii] $10.1037 / \mathrm{a} 0015761$

Silverman, W. K., \& Nelles, W. B. (1988). The Anxiety Disorders Interview Schedule for Children. Journal of the American Academy of Child and Adolescent Psychiatry, 27(6), 772-778. doi:10.1097/00004583-198811000-00019

Silverman, W. K., \& Ollendick, T. H. (2005). Evidence-based assessment of anxiety and its disorders in children and adolescents. Journal of Clinical Child and Adolescent Psychology, 34(3), 380-411.

Silverman, W. K., Pina, A. A., \& Viswesvaran, C. (2008). Evidence-based psychosocial treatments for phobic and anxiety disorders in children and adolescents. Journal of Clinical Child and Adolescent Psychology, 37(1), 105-130. doi:Doi 10.1080/15374410701817907

Simon, E., Dirksen, C., Bögels, S., \& Bodden, D. (2012). Cost-effectiveness of childfocused and parent-focused interventions in a child anxiety prevention program. Journal of Anxiety Disorders, 26(2), 287-296.

SPSS, I. (2013). IBM SPSS statistics 22. Algorithms. Chicago: IBM SPSS Inc.

Staugaard, S. R. (2009). Reliability of two versions of the dot-probe task using photographic faces. Psychology Science Quarterly, 51(3), 339-350.

Susa, G., Pitică, I., Benga, O., \& Miclea, M. (2012). The self regulatory effect of attentional control in modulating the relationship between attentional biases toward threat and anxiety symptoms in children. Cognition and Emotion, 26(6), 1069-1083. doi:http://dx.doi.org.ezproxy.fiu.edu/10.1080/02699931.2011.638910 
Suway, J. G., White, L. K., Vanderwert, R. E., Bar-Haim, Y., Pine, D. S., \& Fox, N. A. (2013). Modification of threat-processing in non-anxious individuals: A preliminary behavioral and ERP study. Journal of Behavior Therapy and Experimental Psychiatry, 44(3), 285-292. doi:http://dx.doi.org.ezproxy.fiu.edu/10.1016/j.jbtep.2012.11.006

Taylor, M. J., Edmonds, G. E., McCarthy, G., \& Allison, T. (2001). Eyes first! Eye processing develops before face processing in children. Neuroreport, 12(8), 16711676.

Telzer, E. H., Mogg, K., Bradley, B. P., Mai, X., Ernst, M., Pine, D. S., \& Monk, C. S. (2008). Relationship between trait anxiety, prefrontal cortex, and attention bias to angry faces in children and adolescents. Biol Psychol, 79(2), 216-222. doi:S03010511(08)00125-7 [pii] 10.1016/j.biopsycho.2008.05.004

Thai, N., Taber-Thomas, B. C., \& Pérez-Edgar, K. E. (2016). Neural correlates of attention biases, behavioral inhibition, and social anxiety in children: An ERP study. Developmental Cognitive Neuroscience, 19, 200-210.

Tottenham, N., Tanaka, J. W., Leon, A. C., McCarry, T., Nurse, M., Hare, T. A., . . Nelson, C. (2009). The NimStim set of facial expressions: judgments from untrained research participants. Psychiatry research, 168(3), 242-249.

Vasey, M. W., Daleiden, E. L., Williams, L. L., \& Brown, L. M. (1995). Biased attention in childhood anxiety disorders: A preliminary study. Journal of Abnormal Child Psychology, 23(2), 267-279. doi:http://dx.doi.org.ezproxy.fiu.edu/10.1007/BF01447092

Vasey, M. W., el-Hag, N., \& Daleiden, E. L. (1996). Anxiety and the processing of emotionally threatening stimuli: distinctive patterns of selective attention among high- and low-test-anxious children. Child Dev, 67(3), 1173-1185.

Verleger, R. (1997). On the utility of P3 latency as an index of mental chronometry. Psychophysiology, 34(2), 131-156.

Waechter, S., Nelson, A. L., Wright, C., Hyatt, A., \& Oakman, J. (2014). Measuring attentional bias to threat: Reliability of dot probe and eye movement indices. Cognitive Therapy and Research, 38(3), 313-333.

Waechter, S., \& Stolz, J. A. (2015). Trait anxiety, state anxiety, and attentional bias to threat: Assessing the psychometric properties of response time measures. Cognitive Therapy and Research, 39(4), 441-458.

Waters, Lipp, O., \& Spence, S. (2004). Attentional bias toward fear-related stimuli:: An investigation with nonselected children and adults and children with anxiety disorders. Journal of experimental child psychology, 89(4), 320-337. 
Waters, Mogg, K., Bradley, B. P., \& Pine, D. S. (2008). Attentional bias for emotional faces in children with generalized anxiety disorder. Journal of the American Academy of Child \& Adolescent Psychiatry, 47(4), 435-442.

Waters, A. M., Henry, J., Mogg, K., Bradley, B. P., \& Pine, D. S. (2010). Attentional bias towards angry faces in childhood anxiety disorders. J Behav Ther Exp Psychiatry, 41(2), 158-164. doi:S0005-7916(09)00100-1 [pii] 10.1016/j.jbtep.2009.12.001

Waters, A. M., Mogg, K., Bradley, B. P., \& Pine, D. S. (2008). Attentional bias for emotional faces in children with generalized anxiety disorder. $J$ Am Acad Child Adolesc Psychiatry, 47(4), 435-442. doi:10.1097/CHI.0b013e3181642992

Weissman, A. S., Chu, B. C., Reddy, L. A., \& Mohlman, J. (2012). Attention mechanisms in children with anxiety disorders and in children with attention deficit hyperactivity disorder: Implications for research and practice. Journal of Clinical Child and Adolescent Psychology, 41(2), 117-126. doi:http://dx.doi.org.ezproxy.fiu.edu/10.1080/15374416.2012.651993

White, Britton, J. C., Sequeira, S., Ronkin, E. G., Chen, G., Bar-Haim, Y., . . Leibenluft, E. (2016). Behavioral and neural stability of attention bias to threat in healthy adolescents. NeuroImage.

Wren, F. J., Berg, E. A., Heiden, L. A., Kinnamon, C. J., Ohlson, L. A., Bridge, J. A., . . . Bernal, M. P. (2007). Childhood anxiety in a diverse primary care population: parent-child reports, ethnicity and SCARED factor structure. Journal of the American Academy of Child \& Adolescent Psychiatry, 46(3), 332-340.

Wronka, E., \& Walentowska, W. (2011). Attention modulates emotional expression processing. Psychophysiology, 48(8), 1047-1056.

\section{Acknowledgements}

Work on this project was supported by National Institute of Mental Health grants R34 MH097931 and R01 MH079943 to Jeremy W. Pettit and Wendy K. Silverman, a National Institute of Mental Health grant F31 MH105144-01A1 to Michele Bechor and a NIDA K01DA034125 grant to Michael J. Crowley. The content is solely the responsibility of the authors and does not necessarily represent the official views of the National Institutes of Health. 
Table 1. Diagnostic Information, Age, Behavioral Questionnaire and Dot Probe task scores. $\mathrm{CT}=$ Control Task arm, $\mathrm{ABMT}=$ treatment arm, $\mathrm{M}=$ mean, $\mathrm{SD}=$ standard deviation, $\mathrm{RT}=$ reaction time, $8 \mathrm{WFU}=$ Eight-week Follow-up, ADIS-C/P = Anxiety Disorders Interview Schedule, Child \& Parent versions, PARS = Pediatric Anxiety Rating Scale, SCARED-P\&C = Screen for Child Anxiety Related \& Emotional Disorders, Parent $\&$ Child versions, NT $=$ Neutral-Threat, $\mathrm{N}=$ Neutral-Neutral. $*$ denotes statistical significance $(\alpha=.05)$.

\begin{tabular}{|c|c|c|c|c|c|c|}
\hline & CT & ABMT & & & & \\
\hline$N$ & 16 & 14 & & & & \\
\hline \multicolumn{7}{|l|}{$\begin{array}{l}\text { ADIS-C/P Primary } \\
\text { Diagnosis }\end{array}$} \\
\hline $\begin{array}{l}\text { Generalized } \\
\text { Anxiety Disorder }\end{array}$ & 6 & 5 & & & & \\
\hline Social Phobia & 5 & 8 & & & & \\
\hline $\begin{array}{l}\text { Separation } \\
\text { Anxiety Disorder }\end{array}$ & 2 & 1 & & & & \\
\hline Specific Phobia & 1 & & & & & \\
\hline Panic Disorder & 1 & & & & & \\
\hline \multirow[t]{2}{*}{$\begin{array}{l}\text { Obsessive- } \\
\text { Compulsive } \\
\text { Disorder } \\
\end{array}$} & 1 & & & & & \\
\hline & $M(S D)$ & $M(S D)$ & $t$ & $d f$ & $p$ & $d$ \\
\hline Age & $11.19(2.86)$ & $12.86(2.77)$ & -1.62 & 28 & .12 & .59 \\
\hline \multicolumn{7}{|l|}{ PARS } \\
\hline Pre-treatment & $17.00(5.02)$ & $18.77(4.34)$ & -1.00 & 27 & .33 & .38 \\
\hline Post-treatment & $11.75(6.54)$ & $10.85(7.73)$ & .341 & 27 & .74 & .13 \\
\hline 8WFU & $9.14(6.07)$ & $12.10(5.90)$ & -1.19 & 22 & .25 & .49 \\
\hline \multicolumn{7}{|l|}{ SCARED-P } \\
\hline Pre-treatment & $25.69(10.29)$ & $33.93(14.65)$ & -1.80 & 28 & .08 & .65 \\
\hline Post-treatment & $22.40(12.75)$ & $28.00(15.05)$ & -1.05 & 25 & .31 & .40 \\
\hline 8WFU & $17.53(12.74)$ & $26.80(15.50)$ & -1.25 & 23 & .22 & .65 \\
\hline \multicolumn{7}{|l|}{ SCARED-C } \\
\hline Pre-treatment & $25.44(17.38)$ & $25.14(9.16)$ & .06 & 23.33 & .95 & .02 \\
\hline Post-treatment & $16.60(16.35)$ & $16.08(11.87)$ & .09 & 25 & .93 & .04 \\
\hline 8WFU & $17.53(12.74)$ & $20.81(11.85)$ & -.67 & 24 & .51 & .27 \\
\hline
\end{tabular}




\begin{tabular}{|c|c|c|c|c|c|c|}
\hline Pre-treatment & $-.48(15.58)$ & $.89(15.20)$ & -.24 & 28 & .81 & .09 \\
\hline Post-treatment & $8.17(28.68)$ & $4.36(14.82)$ & .45 & 28 & .66 & .17 \\
\hline 8WFU & $-6.65(20.48)$ & $-2.78(7.75)$ & -.68 & 18.42 & .51 & .25 \\
\hline \multicolumn{7}{|l|}{$\begin{array}{l}\text { Dot Probe Accuracy } \\
(\%)\end{array}$} \\
\hline Pre-treatment & $.97(.02)$ & $.97(.03)$ & -.07 & 28 & .95 & .00 \\
\hline Post-treatment & $.91(.14)$ & $.97(.03)$ & -1.67 & 16.37 & .11 & .10 \\
\hline 8WFU & $.95(.06)$ & $.96(.05)$ & -.21 & 26 & .83 & .18 \\
\hline \multicolumn{7}{|l|}{ Dot Probe RT (ms) } \\
\hline Pre-treatment & $\begin{array}{l}584.88 \\
(119.99)\end{array}$ & $\begin{array}{l}547.43 \\
(81.20)\end{array}$ & 1.01 & 26.45 & .32 & .37 \\
\hline Post-treatment & $\begin{array}{l}560.13 \\
(83.97)\end{array}$ & $\begin{array}{l}506.07 \\
(84.33)\end{array}$ & 1.76 & 28 & .09 & .64 \\
\hline 8WFU & $\begin{array}{l}568.73 \\
(108.52)\end{array}$ & $\begin{array}{l}506.46 \\
(77.92)\end{array}$ & 1.72 & 26 & .10 & .66 \\
\hline \multicolumn{7}{|l|}{$\begin{array}{l}\text { Number of Trials } \\
(\mathbf{N T}+\mathbf{N N})\end{array}$} \\
\hline Pre-treatment & $\begin{array}{l}148.44 \\
(57.40)\end{array}$ & $\begin{array}{l}173.57 \\
(25.52)\end{array}$ & -1.58 & 21.29 & .13 & .57 \\
\hline Post-treatment & $\begin{array}{l}145.81 \\
(53.31)\end{array}$ & $\begin{array}{l}181.79 \\
(26.35)\end{array}$ & -2.39 & 22.52 & $.03 *$ & .86 \\
\hline 8WFU & $\begin{array}{l}148.19 \\
(52.85)\end{array}$ & $\begin{array}{l}189.71 \\
(21.94)\end{array}$ & -2.87 & 20.57 & $.01 *$ & 1.03 \\
\hline
\end{tabular}


Table 2. Correlations between ERP Components and Behavioral Measures. Part I, Hypothesis 1: correlations between ERP components (P1, N170, P2 \& P3) and anxiety symptoms (AB score, SCARED-C/P, PARS) at pre-treatment. AB = attention bias, PARS = Pediatric Anxiety Rating Scale, SCARED-P\&C = Screen for Child Anxiety Related \& Emotional Disorders,

Parent \& Child versions.

\begin{tabular}{|c|c|c|c|c|c|c|c|c|c|c|c|c|c|c|c|c|}
\hline \multirow{3}{*}{ Pre-treatment } & \multicolumn{4}{|c|}{ P1 } & \multicolumn{4}{|c|}{ N170 } & \multicolumn{4}{|c|}{$\mathbf{P 2}$} & \multicolumn{4}{|c|}{ P3 } \\
\hline & $\mathbf{P O z}$ & & $\mathbf{O z}$ & & $\mathbf{P O z}$ & & $\mathbf{O z}$ & & $\mathbf{P O z}$ & & $\mathbf{O z}$ & & $\mathbf{P O z}$ & & $\mathbf{O z}$ & \\
\hline & NT & $\mathbf{N N}$ & NT & $\mathbf{N N}$ & NT & $\mathbf{N N}$ & NT & $\mathbf{N N}$ & NT & $\mathbf{N N}$ & NT & $\mathbf{N N}$ & NT & $\mathbf{N N}$ & NT & $\mathbf{N N}$ \\
\hline AB score & .07 & .08 & .12 & .18 & .08 & .10 & .14 & .25 & -.06 & -.04 & .00 & .15 & .15 & .08 & .16 & .25 \\
\hline SCARED-P & -.12 & -.09 & .02 & .12 & -.18 & -.13 & -.04 & .07 & -.16 & -.13 & -.06 & -.01 & -.12 & -.12 & -.14 & -.04 \\
\hline SCARED-C & .12 & -.12 & .15 & .07 & .01 & .02 & .07 & .08 & .13 & .11 & .06 & .07 & .13 & .10 & .07 & .03 \\
\hline PARS & .02 & .10 & .17 & .23 & -.30 & -.25 & -.06 & -.02 & -.10 & -.04 & .02 & .05 & -.07 & .04 & .09 & .18 \\
\hline
\end{tabular}


Table 3. Main effects of stimulus type and arm at pre-treatment as calculated in a) Part I and b) main effects of arm in Part II. 3a) Part I.

\begin{tabular}{llrrrrrr}
\hline Site & \multicolumn{3}{c}{$\mathbf{P O z}$} & \multicolumn{3}{c}{$\mathbf{O z}$} \\
\hline Component & Main Effect & $\boldsymbol{F}$ & $\boldsymbol{p}$ & $\boldsymbol{\eta 2}$ & $\boldsymbol{F}$ & $\boldsymbol{p}$ & $\boldsymbol{\eta} 2$ \\
\hline P1 & Arm & 2.49 & .13 & .09 & 4.27 & $.05^{*}$ & .15 \\
\hline & Stimulus Type & 5.61 & $.03^{*}$ & .18 & 1.29 & $.00^{* *}$ \\
\hline N170 & Arm & 1.71 & $.00^{* *}$ & .30 & 1.67 & .21 \\
\hline & Stimulus Type & .09 & .77 & .00 & 12.78 & $.00^{* *}$ \\
\hline P2 & Arm & 6.21 & $.02^{*}$ & .20 & 9.85 & $.00^{* *}$ \\
\hline & Stimulus Type & .77 & .39 & .03 & 1.57 & .34 \\
\hline P3 & Arm & 3.22 & .09 & .11 & 4.35 & .22 \\
\hline & Stimulus Type & 1.05 & .32 & .04 & 2.64 & .06 \\
\hline
\end{tabular}

3b) Part II.

\begin{tabular}{llrrrrrr}
\hline Site & \multicolumn{3}{c}{ POz } & \multicolumn{3}{c}{$\mathbf{O z}$} \\
\hline Component & Main Effect & $\boldsymbol{F}$ & $\boldsymbol{p}$ & $\boldsymbol{\eta 2}$ & $\boldsymbol{F}$ & $\boldsymbol{p}$ & $\boldsymbol{\eta}$ \\
\hline P1 & Arm & .46 & .50 & .02 & 1.09 & .31 \\
\hline N170 & Arm & .06 & .80 & .00 & .10 & .75 \\
\hline P2 & Arm & .00 & .95 & .00 & .09 & .04 \\
\hline P3 & Arm & .69 & .41 & .03 & .72 & .40 & .00 \\
\hline
\end{tabular}

$* \alpha<.05, * * \alpha<.01$ 
Table 4. Part II, Hypothesis 1: correlations between ERP components (P1, N170, P2 \& P3) and anxiety symptoms (AB score, SCARED-C/P, PARS) utilizing NT-NN difference scores at pre-treatment. AB = attention bias, PARS = Pediatric Anxiety Rating Scale, SCARED-P\&C = Screen for Child Anxiety Related \& Emotional Disorders, Parent \& Child versions.

\begin{tabular}{cccccccccc}
\hline \multirow{2}{*}{ Pre-treatment } & \multicolumn{2}{c}{$\mathbf{P 1}$} & \multicolumn{2}{c}{$\mathbf{N 1 7 0}$} & \multicolumn{2}{c}{} & \multicolumn{2}{c}{$\mathbf{P 3}$} \\
\cline { 2 - 9 } & $\mathbf{P O z}$ & $\mathbf{O z}$ & $\mathbf{P O z}$ & $\mathbf{O z}$ & $\mathbf{P O z}$ & $\mathbf{O z}$ & $\mathbf{P O z}$ & $\mathbf{O z}$ \\
\hline AB score & .01 & -.13 & -.04 & -.28 & -.07 & $-.369^{*}$ & .18 & -.27 \\
\hline SCARED-P & -.09 & -.26 & -.17 & -.29 & -.08 & -.10 & -.03 & -.28 \\
\hline SCARED-C & $.354^{*}$ & .30 & -.02 & .00 & .05 & -.04 & .10 & .10 \\
\hline PARS & -.10 & -.09 & -.17 & -.12 & -.16 & -.07 & -.29 & -.27 \\
\hline
\end{tabular}

$* \alpha<.05, * * \alpha<.01$ 
Figure 1. Waveforms across arms at POz. Component windows: P1 (100-160 ms), N170 (170-230 ms), P2 (230-280 ms), and P3 (300-380 ms). CT = Control Task arm, ABMT = Treatment arm.

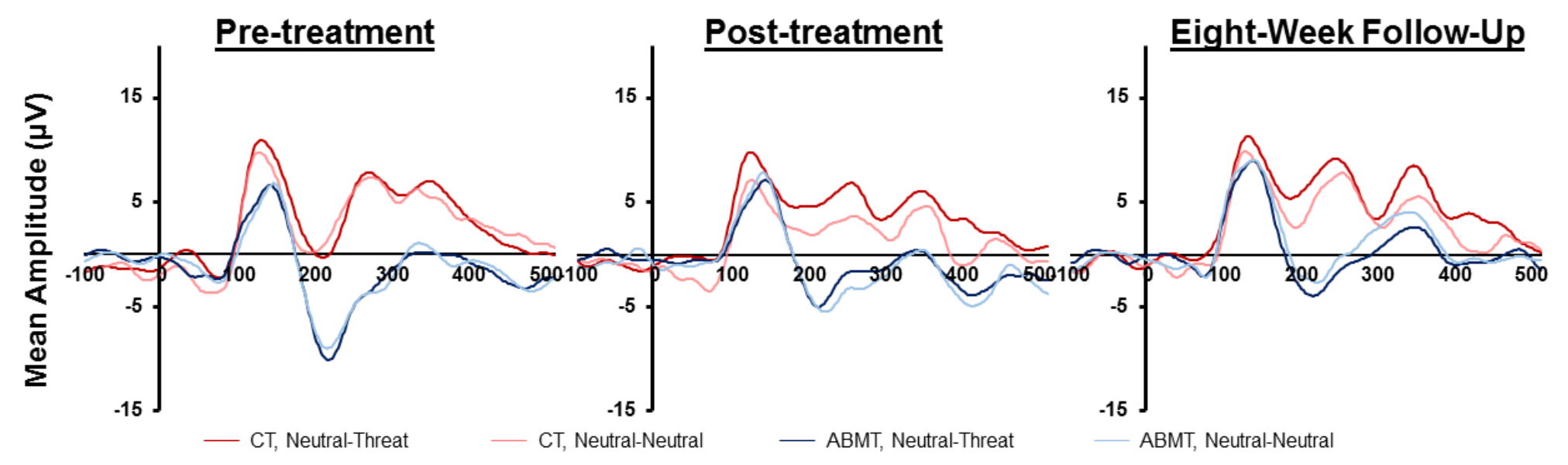


Figure 2. Waveforms across arms at Oz. Component windows: P1 (100-160 ms), N170 (170-230 ms), P2 (230-280 ms), and P3 (300-380 ms). CT = Control Task arm, ABMT = Treatment arm.

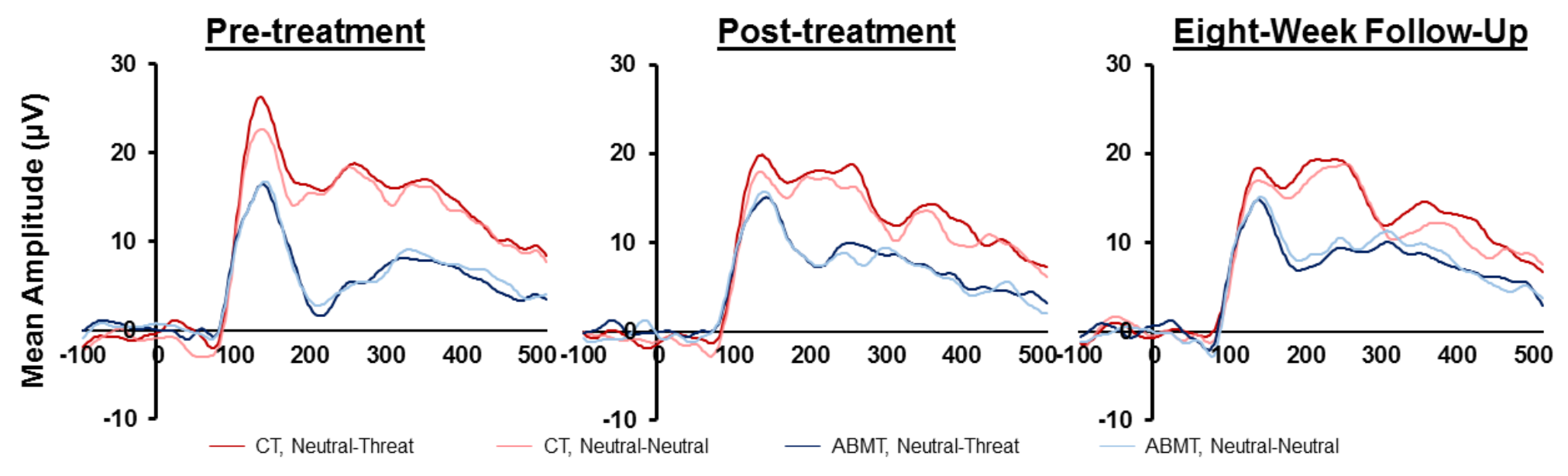


Figure 3. Post-hoc analyses for NT and NN waves across arms at post-treatment (Hypothesis 2) at POz. Figure 3(a) represents the a marginally significant main effect of arm on P1 mean amplitude during NN trials, $F(1,24)=3.14, p=.09, \eta_{p}{ }^{2}=.12$; amplitudes in the ABMT arm $(M=8.39, S E=1.49)$ were higher than in the CT arm $(M=4.39, S E=1.37)$. Figure 3(b) shows the significant stimulus-type-by-arm interaction effect, $F(1,23)=4.53, p=.04, \eta_{p}{ }^{2}=.164$ for P3 mean amplitudes at posttreatment. Post-hoc analyses no significant main effects or arm or stimulus type. There were no significant main or interaction effects at post-treatment Oz. $\mathrm{CT}=$ Control Task arm, ABMT $=$ Treatment arm. ${ }^{*}$ denotes significant effect, $\alpha=.05$.
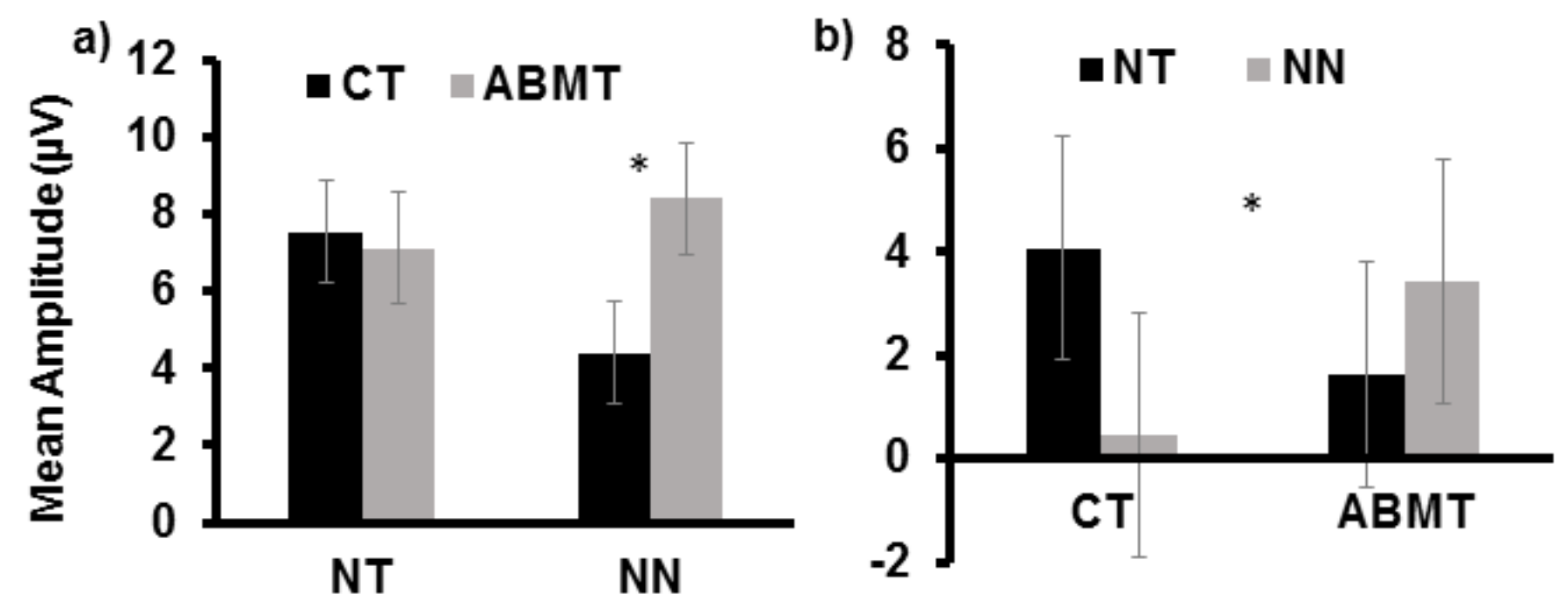
Figure 4. Post-hoc analyses for NT and NN waves across arms at eight-week follow-up (Hypothesis 3) at POz. Figure 4(a) represents the significant main effect of arm on P1 mean amplitude at eight-week follow-up, wherein P1 mean amplitude was significantly larger for the $\mathrm{CT} \operatorname{arm}(M=6.63, S E=2.22)$ than for the ABMT arm, $(\mathrm{M}=-2.31, \mathrm{SE}=2.44)$. Figure 4(b) represents the significant main effect of stimulus type within the $\mathrm{CT}$ arm, $F(1,8)=8.42, p=.02, \eta_{p}{ }^{2}=.51$, wherein $\mathrm{N} 170$ mean amplitude at eight-week follow-up was significantly larger (more negative) during NN trials $(\mathrm{M}=5.06, \mathrm{SE}=1.29)$ than during NT trials, $(\mathrm{M}=7.49, \mathrm{SE}=2.35)$. There were no significant main or interaction effects at post-treatment at $\mathrm{Oz}$. $\mathrm{CT}=\mathrm{Control}$ Task arm, ABMT $=$ Treatment arm. $*$ denotes significant effect, $\alpha=.05$.
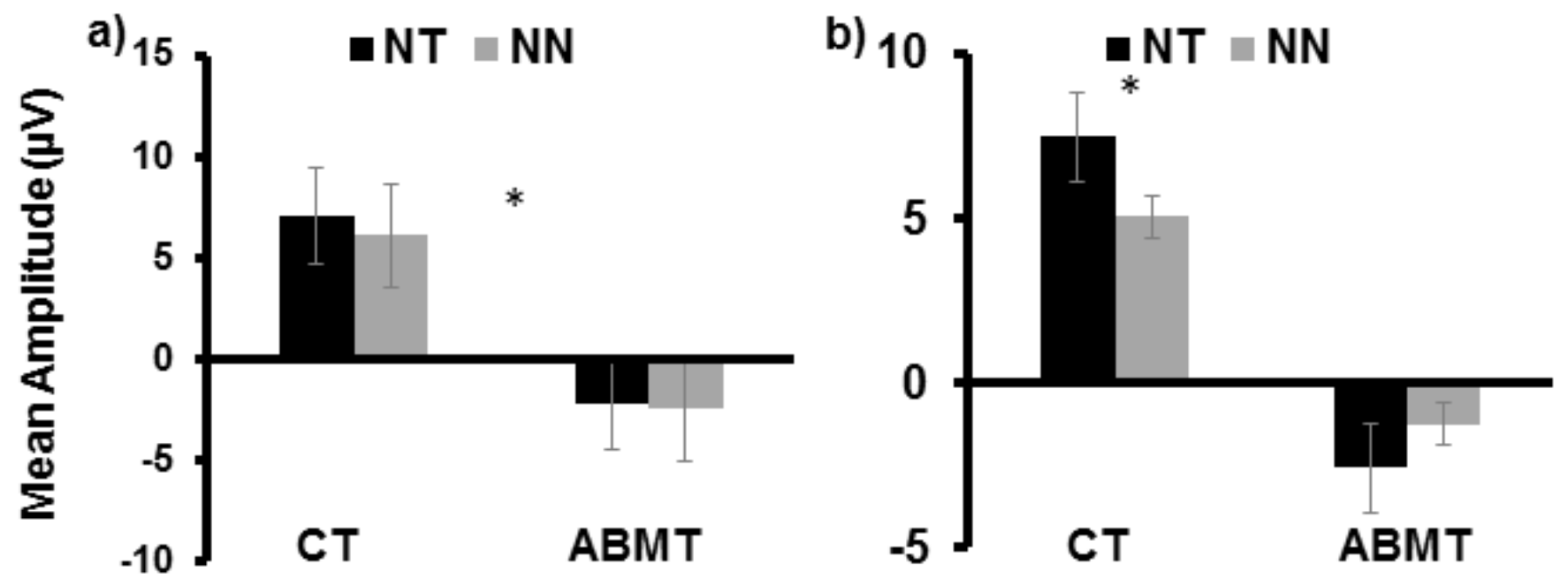
Figure 5. POz differences scores (NT-NN) at pre-treatment, post-treatment and eight-week follow-up. A significant main effect of arm was found at POz at post-treatment, $F(1,24)=4.64, p=.04, \eta_{p}{ }^{2}=.16$, wherein differential attention across stimulus type $(\mathrm{NT}-\mathrm{NN})$ for P1 mean amplitude was more positive for the CT $\operatorname{arm},(M=2.86, S E=1.09)$ than for the ABMT $\operatorname{arm}(\mathrm{M}=-.95$, $\mathrm{SE}=1.18) . \mathrm{CT}=$ Control Task arm, $\mathrm{ABMT}=$ Treatment arm. $*$ denotes significant effect, $\alpha=.05$.

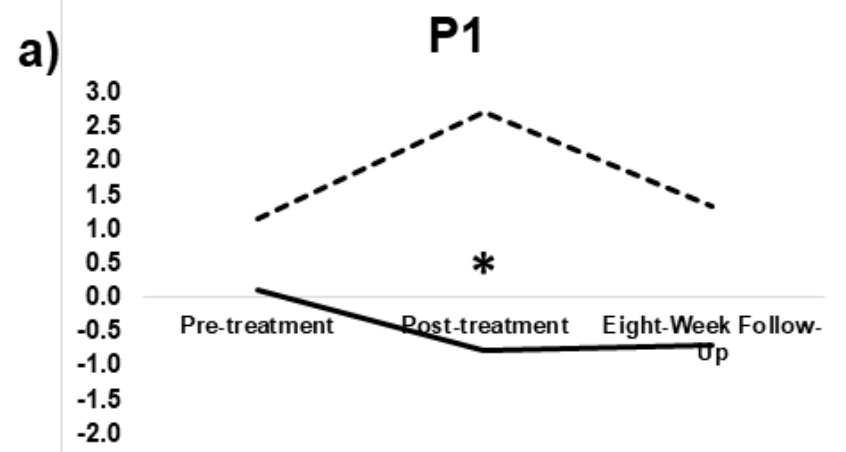

b)

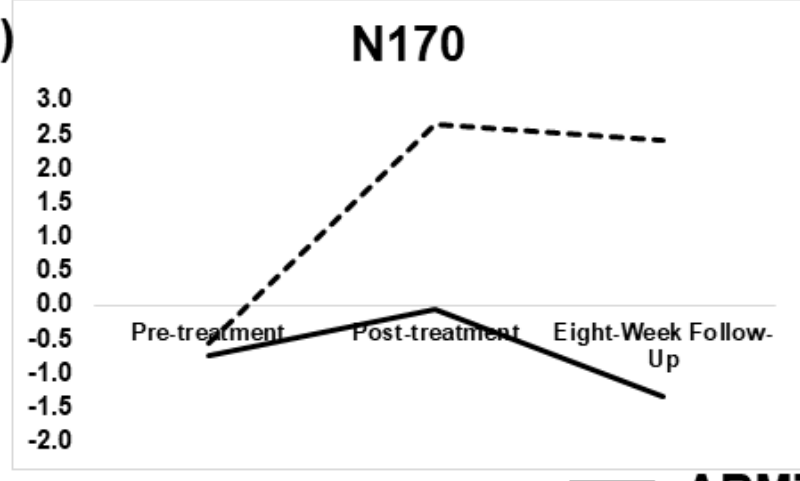

c)

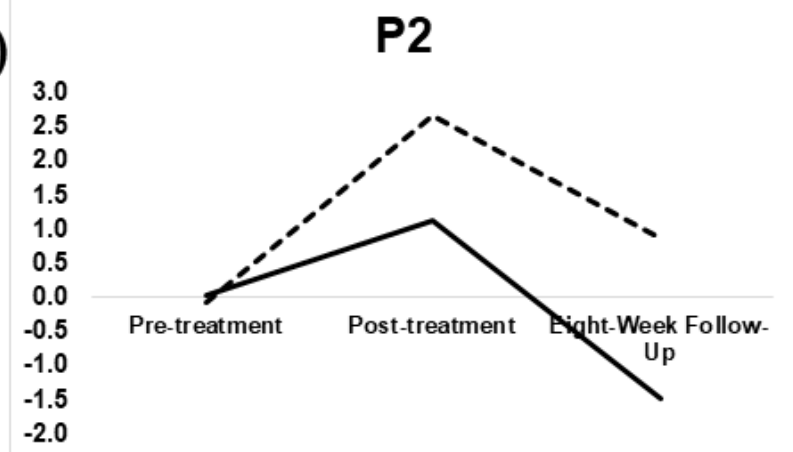

d)

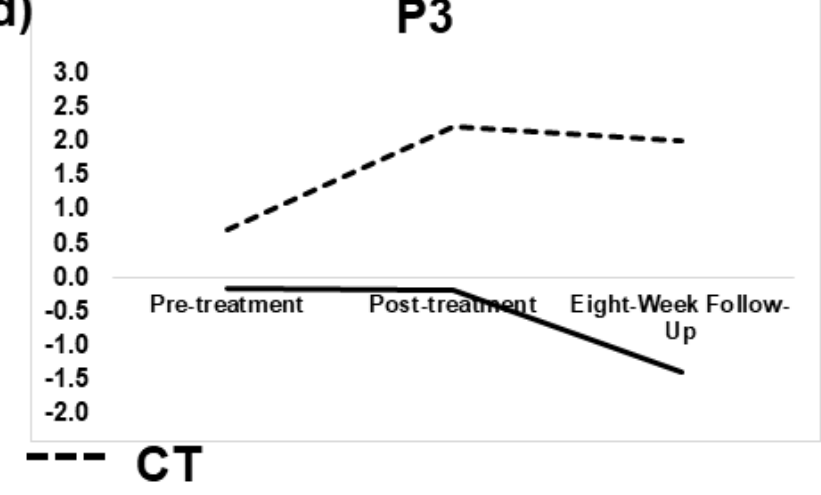


Figure 6. Oz differences scores (NT-NN) at pre-treatment, post-treatment and eight-week follow-up. A significant main effect of arm was found, $F(1,23)=4.92, p=.04, \eta_{p}{ }^{2}=.18$, wherein differential attention across stimulus type (NT-NN) for P3 mean amplitude was more positive for the $\mathrm{CT}$ arm, $(M=3.73, S E=1.76)$ than for the ABMT $\operatorname{arm}(\mathrm{M}=-2.67, \mathrm{SE}=1.91)$. CT $=$ Control Task arm, ABMT $=$ Treatment arm. ${ }^{*}$ denotes significant effect, $\alpha=.05$.

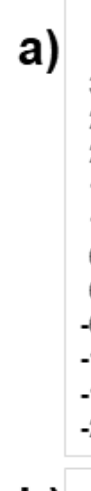

b)

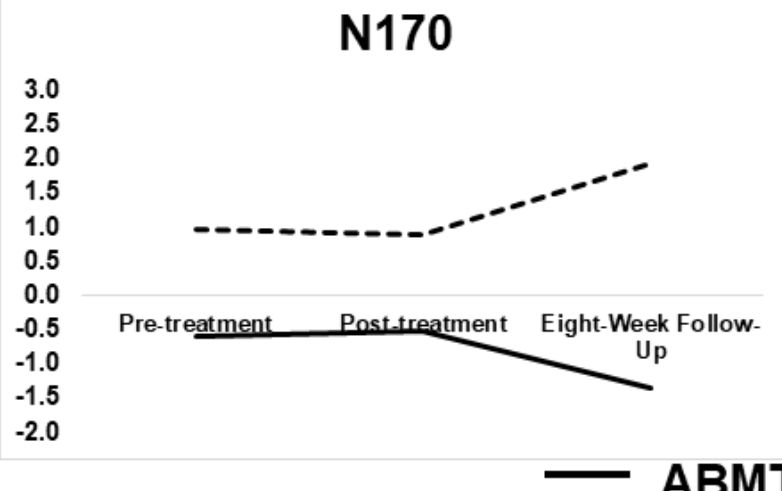

c)

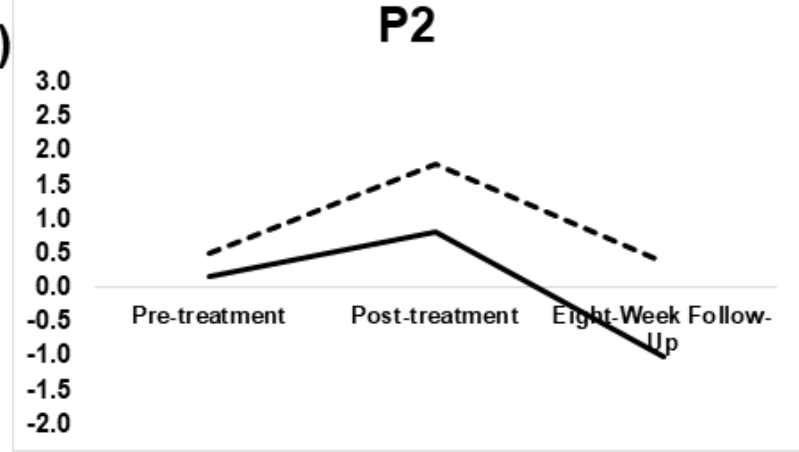

d)

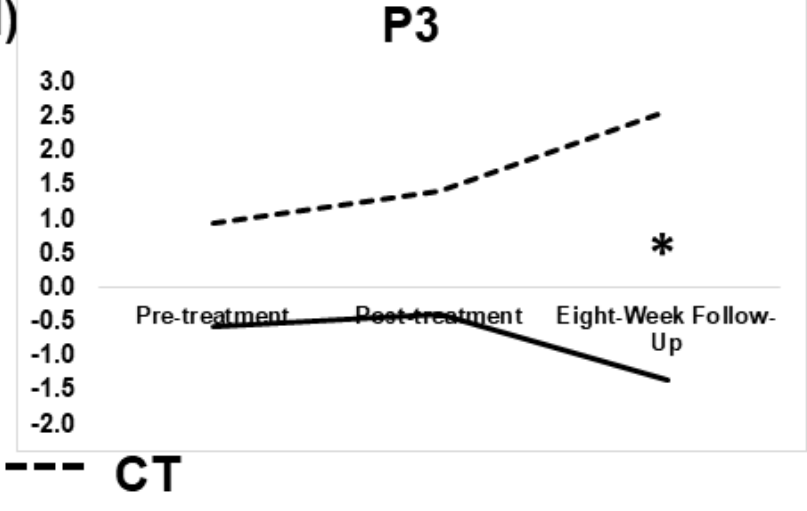


Appendix 1. Measures 


\section{Children's Depression Inventory}

KIDS SOMETIMES HAVE DIFFERENT FEELINGS AND IDEAS.

THIS FORM LISTS THE FEELINGS AND IDEAS IN GROUPS. FROM EACH GROUP, PICK ONE SENTENCE THAT DESCRIBES YOU BEST FOR THE PAST TWO WEEKS. AFTER YOU PICK A SENTENCE FROM THE FIRST GROUP, GO ON TO THE NEXT GROUP.

THERE IS NO RIGHT ANSWER OR WRONG ANSWER. JUST PICK THE SENTENCE THAT BEST DESCRIBES THE WAY YOU HAVE BEEN RECENTLY. PUT A MARK LIKE THIS $X$ NEXT TO YOUR ANSWER. PUT THE MARK ON THE LINE NEXT TO THE SENTENCE THAT YOU PICK.

HERE IS AN EXAMPLE OF HOW THIS FORM WORKS. TRY IT. PUT A MARK NEXT TO THE SENTENCE THAT DESCRIBES YOU BEST.

EXAMPLE:

I READ BOOKS ALL THE TIME I READ BOOKS ONCE IN A WHILE I NEVER READ BOOKS

REMEMBER, PICK OUT THE SENTENCES THAT DESCRIBE YOUR FEELINGS AND IDEAS IN THE PAST TWO WEEKS.

1. I AM SAD ONCE IN A WHILE I AM SAD MANY TIMES I AM SAD ALL THE TIME

2. NOTHING WILL EVER WORK OUT FOR ME I AM NOT SURE IF THINGS WILL WORK OUT FOR ME THINGS WILL WORK OUT FOR ME O.K.

3. I DO MOST THINGS O.K. I DO MANY THINGS WRONG I DO EVERYTHING WRONG

4. I HAVE FUN IN MANY THINGS I HAVE FUN IN SOME THINGS NOTHING IS FUN AT ALL 
5. I AM BAD ALL THE TIME I AM BAD MANY TIMES I AM BAD ONCE IN A WHILE

6. I THINK ABOUT BAD THINGS HAPPENING TO ME ONCE IN A WHILE I WORRY THAT BAD THINGS WILL HAPPEN TO ME I AM SURE THAT TERRIBLE THINGS WILL HAPPEN TO ME

7. I HATE MYSELF I DO NOT LIKE MYSELF I LIKE MYSELF

8. ALL BAD THINGS ARE MY FAULT MANY BAD THINGS ARE MY FAULT BAD THINGS ARE NOT USUALLY MY FAULT

9. I DO NOT THINK ABOUT KILLING MYSELF I THINK ABOUT KILLING MYSELF BUT I WOULD NOT DO IT I WANT TO KILL MYSELF

10. I FEEL LIKE CRYING EVERYDAY I FEEL LIKE CRYING MANY DAYS I FEEL LIKE CRYING ONCE IN A WHILE

11. THINGS BOTHER ME ALL THE TIME THINGS BOTHER ME MANY TIMES THINGS BOTHER ME ONCE IN A WHILE

12. I LIKE BEING WITH PEOPLE I DO NOT LIKE BEING WITH PEOPLE MANY TIMES I DO NOT WANT TO BE WITH PEOPLE AT ALL

13. I CANNOT MAKE UP MY MIND ABOUT THINGS IT IS HARD TO MAKE UP MY MIND ABOUT THINGS 
14. I LOOK O.K. THERE ARE SOME BAD THINGS ABOUT MY LOOKS I LOOK UGLY

15. I HAVE TO PUSH MYSELF ALL THE TIME TO DO MY SCHOOLWORK I HAVE TO PUSH MYSELF MANY TIMES TO DO MY SCHOOLWORK DOING SCHOOLWORK IS NOT A BIG PROBLEM

16. I HAVE TROUBLE SLEEPING EVERY NIGHT I HAVE TROUBLE SLEEPING MANY NIGHTS I SLEEP PRETTY WELL

17. I AM TIRED ONCE IN A WHILE I AM TIRED MANY DAYS I AM TIRED ALL THE TIME

18. MOST DAYS I DO NOT FEEL LIKE EATING MANY DAYS I DO NOT FEEL LIKE EATING IEAT PRETTY WELL

19. I DO NOT WORRY ABOUT ACHES AND PAINS I WORRY ABOUT ACHES AND PAINS MANY TIMES I WORRY ABOUT ACHES AND PAINS ALL THE TIME

20. I DO NOT FEEL ALONE I FEEL ALONE MANY TIMES I FEEL ALONE ALL THE TIME

21. I NEVER HAVE FUN AT SCHOOL I HAVE FUN AT SCHOOL ONLY ONCE IN A WHILE I HAVE FUN AT SCHOOL MANY TIMES 
22. I HAVE PLENTY OF FRIENDS I HAVE SOME FRIENDS BUT I WISH I HAD MORE I DO NOT HAVE ANY FRIENDS

23. MY SCHOOLWORK IS ALRIGHT MY SCHOOLWORK IS NOT AS GOOD AS BEFORE I DO VERY BADLY IN SUBJECTS I USED TO BE GOOD IN

24. I CAN NEVER BE AS GOOD AS OTHER KIDS I CAN BE AS GOOD AS OTHER KIDS IF I WANT TO I AM JUST AS GOOD AS OTHER KIDS

25. NOBODY REALLY LOVES ME I AM NOT SURE IF ANYBODY LOVES ME I AM SURE THAT SOMEBODY LOVES ME

26. I USUALLY DO WHAT I AM TOLD I DO NOT DO WHAT I AM TOLD MOST TIMES I NEVER DO WHAT I AM TOLD

27. I GET ALONG WITH PEOPLE I GET INTO FIGHTS MANY TIMES I GET INTO FIGHTS ALL THE TIME 


\section{MASC}

This form is about how you might have been thinking, feeling, or acting recently. For each question, please check how often the statement is true for you. If the sentence is true about you a lot of the time, circle OFTEN. If it is true about you some of the time, circle SOMETIMES. If it is true about you once in a while, circle RARELY. If a sentence is hardly ever true about you, circle NEVER. Remember, there are no right or wrong answers, just answers about how you might have been feeling recently.

Example:

\begin{tabular}{|l|c|c|c|c|}
\cline { 2 - 5 } \multicolumn{1}{c|}{} & $\begin{array}{c}\text { Never } \\
\text { true } \\
\text { about } \\
\text { me }\end{array}$ & $\begin{array}{c}\text { Rarely } \\
\text { true } \\
\text { about } \\
\text { me }\end{array}$ & $\begin{array}{c}\text { Sometimes } \\
\text { true about } \\
\text { me }\end{array}$ & $\begin{array}{c}\text { Often } \\
\text { true } \\
\text { about } \\
\text { me }\end{array}$ \\
\hline 1. I'm scared of dogs. & never & rarely & sometimes & often \\
2. I don't like thunderstorms. & never & rarely & sometimes & often \\
\hline
\end{tabular}

\begin{tabular}{|c|c|c|c|c|}
\hline & $\begin{array}{c}\text { Never } \\
\text { true } \\
\text { about me }\end{array}$ & $\begin{array}{c}\text { Rarely } \\
\text { true } \\
\text { about } \\
\text { me }\end{array}$ & $\begin{array}{c}\text { Sometimes } \\
\text { true about } \\
\text { me }\end{array}$ & $\begin{array}{c}\text { Often } \\
\text { true } \\
\text { about } \\
\text { me }\end{array}$ \\
\hline 1. I feel tense or uptight. & never & rarely & sometimes & often \\
\hline 2. I usually ask permission. & never & rarely & sometimes & often \\
\hline $\begin{array}{l}\text { 3. I worry about other people laughing at } \\
\text { me. }\end{array}$ & never & rarely & sometimes & often \\
\hline 4. I get scared when my parents go away. & never & rarely & sometimes & often \\
\hline 5. I have trouble getting my breath. & never & rarely & sometimes & often \\
\hline 6. I keep my eyes open for danger. & never & rarely & sometimes & often \\
\hline $\begin{array}{l}\text { 7. The idea of going away to camp scares } \\
\text { me. }\end{array}$ & never & rarely & sometimes & often \\
\hline 8. I get shaky or jittery. & never & rarely & sometimes & often \\
\hline $\begin{array}{l}\text { 9. I try hard to obey my parents and } \\
\text { teachers. }\end{array}$ & never & rarely & sometimes & often \\
\hline $\begin{array}{l}\text { 10. I'm afraid that other kids will make fun } \\
\text { of me. }\end{array}$ & never & rarely & sometimes & often \\
\hline 11. I try to stay near my mom or dad. & never & rarely & sometimes & often \\
\hline 12. I get dizzy or faint feelings. & never & rarely & sometimes & often \\
\hline
\end{tabular}




\begin{tabular}{|c|c|c|c|c|}
\hline & $\begin{array}{c}\text { Never } \\
\text { true } \\
\text { about me }\end{array}$ & $\begin{array}{c}\text { Rarely } \\
\text { true } \\
\text { about } \\
\text { me }\end{array}$ & $\begin{array}{c}\text { Sometimes } \\
\text { true about } \\
\text { me }\end{array}$ & $\begin{array}{l}\text { Often } \\
\text { true } \\
\text { about } \\
\text { me }\end{array}$ \\
\hline 13. I check things out first. & never & rarely & sometimes & often \\
\hline 14. I worry about getting called on in class. & never & rarely & sometimes & often \\
\hline 15. I'm jumpy. & never & rarely & sometimes & often \\
\hline $\begin{array}{l}\text { 16. I'm afraid other people will think I'm } \\
\text { stupid. }\end{array}$ & never & rarely & sometimes & often \\
\hline 17. I keep the light on at night. & never & rarely & sometimes & often \\
\hline 18. I have pains in my chest. & never & rarely & sometimes & often \\
\hline $\begin{array}{l}\text { 19. I avoid going to places without my } \\
\text { family. }\end{array}$ & never & rarely & sometimes & often \\
\hline 20. I feel strange, weird, or unreal. & never & rarely & sometimes & often \\
\hline 21. I try to do things other people will like. & never & rarely & sometimes & often \\
\hline $\begin{array}{l}\text { 22. I worry about what other people think of } \\
\text { me. }\end{array}$ & never & rarely & sometimes & often \\
\hline $\begin{array}{l}\text { 23. I avoid watching scary movies and TV } \\
\text { shows. }\end{array}$ & never & rarely & sometimes & often \\
\hline 24. My heart races or skips beats. & never & rarely & sometimes & often \\
\hline 25. I stay away from things that upset me. & never & rarely & sometimes & often \\
\hline 26. I sleep next to someone from my family. & never & rarely & sometimes & often \\
\hline 27. I feel restless and on edge. & never & rarely & sometimes & often \\
\hline 28. I try to do everything exactly right. & never & rarely & sometimes & often \\
\hline $\begin{array}{l}\text { 29. I worry about doing something stupid or } \\
\text { embarrassing. }\end{array}$ & never & rarely & sometimes & often \\
\hline $\begin{array}{l}\text { 30. I get scared riding in the car or on the } \\
\text { bus. }\end{array}$ & never & rarely & sometimes & often \\
\hline 31. I feel sick to my stomach. & never & rarely & sometimes & often \\
\hline $\begin{array}{l}\text { 32. If I get upset or scared, I let someone } \\
\text { know right away. }\end{array}$ & never & rarely & sometimes & often \\
\hline $\begin{array}{l}\text { 33. I get nervous if I have to perform in } \\
\text { public. }\end{array}$ & never & rarely & sometimes & often \\
\hline $\begin{array}{l}\text { 34. Bad weather, the dark, heights, animals, } \\
\text { or bugs scare me. }\end{array}$ & never & rarely & sometimes & often \\
\hline
\end{tabular}




\begin{tabular}{|c|c|c|c|c|}
\hline & $\begin{array}{c}\text { Never } \\
\text { true } \\
\text { about me }\end{array}$ & $\begin{array}{c}\text { Rarely } \\
\text { true } \\
\text { about } \\
\text { me }\end{array}$ & $\begin{array}{c}\text { Sometimes } \\
\text { true about } \\
\text { me }\end{array}$ & $\begin{array}{c}\text { Often } \\
\text { true } \\
\text { about } \\
\text { me }\end{array}$ \\
\hline 35. My hands shake. & never & rarely & sometimes & often \\
\hline 36. I check to make sure things are safe. & never & rarely & sometimes & often \\
\hline $\begin{array}{l}\text { 37. I have trouble asking other kids to play } \\
\text { with me. }\end{array}$ & never & rarely & sometimes & often \\
\hline 38. My hands feel sweaty or cold. & never & rarely & sometimes & often \\
\hline 39. I feel shy. & never & rarely & sometimes & often \\
\hline
\end{tabular}




\section{$\underline{\text { RCMAS-Child }}$}

Instructions: Read each question carefully. Put a circle around the word YES if you think it is true about you. Put a circle around the word NO if you think it is not true about you.

1. I have trouble making up my mind. $\quad$ yes no

2. I get nervous when things do not go the right way. yes no

3. Others seem to do things easier than I can. yes no

4. I like everyone I know. yes No

5. Often I have trouble getting my breath. $\quad$ yes No

6. I worry a lot of the time. $\quad$ yes no

7. I am afraid of a lot of things. $\quad$ yes no

8. I am always kind. $\quad$ yes no

9. I get mad easily. $\quad$ yes no

10. I worry about what my parents will say to me. $\quad$ yes no

11. I feel that others do not like the way I do things. yes no

12. I always have good manners. $\quad$ yes no

13. It is hard for me to get to sleep at night. $\quad$ yes no

14. I worry about what other people think about me. yes no

15. I feel alone even when there are people with me. $\quad$ yes no

16. I am always good. $\quad$ yes no

17. Often I feel sick in my stomach. $\quad$ yes no

18. My feelings get hurt easily. $\quad$ yes no

19. My hands feel sweaty. $\quad$ yes no

20. I am always nice to everyone. $\quad$ yes no 
21. I am tired a lot.

yes no

22. I worry about what is going to happen.

yes no

23. Other children are happier than I.

yes no

24. I tell the truth every single time.

yes no

25. I have bad dreams.

yes no

26. My feelings get hurt easily when I am fussed at.

yes no

27. I feel someone will tell me I do things the wrong way.

yes no

28. I never get angry.

yes no

29. I wake up scared some of the time.

yes no

30. I worry when I go to bed at night.

yes no

31. It is hard for me to keep my mind on my schoolwork.

yes no

32. I never say things I shouldn't.

yes no

33. I wiggle in my seat a lot.

yes no

34. I am nervous.

yes no

35. A lot of people are against me.

yes no

36. I never lie.

yes no

37. I often worry about something bad happening to me.

yes no 


\section{$\underline{\text { RCMAS-Parent }}$}

Instructions: Read each question carefully. Put a circle around the word YES if you think it is true about your child. Put a circle around the word NO if you think it is not true about your child.

1. My child has trouble making up his/her mind. yes no

2. My child gets nervous when things do not go the right way. yes No

3. Others seem to do things easier than my child can. yes no

4. My child likes everyone he/she knows. $\quad$ yes no

5. Often my child has trouble getting his/her breath. yes no

6. My child worries a lot of the time. $\quad$ yes no

7. My child is afraid of a lot of things. $\quad$ yes no

8. My child is always kind. $\quad$ yes no

9. My child gets mad easily. $\quad$ yes no

10. My child worries about what I will say to him/her. yes no

11. My child feels that others do not like the way he/she does things. yes no

12. My child always has good manners. $\quad$ yes no

13. It is hard for my child to get to sleep at night. $\quad$ yes no

14. My child worries about what other people think about him/her. $\quad$ yes no

15. My child feels alone even when there are people with him/her. $\quad$ yes no

16. My child is always good. $\quad$ yes no

17. Often my child feels sick in his/her stomach. $\quad$ yes no

18. My child's feelings get hurt easily. $\quad$ yes no

19. My child's hands feel sweaty. $\quad$ yes no

20. My child is always nice to everyone. $\quad$ yes no 
21. My child is tired a lot.

$$
\text { yes }
$$
no

22. My child worries about what is going to happen. yes no

23. Other children are happier than my child.

yes no

24. My child tells the truth every single time.

yes no

25. My child has bad dreams.

yes no

26. My child's feelings get hurt easily when he/she is fussed at.

yes no

27. My child feels someone will tell him/her that he/she does things the wrong way.

28. My child never gets angry.

yes no

29. My child wakes up scared some of the time.

yes no

30. My child worries when he/she goes to bed at night.

yes

no

31. It is hard for my child to keep his/her mind on his/her schoolwork.

yes no

32. My child never says things he/she shouldn't.

yes no

33. My child wiggles in his/her seat a lot.

yes no

34. My child is nervous.

yes no

35. A lot of people are against my child.

yes no

36. My child never lies.

yes no

37. My child often worries about something bad happening to him/her. yes no 


\section{Screen for Child Anxiety Related Disorders (SCARED) \\ Child Version-Pg. 1 of 2 (To be filled out by the CHILD)}

Name:

Date:

\section{Directions:}

Below is a list of sentences that describe how people feel. Read each phrase and decide if it is "Not True or Hardly Ever True" or "Somewhat True or Sometimes True" or "Very True or Often True" for you. Then for each sentence, fill in one circle that corresponds to the response that seems to describe you for the last 3 months.

\begin{tabular}{|c|c|c|c|}
\hline & $\begin{array}{c}\mathbf{0} \\
\text { Not True or } \\
\text { Hardly } \\
\text { Ever True }\end{array}$ & $\begin{array}{c}1 \\
\text { Somewhat } \\
\text { True or } \\
\text { Sometimes } \\
\text { True }\end{array}$ & $\begin{array}{c}2 \\
\text { Very True } \\
\text { or Often } \\
\text { True }\end{array}$ \\
\hline 1. When I feel frightened, it is hard to breathe. & & & \\
\hline 2. I get headaches when I am at school. & & & \\
\hline 3. I don't like to be with people I don't know well. & & & \\
\hline 4. I get scared if I sleep away from home. & & & \\
\hline 5. I worry about other people liking me. & & & \\
\hline 6. When I get frightened, I feel like passing out. & & & \\
\hline 7. I am nervous. & & & \\
\hline 8. I follow my mother or father wherever they go. & & & \\
\hline 9. People tell me that I look nervous. & & & \\
\hline 10. I feel nervous with people I don't know well. & & & \\
\hline 11. I get stomachaches at school. & & & \\
\hline 12. When I get frightened, I feel like I am going crazy. & & & \\
\hline 13. I worry about sleeping alone. & & & \\
\hline 14. I worry about being as good as other kids. & & & \\
\hline 15. When I get frightened, I feel like things are not real. & & & \\
\hline $\begin{array}{l}\text { 16. I have nightmares about something bad happening to my } \\
\text { parents. }\end{array}$ & & & \\
\hline 17. I worry about going to school. & & & \\
\hline 18. When I get frightened, my heart beats fast. & & & \\
\hline 19. I get shaky. & & & \\
\hline 20. I have nightmares about something bad happening to me. & & & \\
\hline
\end{tabular}




\section{Screen for Child Anxiety Related Disorders (SCARED) \\ Child Version-Pg. 2 of 2 (To be filled out by the CHILD)}

\begin{tabular}{|c|c|c|c|}
\hline & $\begin{array}{c}\mathbf{0} \\
\text { Not True } \\
\text { or } \\
\text { Hardly } \\
\text { Ever True }\end{array}$ & $\begin{array}{c}1 \\
\text { Somewhat } \\
\text { True or } \\
\text { Sometimes } \\
\text { True }\end{array}$ & $\begin{array}{c}2 \\
\text { Very True } \\
\text { or Often } \\
\text { True }\end{array}$ \\
\hline 21. I worry about things working out for me. & & & \\
\hline 22. When I get frightened, I sweat a lot. & & & \\
\hline 23. I am a worrier. & & & \\
\hline 24. I get really frightened for no reason at all. & & & \\
\hline 25. I am afraid to be alone in the house. & & & \\
\hline 26. It is hard for me to talk with people I don't know well. & & & \\
\hline 27. When I get frightened, I feel like I am choking. & & & \\
\hline 28. People tell me that I worry too much. & & & \\
\hline 29. I don't like to be away from my family. & & & \\
\hline 30. I am afraid of having anxiety (or panic) attacks. & & & \\
\hline 31. I worry that something bad might happen to my parents. & & & \\
\hline 32. I feel shy with people I don't know well. & & & \\
\hline 33. I worry about what is going to happen in the future. & & & \\
\hline 34. When I get frightened, I feel like throwing up. & & & \\
\hline 35. I worry about how well I do things. & & & \\
\hline 36. I am scared to go to school. & & & \\
\hline 37. I worry about things that have already happened. & & & \\
\hline 38. When I get frightened, I feel dizzy. & & & \\
\hline $\begin{array}{l}\text { 39. I feel nervous when I am with other children or adults and I } \\
\text { have to do something while they watch me (for example: read } \\
\text { aloud, speak, play a game, play a sport.) }\end{array}$ & & & \\
\hline $\begin{array}{l}\text { 40. I feel nervous when I am going to parties, dances, or any } \\
\text { place }\end{array}$ & & & \\
\hline 41. I am shy. & D & D & \\
\hline \multicolumn{4}{|c|}{$\begin{array}{l}\text { SCORING: } \\
\text { A total score of } \geq \mathbf{2 5} \text { may indicate the presence of an Anxiety Disorder. Scores higher that } 30 \text { are more specific. } \\
\text { A score of } 7 \text { for items } 1,6,9,12,15,18,19,22,24,27,30,34,38 \text { may indicate Panic Disorder or Significant Somatic Symptoms. } \\
\text { A score of } 9 \text { for items 5, 7,14,21,23,28,33,35,37 may indicate Generalized Anxiety Disorder. } \\
\text { A score of } 5 \text { for items 4, } 8,13,16,20,25,29,31 \text { may indicate Separation Anxiety Disorder. } \\
\text { A score of } 8 \text { for items 3,10,26,32,39,40,41 may indicate Social Anxiety Disorder. } \\
\text { A score of } 3 \text { for items 2, 11, 17, 36 may indicate Significant School Avoidance. }\end{array}$} \\
\hline
\end{tabular}


*For children ages 8 to 11, it is recommended that the clinician explain all questions, or have the child answer the questionnaire sitting with an adult in case they have any questions.

Developed by Boris Birmaher, M.D., Suneeta Khetarpal, M.D., Marlane Cully, M.Ed., David Brent M.D., and Sandra McKenzie, Ph.D., Western

Psychiatric Institute and Clinic, University of Pgh. (10/95). E-mail: birmaherb@ msx.upmc.edu 


\section{Screen for Child Anxiety Related Disorders (SCARED) \\ Parent Version - Pg. 1 of 2 (To be filled out by the PARENT)}

Name:

Date:

\section{Directions:}

Below is a list of sentences that describe how people feel. Read each phrase and decide if it is "Not True or Hardly Ever True" or "Somewhat True or Sometimes True" or "Very True or Often True" for you. Then for each sentence, fill in one circle that corresponds to the response that seems to describe you for the last 3 months.

\begin{tabular}{|c|c|c|c|}
\hline & $\begin{array}{c}\text { 0 } \\
\text { Not True } \\
\text { or } \\
\text { Hardly } \\
\text { Ever True }\end{array}$ & $\begin{array}{c}1 \\
\text { Somewhat } \\
\text { True or } \\
\text { Sometimes } \\
\text { True }\end{array}$ & $\begin{array}{c}2 \\
\text { Very True } \\
\text { or Often } \\
\text { True }\end{array}$ \\
\hline $\begin{array}{l}\text { 1. When my child feels frightened, it is hard for him/her to } \\
\text { breathe. }\end{array}$ & 0 & O & O \\
\hline 2. My child gets headaches when he/she is at school. & O & O & O \\
\hline $\begin{array}{l}\text { 3. My child doesn't like to be with people he/she doesn't know } \\
\text { well. }\end{array}$ & & O & O \\
\hline 4. My child gets scared if he/she sleeps away from home. & 0 & 0 & 0 \\
\hline 5. My child worries about other people liking him/her. & O & O & O \\
\hline 6. When my child gets frightened, he/she feels like passing out. & O & O & O \\
\hline 7. My child is nervous. & O & O & O \\
\hline 8. My child follows me wherever I go. & O & O & O \\
\hline 9. People tell me that my child looks nervous. & O & O & O \\
\hline 10. My child feels nervous with people he/she doesn't know well. & & O & O \\
\hline 11. My child gets stomachaches at school. & & O & O \\
\hline $\begin{array}{l}\text { 12. When my child gets frightened, he/she feels like he/she is } \\
\text { going crazy. }\end{array}$ & & O & O \\
\hline 13. My child worries about sleeping alone. & & O & O \\
\hline 14. My child worries about being as good as other kids. & & O & O \\
\hline $\begin{array}{l}\text { 15. When he/she gets frightened, he/she feels like things are not } \\
\text { real }\end{array}$ & & O & O \\
\hline $\begin{array}{l}\text { 16. My child has nightmares about something bad happening to } \\
\text { his/her parents. }\end{array}$ & & O & O \\
\hline 17. My child worries about going to school. & O & O & O \\
\hline 18. When my child gets frightened, his/her heart beats fast. & O & O & O \\
\hline 19. He/she gets shaky. & O & O & O \\
\hline $\begin{array}{l}\text { 20. My child has nightmares about something bad happening to } \\
\text { him/her. }\end{array}$ & O & O & O \\
\hline
\end{tabular}




\section{Screen for Child Anxiety Related Disorders (SCARED) Parent Version - Pg. 2 of 2 (To be filled out by the PARENT)}

\begin{tabular}{|c|c|c|c|}
\hline & $\begin{array}{c}\mathbf{0} \\
\text { Not True } \\
\text { or } \\
\text { Hardly } \\
\text { Ever True }\end{array}$ & $\begin{array}{c}1 \\
\text { Somewhat } \\
\text { True or } \\
\text { Sometimes } \\
\text { True }\end{array}$ & $\begin{array}{c}2 \\
\text { Very True } \\
\text { or Often } \\
\text { True }\end{array}$ \\
\hline 21. My child worries about things working out for him/her. & & & \\
\hline 22. When my child gets frightened, he/she sweats a lot. & & & \\
\hline 23. My child is a worrier. & & & \\
\hline 24. My child gets really frightened for no reason at all. & & & \\
\hline 25. My child is afraid to be alone in the house. & & & \\
\hline 26. It is hard for my child to talk with people he/she doesn't know wel & & & \\
\hline 27. When my child gets frightened, he/she feels like he/she is choking & & & \\
\hline 28. People tell me that my child worries too much. & & & \\
\hline 29. My child doesn't like to be away from his/her family. & & & \\
\hline 30. My child is afraid of having anxiety (or panic) attacks. & & & \\
\hline $\begin{array}{l}\text { 31. My child worries that something bad might happen to his/her } \\
\text { parents. }\end{array}$ & & & \\
\hline 32. My child feels shy with people he/she doesn't know well. & & & \\
\hline 33. My child worries about what is going to happen in the future. & & & \\
\hline 34. When my child gets frightened, he/she feels like throwing up. & & & \\
\hline 35. My child worries about how well he/she does things. & & & \\
\hline 36. My child is scared to go to school. & & & \\
\hline 37. My child worries about things that have already happened. & & & \\
\hline 38. When my child gets frightened, he/she feels dizzy. & & & \\
\hline $\begin{array}{l}\text { 39. My child feels nervous when he/she is with other children or } \\
\text { adults and he/she has to do something while they watch him/her (for } \\
\text { example: read aloud, speak, play a game, play a sport.) }\end{array}$ & & & \\
\hline $\begin{array}{l}\text { 40. My child feels nervous when he/she is going to parties, dances, } \\
\text { or any place where there will be people that he/she doesn't know well }\end{array}$ & & & \\
\hline 41. My child is shy. & & & \\
\hline \multicolumn{4}{|c|}{$\begin{array}{l}\text { SCORING: } \\
\text { A total score of } \geq \mathbf{2 5} \text { may indicate the presence of an Anxiety Disorder. Scores higher that } 30 \text { are more specific. } \\
\text { A score of } 7 \text { for items } 1,6,9,12,15,18,19,22,24,27,30,34,38 \text { may indicate Panic Disorder or Significant Somatic Symptoms. } \\
\text { A score of } 9 \text { for items } 5,7,14,21,23,28,33,35,37 \text { may indicate Generalized Anxiety Disorder. } \\
\text { A score of } 5 \text { for items 4, 8,13,16,20,25,29,31 may indicate Separation Anxiety Disorder. } \\
\text { A score of } 8 \text { for items 3, 10,26,32,39, 40,41 may indicate Social Anxiety Disorder. } \\
\text { A score of } 3 \text { for items 2, 11, 17, 36 may indicate Significant School Avoidance. }\end{array}$} \\
\hline
\end{tabular}


Developed by Boris Birmaher, M.D., Suneeta Khetarpal, M.D., Marlane Cully, M.Ed., David Brent M.D., and Sandra McKenzie, Ph.D., Western Psychiatric Institute and Clinic, University of Pgh. (10/95). E-mail: birmaherb@msx.upmc.edu 


\section{PEDIATRIC ANXIETY RATING SCALE (PARS)}

\section{SYMPTOM CHECKLIST}

Instructions: Fill in the blanks with "1" (yes), "2" (no), or "9" (other, e.g., unable or unwilling to answer)

\section{SOCIAL INTERACTIONS or PERFORMANCE SITUATIONS}

"During the past week, have you (has s/he) worried about or avoided social situations? Let me give you some examples (refer to list)."

Parent Child Rater

1. Has fear of and/or avoids participating in group activities.

2. Has fear of and/or avoids going to a party or social event.

3. Has fear of and/or avoids talking with a stranger.

4. Has fear of and/or avoids talking on the phone.

5 . Reluctant or refuses to talk in front of a group.

6 . Reluctant or refuses to write in front of other people.

7. Reluctant or refuses to eat in public.

8. Reluctant or refuses to use a public bathroom.

9. Reluctant or refuses to change into gym clothes or bathing suit

with others present.

\section{SEPARATION}

"Some children worry about being away from their mother or father. What about you (your child)? Let me give you examples."

10. Worry about harm happening to attachment figures.

11. Worry about harm befalling self, including the fear of dying.

12. Distress when separation occurs or is anticipated.

13. Fear or reluctance to be alone.

14. Reluctance or refusal to go to school or elsewhere.

15. Complaints of physical symptoms when separation occurs or is anticipated.

16. Reluctance or refusal to go to sleep alone.

17. Reluctance or refusal to sleep away from home.

18. Nightmares with a separation theme.

19. Clings to parent, or follows parent around the house. 


\section{GENERALIZED}

"Some people worry about a lot of different things. What about you (your child)? What about during the past week? Let me give you some examples."

20. Excessive worry about everyday or real-life problems.

21. Restlessness or feeling keyed-up or on edge.

22. Easily fatigued.

23. Difficulty concentrating or mind going blank.

24. Irritability.

25. Muscle tension or nonspecific tension.

26. Sleep disturbance, especially difficulty falling asleep.

27. Dread or fearful anticipation (nonspecific).

\section{SPECIFIC PHOBIA}

“Do you worry about or have fears of animals (e.g. dog), etc?"

28. Animal: Specify

29. Natural environment:

(e.g., heights, storms) Specify:

30. Blood-injection-injury: Specify:

31. Situational

(e.g., airplane, elevator): Specify:

\section{ACUTE PHYSICAL SIGNS \& SYMPTOMS}

"Sometimes children notice feelings or changes in their bodies when they are anxious or worried? What about you? Let me give examples."

32. Blushing.

33. Feels paralyzed.

34. Trembling or shaking.

35. Feels dizzy, unsteady, lightheaded or going to pass out.

36. Palpitations or pounding heart.

37. Difficult breathing.

(sensation of shortness of breath, smothering or choking).

38. Chills or hot flashes. 
39. Sweating.

40. Feels sick to stomach, nausea or abdominal distress.

41. Recurrent urge to go to bathroom.

42. Chest pain or discomfort.

43. Paresthesias

(numbness or tingling sensation in fingers, toes, or perioral region).

44. Problems swallowing or eating.

\section{OTHER}

45. Crying spells when in anxiety-provoking situations.

46. Temper tantrums when in anxiety-provoking situations.

47. Needs to flee certain anxiety-provoking situations.

48. Keeps distance from other people.

49. Fear of losing control or going crazy.

50. Derealization (feeling of unreality)

or depersonalization (detached from oneself).

Other anxiety symptoms: Specify:

Specify:

Specify: 


\section{SEVERITY ITEMS}

Instructions: For each item circle the number that best characterizes the patient during the past week.

Overall Number of Anxiety Symptoms (Circle code for past week only)

Not applicable

Does not know

No symptoms

1 symptom

2-3 symptoms

4-6 symptoms

7-10 symptoms

More than 10 symptoms

\section{Overall Frequency of Anxiety Symptoms}

Not applicable

Does not know

No symptoms

1 or 2 days a week

3 or 4 days a week

5 or 6 days a week

Daily

Several hours every day

Overall Severity of Anxiety Feelings

Not applicable

Does not know.

None. No anxious symptoms.

Minimal: Very transient discomfort. Not clinically significant.

Mild: Transient discomfort that is mildly disturbing. Borderline clinical significance. Intermediate between 1 and 3 .

Moderate: Clearly nervous when anticipating or confronting the anxiety-provoking situation(s). Often unable to overcome these feelings.

These feelings impact on well-being.

Severe: Very distressed when anxious or when anticipating or confronting the anxiety-provoking situation (s). Usually unable to overcome this feeling.

Intermediate between 3 and 5.

Extreme: Feels wretched when anticipating or confronting

anxiety-provoking situation(s). Often or almost totally unable to overcome this fear.

Very marked impact on well being.

\section{Overall Severity of Physical Symptoms of Anxiety}

Not applicable

Does not know

None. No physical symptoms of anxiety.

Minimal: Very transient physical symptoms of anxiety. Symptoms are not, or are hardly noticeable by others. Not clinically significant. 
Mild: Few physical symptoms: no lasting impact.

Borderline clinical significance. Intermediate between 1 and 3.

Moderate: Persistent physical symptoms of anxiety, especially during exposure to the feared situation(s). Symptoms are noticeable by others and significantly interfere with his/her ability to function in the situation.

Severe: Marked physical symptoms of substantial clinical significance.

Intermediate between 3 and 5 .

Extreme: Severe and persistent physical symptoms of anxiety, especially during

exposure to the feared situations(s). Symptoms are very obvious to others and often result in inability to function in the situation.

\section{Overall Avoidance of Anxiety-Provoking Situations}

NOTE: Rate all avoidance here; include school, home, activities, etc. in rating

Not applicable

Does not know

None. Does not avoid the anxiety-provoking situation(s).

Minimal: Very occasionally avoids the anxiety-provoking situation(s).

Avoided situation(s) is/are not critical to his/her well-being.

Mild: Avoids anxiety-provoking situation(s) some of the time

but no important situation is consistently avoided. Borderline clinical significance. Intermediate between 1 and 3 .

Moderate: Avoid anxiety-provoking situation(s) frequently.

At least one important situation is avoided.

Severe: Avoids anxiety-provoking situation most of the time

or more than one important situation is consistently avoided.

Intermediate between 3 and 5 .

Extreme: Avoids all or almost all anxiety-provoking situations.

\section{Interference with Family Relationships and/or Performance at Home}

Not applicable

Does not know

None. No interference.

Minimal: Very transient interference. No impact on relationships with family members or performance (tasks, etc.) at home.

Mild: Slight impact on relationships or performance outside of the home.

Borderline clinical significance. Intermediate between 1 and 3.

Moderate: Clear interference. Either performance of tasks at home or frequency

or quality of interaction with family members is affected: he/she might

withdraw from interaction, or might be avoided/rejected by family members, or might have many conflicts with them.

Severe: Marked interference in relationships with family members and/or performance at home. Of substantial clinical significance.

Intermediate between 3 and 5 .

Extreme: Totally or almost totally unable to maintain appropriate family relationship 
and/or function at home.

Interference with Peer and Adult Relationships \&/or Performance Outside of Home. NOTE: Out-of-home functioning includes school (not avoidance), activities, etc

$\begin{array}{lr}\text { Not applicable } & 8\end{array}$

$\begin{array}{ll}\text { Does not know } & 9\end{array}$

$\begin{array}{ll}\text { None. No interference. } & 0\end{array}$

Minimal: Very transient interference. No impact on relationships with peers 1 or teachers or other adults outside of the home. No impact on functioning outside of home, e.g., attending and performing group activities.

Mild: Slight impact on relationships or performance outside of the home. 2 Borderline clinical significance. Intermediate between 1 and 3.

Moderate: Clear interference. Either performance outside of the home or frequency or quality of peer or adult interactions is affected: he/she might withdraw from interaction, or might be avoided/rejected by peers or adults, or might have conflicts with them.

Severe: Marked interference in relationship with peers or adults outside of home and/or performance outside of home. Of substantial clinical significance. Intermediate between 3 and 5 .

Extreme: Totally or almost totally unable to maintain appropriate peer or

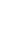
0 adult relationship and/or function outside of home.

Scoring:

\begin{tabular}{|c|c|}
\hline Severity Item & Score \\
\hline 1. Overall number of anxiety symptoms & \\
\hline 2. Overall frequency of anxiety symptoms & \\
\hline 3. Overall severity of anxiety feelings & \\
\hline $\begin{array}{l}\text { 4. Overall severity of physical symptoms of } \\
\text { anxiety }\end{array}$ & \\
\hline $\begin{array}{l}\text { 5. Overall avoidance of anxiety provoking } \\
\text { situations }\end{array}$ & \\
\hline $\begin{array}{l}\text { 6. Interference with family relationships and/or } \\
\text { performance at home }\end{array}$ & \\
\hline $\begin{array}{l}\text { 7. Interference with peer and adult relationships } \\
\text { and/or performance outside of home }\end{array}$ & \\
\hline $\begin{array}{c}\text { TOTAL } \\
\end{array}$ & \\
\hline
\end{tabular}




\section{Tel-Aviv University / National Institute of Mental Health Attention Bias Modification Treatment}

\section{Bias measurement and training: Protocol}

\section{Introduction}

Below, you can review the detailed methods, installation instructions, and general guidelines for running the TAU/NIMH ABMT attention bias measurement and training procedure. This comprehensive tutorial outlines the entire behavioral assessment process.

\section{The dot-probe task}

\section{Overview}

The dot-probe task forms the basis for both threat bias assessment and attention bias modification. Threat-related attention bias should be measured before and after the ABMT or placebo protocol. In the current dot-probe discrimination task, pairs of face stimuli, one angry and one neutral, are presented one above the other on the computer screen, followed by a small visual probe appearing in the location vacated by one of the face pictures (see figure below). Participants are required to respond as quickly as possible to the probe without compromising accuracy.

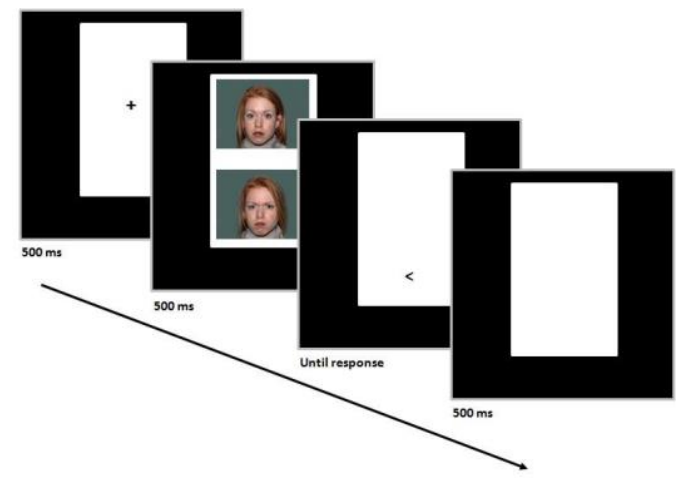




\section{TAU/NIMH Attention Bias Modification Treatment}

Response latencies on the task provide a "snap-shot" of the distribution of the subject's attention, with faster responses to probes presented in the attended relative to the unattended location. For example, attention bias toward threat is evident when participants are faster to respond to probes that replace angry faces rather than neutral faces. The reverse pattern indicates threat-related attentional avoidance.

Care must be taken to standardize the implementation of both the dot-probe task and attention training. The task should be administered in a quiet room with the lights dimmed. A research assistant should be present to ensure the task is being carried out as planned. Neither the research assistant nor the participant should speak during task administration.

\section{Stimuli}

1. All displays are presented within a white rectangle $(58 \mathrm{~mm}$ wide by $94 \mathrm{~mm}$ tall, when screen resolution is configured to $1280 \times 768$ pixels; see Setup and Installation section below) mounted on a black background. The white rectangle is positioned in the mid-top portion of the screen.

2. The fixation display consists of a black cross presented in the center of the white rectangle.

3. The face stimuli are photographs of 20 different individuals (10 male, 10 female) taken from the NimStim stimulus set (Tottenham, et al., 2009), except for one female taken from the Matsumoto and Ekman set (Matsumoto \& Ekman, 1989). All faces were placed on a background as in the Matsumoto and Ekman set. Two different pictures of each individual, depicting angry and neutral expressions, were selected. The face display consists of pairs of angry-neutral or neutral-neutral faces of the same individual. The face photographs are presented with equal distance from the top and bottom of the fixation cross, with a distance of $14 \mathrm{~mm}$ between them. The top photograph is positioned about $20 \mathrm{~mm}$ from the top edge of the screen. Each face photograph subtends $45 \mathrm{~mm}$ in width and $34 \mathrm{~mm}$ in height. 
4. The face pairs were randomly divided into two sets ( $A$ and $B$ ). Each participant should be tested for pre- and post-ABM bias with one set, and trained with the other. Set assignment should be counterbalanced within the ABM and placebo groups. 
5. The target-probe display consists of an arrow head pointing either left or right ("<" or ">"). The target appears at the location previously occupied by one of the faces, with a small, random jitter around the center of the face.

\section{Procedure}

In each trial in the task, the participant is presented with the fixation cross (500ms), followed by the face pair display (500ms), followed by the target display (until response). Response is followed by an inter-trial interval (500ms) composed of only the white rectangle on the black background. Across trials, each expression will equally likely be on the top or bottom position, and the probe will equally likely be $<$ or $>$.

\section{Threat bias measurement}

The pre- and post-ABM measurement protocol consists of 120 trials ( 80 angry-neutral and 40 neutral-neutral presentations). Angry-face location, probe location, probe type, and actor are fully counterbalanced in presentation. If the subject performs with less than $70 \%$ accuracy on the first 10 trials, the program will display a warning and the experiment will be aborted. This warning provides an opportunity to re-brief the subject and initiate data collection again.

\section{ABM/Placebo training}

The ABM/Placebo protocol consists of 160 trials (120 angry-neutral and 40 neutralneutral presentations). In the placebo condition, angry-face location, probe location, and actor are fully counterbalanced in presentation. In the ABM condition, the target appears at the neutral-face location in all angry-neutral trials. Probe type $(<0 r>)$ is not factorially counterbalanced but appears with equal probability for each of the following: angry-face location, probe location, or actor. A short break is delivered every 40 trials. If accuracy is kept above $70 \%$, no indication is provided during the break. However, if accuracy falls below $70 \%$ in the preceding block, a warning will accompany the break slide, providing an opportunity for the experimenter to remind the subject not to compromise accuracy. The participant then continues training. 


\section{Setup and installation}

\section{Technical Requirements}

- A computer running E-Prime 2.x, E-Run application (PST, Pennsylvania, USA; http://www.pstnet.com/eprime.cfm)

- Optimal computer screen resolution: $1280 \times 768$ pixels (with this resolution, the white rectangle display should be $58 \mathrm{~mm}$ wide and $94 \mathrm{~mm}$ tall). We strongly recommend that screen resolution is configured to these values. Variation of $\pm 6 \mathrm{~mm}$ in the white

\section{Package set-up}

- A computer running E-Prime 2.x, E-Run application

- Download the file ABMT.zip

- Unzip its contents into a folder. The contents should include:

- Bias_measure: runs the bias measurement session (E-Run 2.0 Script File)

- Bias_train: runs the bias training session (E-Run 2.0 Script File)

- images: a folder containing 6 image files, and 2 nested folders ("A" and "B") each containing 20 additional image files

- Note: The Bias_measure and Bias_train programs are independent of each other, but both require the relative location of the images folder to remain unchanged

\section{Running the procedures}

\section{Bias measurement}

- Double-click Bias_measure to run a bias measurement session

- Session sequence:

- A series of input dialog boxes will prompt the experimenter to enter:

- Research site number (should be provided by the coordinator) 
- Subject number (1-32767)

- Session number (e.g., 1 = pre, 2 = post)

- Stimuli set to use (A or B)

- Summary of startup info

TAU/NIMH Attention Bias Modification Treatment

- Instructions slide (see Appendix for instructions text)

- 120 trials (no breaks) - 4 minutes

- Goodbye message

- Output: two output files bearing the subject and session numbers will be generated in the same folder following a complete run:

- .edat file (output in E-Prime Edat format)

- .txt file (text log file, generated even when experiment is aborted)

- Note:

- A session cannot be paused midway

- Use Ctrl+Alt+Shift to abort the session only if absolutely necessary. The .edat file will not be created for the trials run before the abort command; use E-Recovery application to transform the text log file into .edat format

\section{Training}

- Double-click Bias_train to run a bias measurement session

- Session sequence:

- A series of input dialog boxes will prompt the experimenter to enter:

- Research site number (provided by the coordinator)

- Subject number (1-32767)

- Session number (e.g., 1 = pre, 2 = post)

- Stimuli set to use (A or B)

- Training type (1-10): should be obtained from the non-blind experimenter responsible for the study (see Information for the Non-Blind Experimenter document)

- Summary of startup info 
- Instructions slide (see Appendix for instructions text)

- 160 trials ( 5-6 minutes)

- Four blocks of 40 trials

- Rest break following each block (duration ad lib; preferably less than 2 minutes). If performance accuracy in preceding blocks was below $70 \%$, a

TAU/NIMH Attention Bias Modification Treatment

message informing of low accuracy will be displayed. This will provide an opportunity for the experimenter to remind the participant that although they are to respond as quickly as possible, accuracy should not be compromised. No break will be given following the last block.

- Goodbye message

- Output: two output files bearing the subject and session numbers will be generated in the same folder following a complete run:

$\circ$.edat file (output in E-Prime Edat format)

$\circ \quad$.txt file (text log file, generated even when experiment is aborted)

- Note:

- A session cannot be paused midway

- Use Ctrl+Alt+Shift to abort the session only if absolutely necessary. The .edat file will not be created for the trials run before the abort command; use E-Recovery application to transform the text log file into .edat format

\section{How many training sessions?}

ABMT studies have used anywhere between one and 12 sessions of training. It appears that 8 bi-weekly sessions produce good clinical results. Thus, we recommend this amount of training, if possible. However, it is up to each participating site to determine the value of this parameter.

\section{Data analysis}

Threat bias scores and other behavioral indices can be directly generated using the provided Data Analysis Tool, a MATLAB standalone utility. Download the utility and consult the Data Analysis Protocol to learn how to transform the output produced by the 
Bias_measure and Bias_train procedures into threat bias scores. The Data Analysis

Tool utility does not require an existing MATLAB license.

\section{Contact}

จ Registration and technical support: yairlab@freud.tau.ac.il

๑ General inquiries: Rany Abend / abend@tau.ac.il

○ TAU Director: Yair Bar-Haim / yair1@post.tau.ac.il

○ NIMH Director: Daniel Pine / daniel.pine@nih.gov

๑ Genetics: Thalia Eley / thalia.eley@kcl.ac.uk

\section{References}

TAU/NIMH Attention Bias Modification Treatment

Beck, A. T., Epstein, N., Brown, G., \& Steer, R. A. (1988). An inventory for measuring clinical anxiety: Psychometric properties. Journal of Consulting and Clinical Psychology, 56, 893-897.

Birmaher, B., Brent, D. A., Chiappetta, L., Bridge, J., Monga, S., \& Baugher, M. (1999). Psychometric properties of the Screen for Child Anxiety Related Emotional Disorders (SCARED): A replication study. Journal of the American Academy of Child and Adolescent Psychiatry, 38(10), 1230-1236.

Birmaher, B., Khetarpal, S., Brent, D., Cully, M., Balach, L., Kaufman, J., et al. (1997). The screen for child anxiety related emotional disorders (SCARED): Scale construction and psychometric characteristics. Journal of the American Academy of Child and Adolescent Psychiatry, 36(4), 545-553.

Matsumoto, D., \& Ekman, P. (1989). he Japanese and Caucasian facial expressions of emotion (JACFEE) and neutrals (JACNeuF). San Francisco State University, San Francisco.

Tottenham, N., Tanaka, J., Leon, A., McCarry, T., Nurse, M., Hare, T., et al. (2009). The NimStim set of facial expressions: Judgments from untrained research participants. Psychiatry Research, 168, 242-249. 


\section{ABMT Analysis Tool v2.0: Installing and Running}

\section{Downloading TAU/NIMH ABMT Analysis Tool v2.0}

1. Download the MATLAB standalone utility installer (v7.9; file name:

MCRInstaller_7.9.exe; 257MB) from http://people.socsci.tau.ac.il/mu/wpcontent/themes/yairbarhaimhome/MCRInstaller_7.9.exe

a. Run the file.

b. "Next" your way through the install process.

c. If no error occurred throughout the process, the MATLAB standalone utility was installed properly.

2. Download the TAU/NIMH ABMT analysis tool v2.0 (file name:

TAU_ABMT_v2.0.exe; 166KB) to a folder of your choice, from http://people.socsci.tau.ac.il/mu/wpcontent/themes/yairbarhaimhome/TAU ABMT v2.0.exe.

\section{Preparing the input data file for analysis}

The analysis tool can read Excel 2003-07 (.xIs) or 2010-13 (.xslx) files that were converted from a merged E-Prime file (.emrg2).

\section{How to merge the output files and convert the merged file to Excel format:}

1. Run E-Merge to merge all the experiment output files (.edat format) you wish to analyze as a group. If you ran several sessions, merge each session separately. The output is an .emrg2 file.

2. Open the merged file using the E-Prime's E-DataAid.

3. Export its contents to Excel format using the Export button. Note that the resulting file will actually be in text format (.txt). 
4. Open the text file using Excel.

5. Delete the first row (it should contain the name of the merged file), so that cell A1 contains the string ExperimentName.

TAU/NIMH Attention Bias Modification Treatment 2015

6. Save the file in Excel format (.xls or .xlsx).

\section{Running the TAU/NIMH ABMT Analysis Tool}

1. Open the file analysis tool by double-clicking the file (TAU_ABMT_v2.0.exe).

2. The tool should open in a small window. Allow up to about a minute for the tool to open. If it fails to open, restart the computer and try again. If that didn't help, contact us at abend@tau.ac.il, and we'll try to help.

3. Click the Load button on the right. Browse and choose the Excel output file you want to analyze. It may take up to a minute for the file to load (depending on its size). When it is done loading, the file's name will appear in the field to the left of the Load button.

4. Click the Analyze button to analyze the data and generate an output file. This file will be saved in the same folder as the input file, and its name will be the same as that of the input file, with the suffix "analyzed". A preview of the output will appear in the Output preview area.

\section{Reading the TAU/NIMH ABMT Analysis Tool v 2.0 output file}

1. Double-click the Excel output file. If a warning about a different format than specified by the file extension, click Yes.

2. Sheet 1 contains the calculated attention bias scores of your data, and additional data.

a. Column A: subject ID

b. Column B: session number

c. Column C: session date (may need to format cells for correct display)

d. Column D: session date (may need to format cells for correct display) 
e. Columns F-J: mean accuracy data (for: all trials, neutral trials, threat trials, all NT trials, all NN trials)

f. Columns K-O: mean RT data (for: all trials, neutral NT trials, threat NT trials, all NT trials, all NN trials)

g. Column P: threat bias score (mean of neutral NT trials minus mean of threat NT trials)

h. Additional columns may appear in case happy stimuli were used

\section{Reaction time cleanup specifications}

1. Trial RTs were cleaned up before being analyzed, using the following method:

2. All trial RTs shorter than 150 ms or longer than 2000 ms or in which an incorrect was response was made were removed.

3. Then, Z-scores were calculated per trial type (neutral-threat/neutralhappy/neutral-neutral) and valence of face preceding the probe (threat/happy/neutral). Trials with Z-scores greater than $|2.5|$ were removed.

4. Analyses were conducted on the remaining trial RTs (generally about $94 \%$ of the original trials). 


\section{Attention Bias \\ Modification Training}

\section{TREATMENT \\ MANUAL}

Child Anxiety \& Phobia Program

Florida International University

Spring 2015 


\section{$\underline{\text { ABMT First Session (A1) }}$}

1. Bring child and parent to room

2. Welcome

a. Counselor thanks family for completing the most recent assessment

b. Empathize that child is still experiencing anxiety

i. "As you know when you came in for your last interview and spoke with [assessor], the two of you still had concerns regarding [child's] anxiety. I'm sorry to hear that! [child] is still having difficulties, and I would like to speak to you both about this, but before I do, I would like to explain more about what we will be doing in the treatment."

c. Review purpose of ABMT/remind them they may be in the Placebo Group

i. "When you come in, you [child] will be doing one of two types of computer tasks, and this task will be the same each time. I do not know which of the two kinds of computer tasks you will be doing, but I will be asking you which one you THINK you were doing at the end of the study. "

ii. "The computer task [child] MAY be doing here for the next four weeks is a type of new computer treatment that has been shown to help some children's anxiety get better. It is equally likely you will be doing a similar task that may or may not help your anxiety get better. The important thing is that you complete all the treatments."

3. Remind parent and child of basic procedure

a. Coming in twice a week for four weeks

b. Every even-numbered session, child and parent will complete measures

i. "This treatment is different from ones you may have heard of up until now. You'll be coming in for two sessions a week for about 30 minutes each time. When you come in the first time that week, you'll come in here and do the computer treatment task. When you come in the second time that week, you'll complete the computer task AND some short questionnaires about your anxious feelings."

4. Have child leave room briefly

5. Inquiry with parent about child's anxiety

a. Ask more about interference

b. Ask what parent would like to change about interference

c. Suggestion: "so when you were last interviewed, you said [child] [SYMPTOM]... How is that progressing?....Do you feel it is interfering? How?...What kind of changes would you like to see regarding this?"

d. Clarify any questions/concerns with parent

6. Have parent leave room briefly 
7. Inquiry with child about anxiety diagnosis

a. Ask more about interference

b. As what child would like to change about interference

c. Suggestion: "so when you were last interviewed, you said you

[SYMPTOM]... How is that progressing?....Do you feel it is interfering? How? ...What kind of changes would you like to see regarding this?"

8. Clarify any questions/concerns with child

9. Child completes Treatment 1 (A1) $\leftarrow$ for this, use completed Treatment A1 Prep Sheet

10. Bring parent back to treatment room

a. Explain that each treatment session may seem short, but research supports its effectiveness

i. Emphasize attendance at EVERY session and completion in 4 WEEKS' time

ii. Treatment must be done with practice, as the child learned in CAPP

iii. Suggestion: "[Child], what did you think of the task? Although this treatment is very brief, it has been shown to help young people with their anxiety. However, the treatment is not going to be effective right after the first session. It is more likely to be effective if you come twice a week, every week."

b. Remind parent of agreed-upon treatment time/upcoming appointments 


\section{A2/Session 2 - Procedure}

1. Bring child to room

2. Remind child of procedure

a. At every even-numbered session, child will complete measures

3. Child completes Treatment 2 (A2) $\leftarrow$ for this, use completed Treatment A2 Prep Sheet

4. Have child and parent complete packet $A 2$

a. Child A2 packet

b. Parent A2 packet

5. Remind parent of agreed-upon treatment time/upcoming appointments 


\section{B1/Session 3 - Procedure}

1. Bring child to room

2. Child completes Treatment 3 (B1) $\leftarrow$ for this, use completed Treatment B1 Prep Sheet

3. Remind parent of agreed-upon treatment time/upcoming appointments 


\section{B2/Session 4 - Procedure}

1. Bring child to room

2. Child completes Treatment 4 (B2) $\leftarrow$ for this, use completed Treatment B2 Prep Sheet

3. Have child and parent complete packet B2

a. Child B2 packet

b. Parent B2 packet

4. Remind parent of agreed-upon treatment time/upcoming appointments

5. **After this appointment, Counselor informs CCs about family's needing POST assessment

a. Assessment coordinator calls family and assigns counselor

b. Assessment coordinator inquires about scheduling $2 \mathrm{MO} \mathrm{FU}$ assessment with parent 


\section{C1/Session 5 - Procedure}

1. Bring child to room

2. Child completes Treatment 5 (C1) $\leftarrow$ for this, use completed Treatment C1 Prep Sheet

3. Remind parent of agreed-upon treatment time/upcoming appointments 


\section{C2/Session 6 - Procedure}

1. Bring child to room

2. Child completes Treatment $6(\mathrm{C} 2) \leftarrow$ for this, use completed Treatment C2 Prep Sheet

3. Have child and parent complete packet $\mathrm{C} 2$

a. Child C2 packet

b. Parent $\mathrm{C} 2$ packet

4. Remind parent of agreed-upon treatment time/upcoming appointments 


\section{D1/Session 7 - Procedure}

1. Bring child to room

2. Child completes Treatment 7 (D1) $\leftarrow$ for this, use completed Treatment D1 Prep Sheet

3. Remind parent of agreed-upon treatment time/upcoming appointments 


\section{$\underline{D 2 / S e s s i o n ~} 8$ - Procedure}

1. Bring child to room

2. Child completes Treatment 6 (C2)

3. Have child and parent complete packet D2

a. Child D2 packet

b. Parent D2 packet

4. Remind parent of agreed-upon treatment time/upcoming appointments

a. Wrap up treatment

i. Note progress of child symptoms/review

ii. Remind family to abstain from outside treatments until $2 \mathrm{MO}$ FU assessment

b. Remind parent of POST appointment

c. Remind parent of $2 \mathrm{MO}$ FU appointment 


\section{APPENDICES}

Appendix A: Measurement/Treatment Task Instructions

Appendix B: Group Placement Perception Form

Appendix C: Prep Sheets: Assessment, Treatment, Re-Run 
Appendix A: Measurement/Treatment Task Instructions 


\section{ABMT - Attention Bias Measurement Program: PRE/POST/2MO FU Assessments}

1. On the Desktop, find the 'ABMT' Folder. Double-click on:

"Bias_measure_match_screen_res.ebs2"

a. NOTES: Purple icon, E-Run 2.0 Script File; should be the first file

2. If you get the message "The file chosen is not recognized by E-Run..." click OK

3. Enter the following information:

a. Research Site Number $\rightarrow \mathbf{3}$

b. Subject Number

i. [Case ID] (example: 0000) OR

ii. [ABMT Case ID without 'A'] (ex: A000 $\rightarrow$ '000')

c. Session Number

i. If this is a PRE $[\mathrm{ABMT}] \rightarrow[\mathbf{1}]$ or $[\mathrm{IA} 2] \rightarrow[\mathbf{1 . 2}]$

ii. If this is a POST $\rightarrow$ [2]

iii. If this is a $2 \mathrm{MO}$ Follow-Up $[\mathrm{ABMT}] \rightarrow[4]$

d. Stimuli Set to Use (A or B)

i. If the Case ID ends in an ODD number $\rightarrow \mathbf{A}$

ii. If the Case ID ends in an EVEN number or ZERO $\rightarrow \mathbf{B}$

4. Summary dialog box appears

a. Confirm that all is correct

5. Guide child through the instructions on the screen

a. MAKE SURE the child uses dominant hand when clicking

b. Encourage the child to go as fast as he/she can

c. Stand by in case the child needs assistance

i. Stay out of direct line of sight of child

1. Minimize distractions/interruptions as much as possible

6. IF NEEDED: abort the program by pressing CTRL + ALT +SHIFT

7. The measurement file should save automatically to the ABMT Folder

a. The file will be called "Bias_measure_match_screen_res-XXXX-X" (where XXXX is CAPP Case ID and X is the Session Number code) 


\section{$\underline{\text { ABMT and CAPP- Attention Bias Treatment Program }}$}

1. On the Desktop, find the 'ABMT' Folder. Double-click on:

\section{"Bias_train_match_screen_res.ebs2"}

\section{a. NOTES: Purple icon, E-Run 2.0 Script File; should be the first file}

2. If you get the message "The file chosen is not recognized by E-Run..." click OK

3. Enter the following information:

a. Research Site Number $\rightarrow \mathbf{3}$

b. Subject Number

i. [Case ID without letters] (ex: A000 $\rightarrow$ '000')

c. Session Number

i. If this is Session A1 $\rightarrow$ [1]

ii. If this is Session A2 $\rightarrow$ [2]

iii. If this is Session $\mathrm{B} 1 \rightarrow$ [3]

iv. If this is Session B2 $\rightarrow$ [4]

v. If this is Session $\mathrm{C} 1 \rightarrow$ [5]

vi. If this is Session $\mathrm{C} 2 \rightarrow$ [6]

vii. If this is Session D1 $\rightarrow$ [7]

viii. If this is Session D2 $\rightarrow$ [8]

d. Stimuli Set to Use (A or B) - REVERSE COUNTERBALANCE

i. If the Case ID ends in an ODD number $\rightarrow \mathbf{B}$

ii. If the Case ID ends in an EVEN number or ZERO $\rightarrow \mathbf{A}$

e. Training Type

i. If the Subject is in CONDITION $1 \rightarrow \mathbf{3}$

ii. If the Subject is in CONDITION $2 \rightarrow \mathbf{8}$

4. Summary dialog box appears

a. Confirm that all is correct

5. Guide child through the instructions on the screen

a. MAKE SURE the child uses dominant hand when clicking

b. Encourage the child to go as fast as he/she can

c. Stand by in case the child needs assistance

i. Stay out of direct line of sight of child 
1. Minimize distractions/interruptions as much as possible

6. IF NEEDED: abort the program by pressing CTRL + ALT +SHIFT

7. The treatment file should save automatically to the ABMT Folder

a. The file will be called "Bias_train_match_screen_res-XXX-X" (where $\mathrm{XXX}$ is ABMT without $\mathrm{A}$ and $\mathrm{X}$ is the Session Number code)

\section{Troubleshooting ABMT Measurement/Treatment Tasks}

Problem: When opening the ABMT program for measurement, there are times that an error may occur pertaining to the screen resolution. The message states the following:

The following runtime error occurred: Application-defined or object-defined error Line: 939

Error Number: -999

Solution:

(1) Go to the start Menu on the bottom right of the Desktop and type "resolution"

(2) Click "Adjust Screen Resolution"

(3) Click "Advanced Settings"

(4) Click on the second tab labeled "Monitor"

(5) Open the drop down menu labeled "Screen refresh rate" and select 60 Hertz

(6) Click Apply and reattempt the ABMT task

(7) re-run task to confirm flicker rate has been changed

Suggestion: Check this option when setting up the computer to make the process faster. 
Appendix B: Group Placement Perception Form 


\title{
Group Placement Perception Form
}

\section{Parent:}

Now that you and your child have completed the Eight-Week Follow-Up

Assessment, in which condition do you think your child was placed? (circle)

\author{
PLACEBO CONDITION
}

TREATMENT CONDITION

Child:

Now that you and your parent have completed the Eight-Week Follow-Up Assessment, in which condition do you think you were placed? (circle) 
Appendix C: Prep Sheets 


\section{ABMT RCT ASSESSMENT - PREP SHEET}

Last Name:

Child First Name:

Parent Last Name:

Time Point (Circle): PRE POST $8 \mathrm{~W}$ $\mathrm{FU}$

\begin{tabular}{|c|c|}
\hline $\begin{array}{c}\text { Research Site } \\
\text { Number }\end{array}$ & 3 \\
\hline Case ID & \\
\hline Session & \\
Number & \\
\hline Stimuli Set & \\
\hline
\end{tabular}

Next Appointment Date: 
Notes:

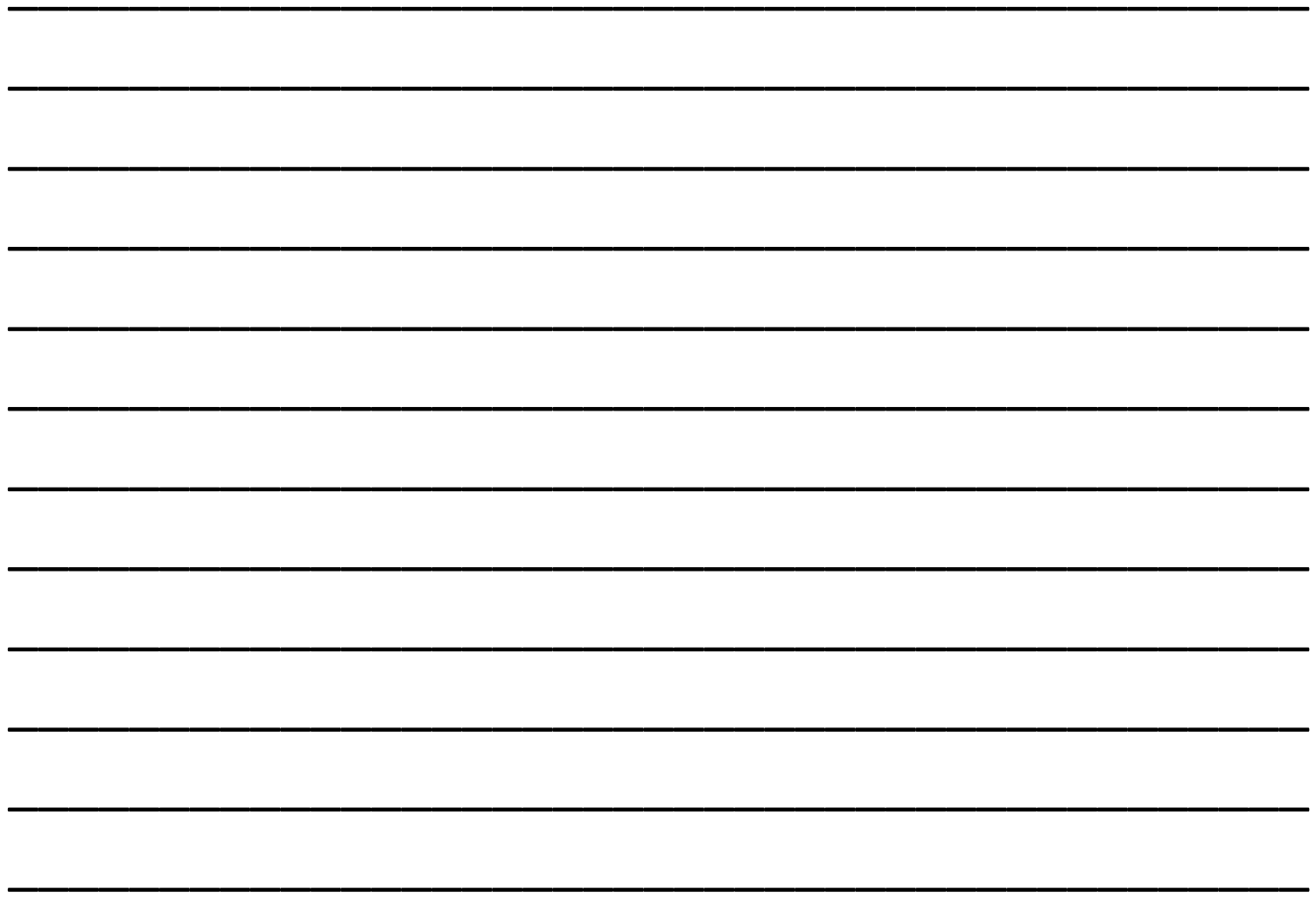




\section{ABMT TREATMENT SESSION - PREP \\ SHEET}

Last Name:

Child First Name:

Parent Last Name:

\begin{tabular}{|c|c|}
\hline $\begin{array}{c}\text { Research Site } \\
\text { Number }\end{array}$ & 3 \\
\hline Case ID & \\
\hline Session & \\
Number & \\
\hline Stimuli Set & \\
\hline Training Type & \\
\hline
\end{tabular}

Next Appointment Date: 
Notes:

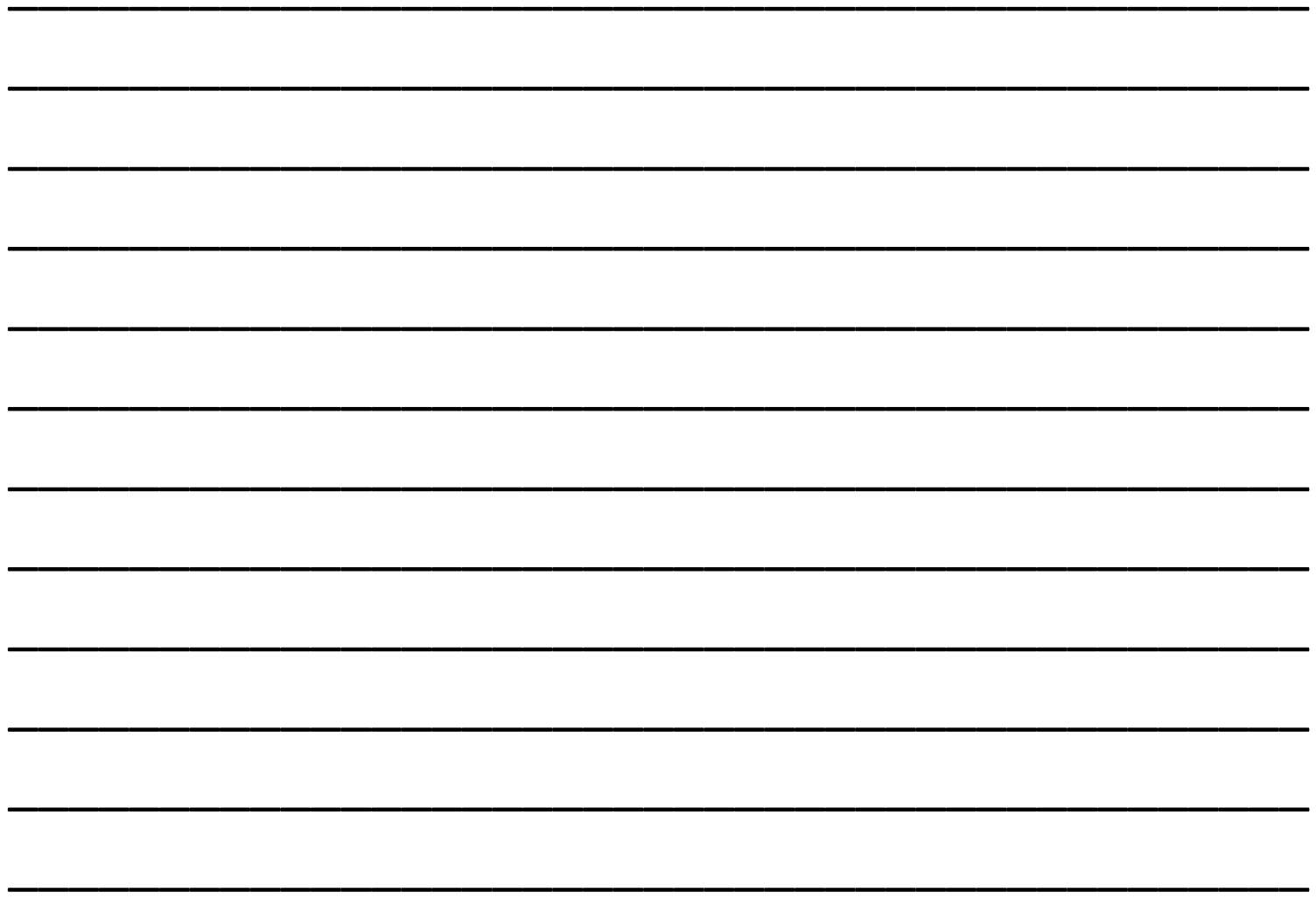


VITA

\section{MICHELE BECHOR}

2007-2011

2011-2015

2015-2017

2017-2018
B.A., Florida International University

Miami, FL

M.S., Florida International University

Miami, FL

Doctoral Candidate

Florida International University

Miami, FL

Predoctoral Clinical Intern

Center for Children \& Families, Florida International University

Miami, Florida

Neural Correlates of Attention Training in Children with Anxiety Disorders

F31 MH105144-01A1

2015-2017

Bechor, M. (Fellow/Principal Investigator) with Jeremy Pettit, Ph.D., Wendy K. Silverman, Ph.D., Bethany Reeb-Sutherland, Ph.D., \& Michael Crowley, Ph.D.

Ruth L. Kirschstein National Research Service Award

National Institutes of Mental Health

\section{PUBLICATIONS AND PRESENTATIONS}

Bechor, M., Pettit, J.W., Silverman, W.K., Bar-Haim, Y., Abend, R., Pine, D.S., Vasey, M., \& Jaccard, J. (2014). Attention bias modification treatment for children with anxiety disorders who do not respond to cognitive behavioral therapy: A case series. Journal of Anxiety Disorders, 28(2), 154-159. DOI:1.1016/j.janxdis.2013.09.001.

Bechor, M., Pettit, J.W., Silverman, W.K., Rey, Y., Pine, D.S., Bar-Haim, Y., \& Vasey, M.W., (2015, April). Preliminary Findings of a Randomized Controlled Trial of Attention Bias Modification for Child Anxiety CBT Nonresponders. In J. Pettit (Chair), Novel Strategies for Enhancing CBT Outcomes for Children with Anxiety and Related Disorders. Symposium conducted at the 2015 annual conference of the Anxiety Disorders Association of America, Miami, FL.

Bechor, M., Reeb-Sutherland, B.C., Ramos, M.L., Pettit, J.W. \& Silverman, W.K. (2015, May). Neural Correlates of Attentional Bias to Threat among Youth with and without Anxiety Disorders. Paper presented at the 2015 Center for Children \& Families Speaker 
Series, Graduate Professional Development Series, Graduate Student Data Blitz, Department of Psychology, Florida International University, Miami, FL.

Bechor, M., Melendez, R., Hill, R.M., \& Pettit, J.W. (2015). Anxiety disorders and suicide-related behaviors. In D.A. Lamis \& N.J. Kaslow (Eds.), Advancing the science of suicidal behavior: Understanding and intervention (pp. 391-403). Hauppauge, NY: Nova Science Publishers.

Boustani, M.M., Frazier, S.L., Becker, K., Bechor, M., Dinizulu, S.M., Hedemann, E.R., Ogle, R., Pasalich, D.S. (2014). Common Elements of Adolescent Prevention Programs: Minimizing Burden while Maximizing Reach. Administration and Policy in Mental Health and Mental Health Services Research, 1-11. DOI: 1.1007/s 10488-014-0541-9.

Melendez, R., Bechor, M., Rey, Y., Pettit, J. W., \& Silverman, W. K. (2017). Attentional control scale for children: Factor structure and concurrent validity among children and adolescents referred for anxiety disorders. Journal of Clinical Psychology, 73(4), 489499. DOI: $1.1002 /$ jclp. 22346.

Motoca, L.M., del Busto, C. T., Hedemann, E.R., Bechor, M., Silverman, W.K. (2013, April). The Impact of Parenting Behaviors on Child Anxiety and Avoidance in a Clinic Referred Sample: An Observational Study. In R. Carter (Chair), Contextual Influences on Childhood Anxiety, symposium conducted at the biennial meeting of the Society for Research in Child Development, Seattle, WA.

Pettit, J.W., Silverman, W.K., Rey, Y., Bechor, M., Melendez, R., Vaclavik, D., \& Buitron, V. (2016, October). A Stepped Care Treatment Approach for Child and Adolescent Anxiety Disorders. In J. Pettit \& W.K. Silverman (Chairs), Novel Strategies for Sequencing Treatments for Child and Adolescent Behavior Problems. Symposium conducted at the 2016 annual conference of the Association of Behavioral \& Cognitive Therapies, New York, NY.

Pettit, J.W., Rey, Y., Bechor, M., Melendez, R., Vaclavik, D., Buitron, V., Bar-Haim, Y., Pine, D.S., \& Silverman, W.K. (2017). Can less be more? Open trial of a stepped care approach for child and adolescent anxiety disorders. Journal of Anxiety Disorders, 51, 713. DOI: 1.1016/j.janxdis.2017.08.004.

Ramos, M. L., Bechor, M., Pettit, J.W., Silverman, W.K., \& Reeb-Sutherland, B.C. (2015, December). Error-related Brain Activity in Youth with and without Anxiety. Paper presented at the 2015 Center for Children \& Families Speaker Series, Graduate Professional Development Series, Graduate Student Data Blitz, Department of Psychology, Florida International University, Miami, FL. 